University of South Florida

DIGITAL COMMONS

Digital Commons @ University of

@ UNIVERSITY OF SOUTH FLORIDA

South Florida

Integrative Biology Books

Integrative Biology

1909

\title{
Asteroids, Ophiuroids and Echinoids of the Scottish National Antarctic Expedition: A translation of Astéries, Ophiures et Échinides de l'Expédition Antarctique Nationale Écossaise
}

René Koehler

John Lawrence

University of South Florida, lawr@usf.edu

Follow this and additional works at: https://digitalcommons.usf.edu/bin_books

\section{Recommended Citation}

Koehler, R. (2021). Asteroids, Ophiuroids and Echinoids of the Scottish National Antarctic Expedition: A translation of Astéries, Ophiures et Échinides de l'Expédition Antarctique Nationale Écossaise.

Transactions of the Royal Society of Edinburgh, Volume 46, Issue 3, 1909, pp. 529 - 649 (J. M. Lawrence, Trans.). Herizos Press, Tampa.

This Book is brought to you for free and open access by the Integrative Biology at Digital Commons @ University of South Florida. It has been accepted for inclusion in Integrative Biology Books by an authorized administrator of Digital Commons @ University of South Florida. For more information, please contact digitalcommons@usf.edu. 


\author{
TR A N S A T I O N S \\ OF THE \\ R O Y A L S O C I E T Y \\ or

\section{EDINBURGH.}

VOL. XIVI.

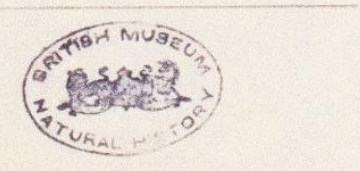

EDINBURGH :

PUBLISHED BY ROBERT GRANT \& SON, 107 PRINCES STREET, AND WILLIAMS \& NORGATE, 14 HENRIETTA STREET, COVENT GARDEN, LONDON. IDCCCCIX. 


\title{
SCOTTISH NATIONAL ANTARCTIC EXPEDITION
}

\author{
R E P O R T \\ ON THE \\ SCIENTIFIC RESULTS \\ OF THF:

\section{VOYAGE OF S.Y. "SCOTIA"}

DURING: THE YliAtis 1902, 1903, INI, 1904.

INDER THE LEAIEERSHIP OF

WILLIA M S. BRUGE,

L.L.J., F.R.S.F.

Tolume T.- zoology.

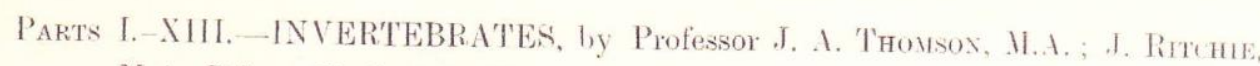
M.A., B.Se.; Sir Charles Eliot, C.M.G.; J James Murray ; Johx Renne, D.Sc.: Dr von Linstow; Prof. G. H. Carpenter, B.Sice; John J. C: Melutel, M.A. F.L.S.; R. Standen; J. F. GeMmLL, M.A., M.B., С...; R. T. Leiper, М.B. C.M. ; T. V. Hormison, F.L.S.; E. T. Browne, M.A. ; Dr R. KuEhlek.

Thirty-six Plates.

\section{EDINBURGH :}

\section{The Scottist) Dreanographical sLaborator.}

Sol. A A

THE SCOTTISH OCEANOGRAPHICAL, LABORATORY

JAMES THIN, 55 SOUTH BRIDGE, EDINBURGH :

JAMES MACLEHOSE \& SONS, 61 ST VINCENT STREET, GLASGOW.

1909.

Price Twenty-three Shillings and Sicpence in cloth; One Guinew in paper. 
Kœhler, R. 1909. Asteroids, ophiuroids and echinoids of the Scottish National Antarctic Expedition. A translation of Kohler, R. Astéries, Ophiures et Échinides de l'Expédition Antarctique Nationale Écossaise. Transactions of The Royal Society of Edinburgh, Volume 46 , Issue 3, 1909 , pp. 529 - 649. (J. M. Lawrence, Trans.).

(C) J. M. Lawrence. 2021. Herizos Press, Tampa. 
Translator's notes:

Kœhler's memoir was issued on December 26, 1908, in Transactions of the Royal Society of Edinburgh, Volume 46, Part III, Session 1908. The complete volume of the Transactions was published in 1909.

The memoir was also published by the Scottish Oceanographical Laboratory in 1909 as "Report on the scientific results of the voyage of S.Y. "Scotia" during the years 1902, 1903, and 1904, under the leadership of William S. Bruce".

I have not changed apparent misspellings or typographical errors in the text. Examples are:

1. Astrotoma Agassizii is spelled Astrotoma agassizi in the text. I have not changed this. The species name is spelled Astrotoma agassizii in the caption to Plate XIII, fig. 120.

2. Kœhler's name is spelled Koehler throughout the text. I have not changed this.

3. I have not changed the obvious error in this station listing " $1{ }^{\text {st }}$ December 1903, Burdwood Bank, $54^{\circ} 25^{\prime}$ lat. S., $57^{\circ} 32^{\prime}$ long. S.; depth 56 fathoms." This should be "long. W."

4. "Fig. 100. Ophiocten Ludwigi. Dorsal surface. Mag. = 55." The magnification probably is 5.5 because the magnification of the ventral surface is 5 .

I thank my good friend, Michel Jangoux, for his help with some very difficult words.

I thank Janessa Fletcher for her kindness in preparing the photographs of the plates. 


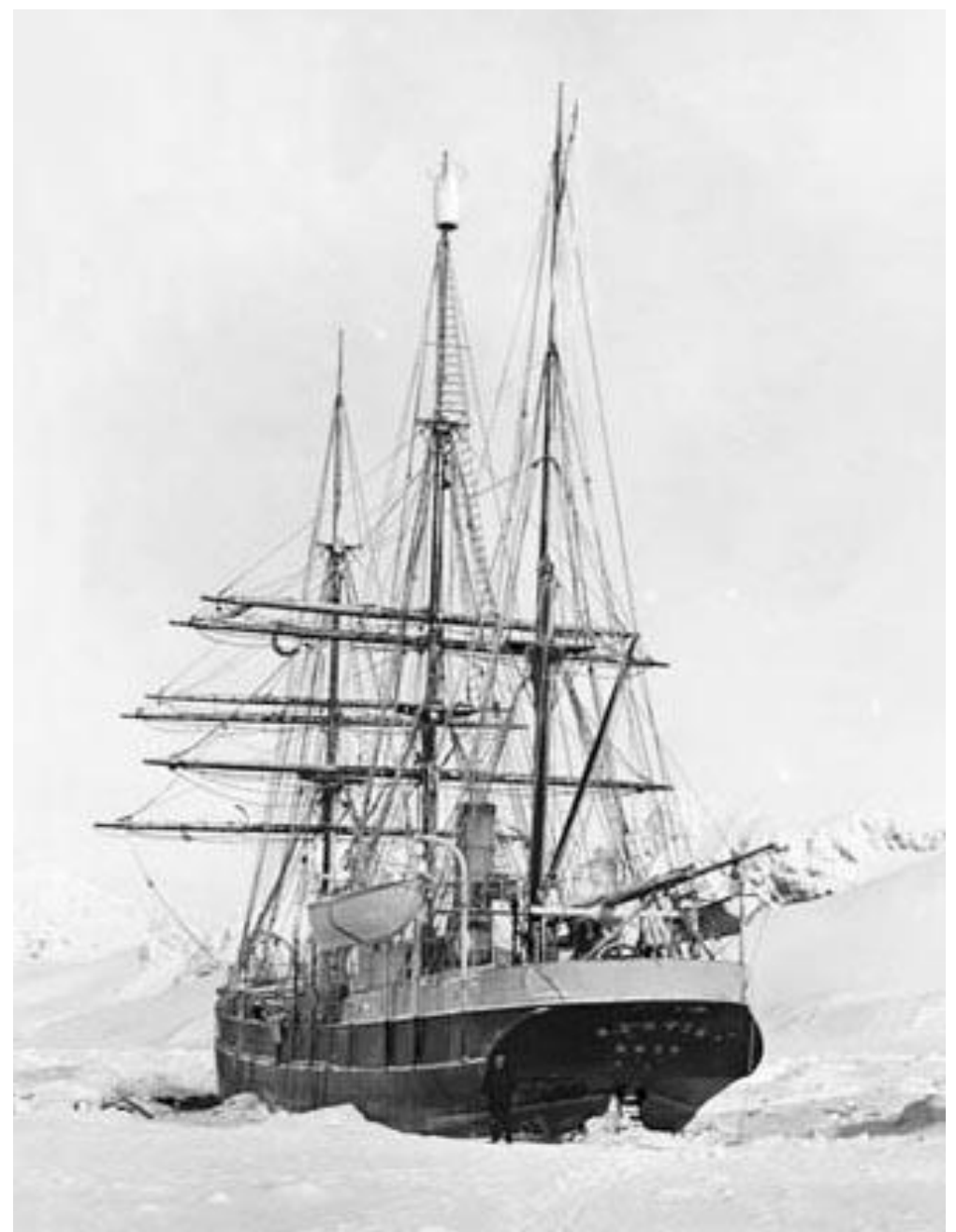

SNAE expedition ship Scotia, in the ice at Laurie Island, South Orkneys, 1903-1904 


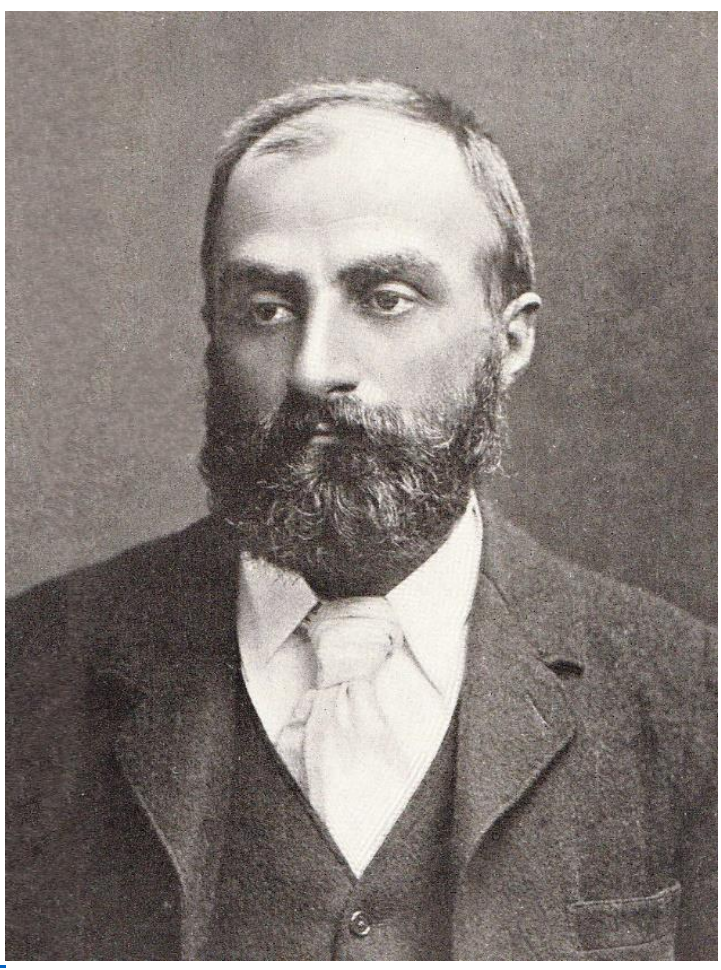

William Speirs Bruce, SNAE expedition leader

William Speirs Bruce (1 August 1867 - 28 October 1921) was a medical student at the University of Edinburgh but gave up his studies to join the Dundee Whaling Expedition to Antarctica as a scientific assistant. He then went on Arctic voyages to Novaya Zemlya, Spitsbergen and Franz Josef Land. Between 1907 and 1920 Bruce made many journeys to the Arctic regions. He obtained financial support with which he acquired a Norwegian whaler that he converted into a fully equipped Antarctic research ship, renamed Scotia. He organized and led the SNAE. He appointed an all-Scottish crew and scientific team. He founded the Scottish Oceanographical Laboratory in Edinburgh in 1907. His endeavors ended with his death in 1921. 


\section{Asteroids, Ophiuroids and Echinoids of the Scottish National Antarctic Expedition}

By Dr. R. Koehler, Professor of Zoology at the University of Lyon.

Presented by Dr. W. S. Bruce (With sixteen Plates)

(Ms. received September 5, 1907. Read June 15, 1908. Issued separately December 16, 1908)

The collection of asteroids, ophiuroids and echinoids that Dr. WILLIAM S. BRUCE has very kindly confided to me, contains especially specimens collected by the Scottish Expedition during his visit in the Antarctic and some others coming from the Falkland Islands, the Burdwood Bank and Gough Island where dredges were made between 46 and $51^{\circ}$ lat. S. BRUCE has added some specimens collected during the return trip of the Scotia at the Cape, Saint Helena, Ascension and Saint Vincent.

In order not to mix species of such different origins, I have believed it necessary to divide my descriptive memoir into the Antarctic and sub-Antarctic forms reported by the Scotia and that are new for the most part. The other contains the species encountered during the return voyage of the Scotia and, with the exception of two, have already been observed. But among the latter, some are insufficiently known and merit a special description.

Having already had the opportunity of examining the specimens of the Belgica and the Charcot Expedition, I have accepted with the greatest pleasure the kind offer that BRUCE has made to study the asteroids, ophiuroids and echinoids collected by the Scotia. I am very grateful for the confidence that he has shown in me and am infinitely grateful to him for placing at my disposal the most important collection of Antarctic echinoderms that has been made to this day.

I likewise thank my colleagues who have helped in completing my work. I especially address my thanks and the expression of my deep gratitude to my excellent friend, Dr. MORTENSEN who has helped me in the friendliest way by his great knowledge of echinoids and kind examination of several of my species.

Professor VAn BENEDEn, Professor Joubin and Dr. Steinhauss have greatly facilitated my identifications. I am extremely aware of their great kindness and ask them to accept my most sincere thanks. 


\title{
FIRST PART.
}

\section{ASTEROIDS, OPHIUROIDS AND ECHINOIDS}

\author{
collected by the Scotia in the Antarctic regions.
}

Some of the echinoderms have been collected at the Falkland Islands and on the Burdwood Bank, i.e., below $50^{\circ}$ lat. S. The others come from much higher latitudes, between $60^{\circ}$ and $72^{\circ}$ lat. S. Finally, some species were collected at Gough Island, to the south of Tristan d'Acunha, that the French map called Diégo Alvarez.

The navigators who have explored the southern regions of our globe generally agree to begin Antarctica at the limit of the iceshelf. This limit varies with longitude. Thus, at a point in the Drake Passage, it does not pass $60^{\circ}$ lat. S. Then it increases progressively to the height of Cape Horn and the Falkland Islands. Then it intersects $55^{\circ}$ lat. S., leaving Burdwood bank to the north. At South Georgia, this limit approaches $50^{\circ}$, which it can even reach further east. It is convenient to adopt for zoogeography this same limit of the Antarctic region.

As for the sub-Antarctic region that follows the preceding and that is connected to it by numerous common species, its limits to the north are more difficult to indicate because they appear to have inflexions that perhaps correspond to those of the same region to the south. Moreover, we often lack accurate information of much of the southern regions, Tierra del Fuego, the Falkland Islands and the Burdwood Bank, explored by the Scotia, belongs incontestably to this region. It is very probable that south of America, its limits should be near $50^{\circ}$, in a way to include in the subAntarctic region the islands of Marion, Crozet, Kerguelen, etc.

As for Gough Island, which the Scotia touched during its return and where it collected some species that I study in the first part of this work, it is located at the extreme southern limit of the sub-Antarctic region. Its echinoderm fauna contains a curious association as follows:

Crossaster penicillatus, Sladen.

Cribrella Pagenstecheri, Studer.

Amphiura magellanica, Ljungmann.

squamata (Delle Chiaje).

Ophiacantha Valenciennesi, Lyman.

Ophiomitrella ingrata, nov. sp.

Notechinus magellanicus, var. neu-amsterdami, Döderlein.

Among these species, Ophiacantha Valenciennesi and Amphiura squamata are cosmopolitan. Crossaster penicillatus is not known at Tristan d'Acunha and the variety neu-amsterdami of Notechinus magellanicus has been collected at the Amsterdam Island. On the other hand, Cribrella Pagenstecheri and Amphiura magellanica are known in the Strait of Magellan. Ophiomitrella ingrata, new species, cannot affect this comparison.

During its visit in the Antarctic, the Scotia made numerous dredges at great depths. It is the first boat that has made abyssal dredges at these high southern latitudes. In the pages that follow, I shall describe several species that have been collected at depths between 1410 and 2645 fathoms. It is not surprising that the species coming from these completely unexplored areas are nearly all new. 
Before going to the study of the species, it appears to me useful to make a preliminary enumeration separating the deep and littoral forms and indicating the stations.

\section{ASTEROIDS.}

Twenty-five species in all have been collected. Twenty are forms of deep water and fifteen are littoral.

The forms of the deep water are the following:

\begin{tabular}{|c|c|c|c|}
\hline & Lat. $\mathrm{S}$ & Long. W. & Depth in fathoms \\
\hline & & $\circ$ & \\
\hline Dystaster felix, nov. sp. & $71 \quad 22$ & $16 \quad 34$ & 1410 \\
\hline Psilasteropsis facetus, nov. sp. ..... & 48 & 10 & 1742 \\
\hline Ripaster Charcoti, Koehler ....... & 6210 & 4120 & 1775 \\
\hline Odontater pusillua, nov. sp. ....... & 48 & 10 & 1742 \\
\hline Chitonaster Johanna, nov. sp. & 6210 & 4120 & 1775 \\
\hline Marcelaster antarcticus, nov. gen., nov. sp. . & $62 \quad 10$ & 4120 & 1775 \\
\hline Gameria attenuata, nov. sp. ... & $62 \quad 10$ & 4120 & 1775 \\
\hline Scotiaster inornatus, nov. gen., nov. sp. . & 51 & 931 & 2103 \\
\hline Hymenaster campanulatus, nov. sp. & 7122 & 1634 & 1410 \\
\hline “ $\quad$ edax, nov. sp.............. & 6217 & 4120 & 1775 \\
\hline “ $\quad$ fucatus, nov. sp. .................. & 7122 & 1634 & 1410 \\
\hline densus, nov. sp.......... & 6933 & $15 \quad 19$ & 2620 \\
\hline Lophaster abbreviatus, nov. sp....... & 6210 & 4120 & 1775 \\
\hline Solaster Lorioli, nov. sp. $\ldots \ldots \ldots \ldots \ldots \ldots \ldots \ldots \ldots \ldots \ldots \ldots \ldots \ldots \ldots \ldots \ldots \ldots$ & $67 \quad 33$ & $36 \quad 35$ & 2500 \\
\hline Styracaster robustus, nov. sp. ................. & 51 & 931 & 2103 \\
\hline 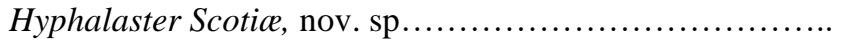 & 7122 & 1634 & 1410 \\
\hline 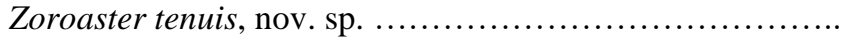 & 48 & 10 & 1742 \\
\hline Asterias pedicellaris, nov. sp. ................................. & $71 \quad 22$ & 1634 & 110 \\
\hline 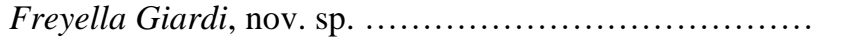 & 6733 & 3635 & 2500 \\
\hline & 6933 & 1519 & 2620 \\
\hline Belgicella racovitzana, Ludwig ........................... & $71 \quad 22$ & $16 \quad 34$ & 1410 \\
\hline
\end{tabular}

Of these twenty species, only three are known. These are Ripaster Charcoti, Belgicella racovitzana and Odontaster tenuis. The first two come from Antarctic regions, but Ripaster Charcoti has still been encountered only in littoral stations. Belgicella racovitzana has been dredged by the Belgica at 2800 meters, while Zoroaster tenuis was discovered by the Challenger at $2^{\circ}$ lat. S. and $144^{\circ}$ long. W., at a depth of 1070 fathoms.

Among the new species, thirteen come from absolutely Antarctic regions and have been dredged between $62^{\circ}$ and $71^{\circ}$ lat. S. Scotiaster inornatus and Styracaster robustus have been found at $51^{\circ}$, Psilasteropsis facetus and Odontaster pusillus at 48 lat. S. All these forms come from depths between 1410 and 2620 fathoms. Two of these species are types of the new genera Marcelaster and Scotiaster.

The littoral forms are the following:

\begin{tabular}{|c|c|c|}
\hline & Localities. & Depths in fathoms. \\
\hline 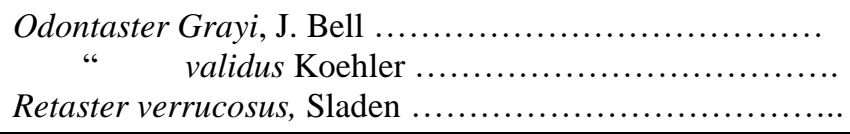 & $\begin{array}{l}\text { Burdwood Bank } \\
\text { South Orkneys } \\
\text { Burdwood Bank }\end{array}$ & $\begin{array}{c}56 \\
5-10 \\
56\end{array}$ \\
\hline
\end{tabular}




\begin{tabular}{|c|c|c|}
\hline 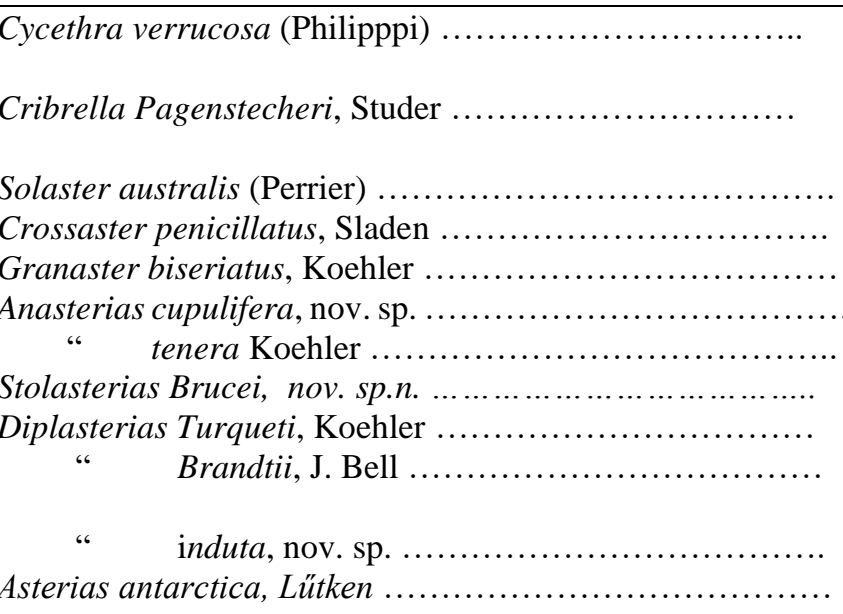 & $\begin{array}{l}\text { Burdwood Bank } \\
\text { Falkland Islands } \\
\text { Burdwood Bank } \\
\text { Gough Island } \\
\text { Burdwood Bank } \\
\text { Gough Island } \\
\text { South Orkneys } \\
\text { South Orkneys } \\
\text { South Orkneys } \\
\text { South Orkneys } \\
\text { South Orkneys } \\
\text { Falkland Islands } \\
\text { Burdwood Bank } \\
\text { South Orkneys } \\
\text { Falkland Islands }\end{array}$ & $\begin{array}{c}56 \\
5-20 \\
56 \\
25 \\
56 \\
25 \\
0-5 \\
10 \\
0-20 \\
10 \\
10-20 \\
5-20 \\
56 \\
10-20 \\
0-6\end{array}$ \\
\hline
\end{tabular}

Of the fifteen species, three are new. These are:

\section{Solasterias Brucei. \\ Anasterias cupulifera. \\ Diplasterias induta.}

The other species have nearly all been found in areas near to where they had already been encountered. Except for Crossaster penicillatus that the Scotia reported from Gough Island and that had been discovered by Challenger at Tristan d'Acunha, all the other species come from the Falkland Islands, South Orkneys and Burdwood Bank. Cribrella Pagenstecheri has been encountered both at Burdwood Bank and Gough Island. This form, as I shall say later, belongs without doubt to a very polymorphic species and is distributed in all sub-Antarctic regions.

It is very probable that some species of asteroids that have just been cited can be found indifferently in littoral stations and in abyssal stations, as we already saw in Ripaster Charcoti and Belgicella racovitzana.

\section{OPHIUROIDS.}

The total number of ophiuroids collected by the Scotia is thirty-one. Nineteen come from great depths. These are:

\begin{tabular}{|c|c|c|c|c|}
\hline & & Lat. S & Long. W. & Depth in fathoms \\
\hline & & $\circ$ & $\circ$ & \\
\hline Ophiog & Brucei, nov. sp. .... & 6640 & $40 \quad 35$ & 2425 \\
\hline “ & integra, nov. sp.... & 6210 & 4120 & 1755 \\
\hline 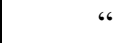 & lenticularis, nov. sp. ....................... & 51 & 931 & 2103 \\
\hline “ & figurata, nov. sp. ........ & $62 \quad 10$ & 4120 & 1775 \\
\hline “ & ossiculata, nov. sp. ......................... & 7122 & 1634 & 1410 \\
\hline “ & 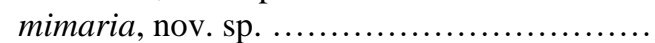 & 7122 & $16 \quad 34$ & 1410 \\
\hline “ & ancepts, nov. sp. .............................. & $71 \quad 22$ & 1634 & 1410 \\
\hline “ & scissa, nov. sp. ............................. & $71 \quad 22$ & 1634 & 1410 \\
\hline “ & 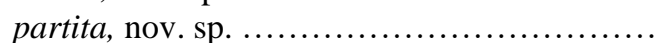 & $62 \quad 10$ & 4120 & 1775 \\
\hline
\end{tabular}




\begin{tabular}{|c|c|c|c|}
\hline inops, nov. sp. ................................ & 7122 & $16 \quad 34$ & 1410 \\
\hline bullata, Wyville Thomson .................... & 3948 & 233 & 2645 \\
\hline Ophiocten Ludwigi, nov. sp. .............................. & $62 \quad 10$ & 4120 & 1775 \\
\hline Ophiernus quadrispinus, Koehler ........................ & $62 \quad 10$ & 4120 & 1775 \\
\hline Amphiura magnifica, nov. sp. ............ & 51 & 931 & 2103 \\
\hline “ consors, nov. sp........ & 6933 & $15 \quad 19$ & 2620 \\
\hline Ophiacantha frigida, nov. sp. .......................... & $62 \quad 10$ & 4120 & 1775 \\
\hline opulenta, nov. sp. ........................... & $62 \quad 10$ & 4120 & 1775 \\
\hline cosmica, Lyman. ......... & $66 \quad 40$ & $40 \quad 35$ & 2425 \\
\hline & 3948 & $233 \mathrm{E}$. & 2645 \\
\hline Ophiotrema Alberti, Koehler & 51 & $931 \mathrm{~W}$. & 2103 \\
\hline
\end{tabular}

Of these species, only three are known. These are:

Ophioglypha bullata.

Ophiacantha cosmica.

Ophiotrema Alberti.

Ophioglypha bullata has already been found in the South Atlantic by the Challenger. It is known from several stations in the North Atlantic. It appears to be cosmopolitan at great depths. It is the same for Ophiacantha cosmica, encountered in the South Indian Ocean and the Atlantic and in the equatorial Pacific. As for Ophiotrema Alberti, it was known only in the North Atlantic.

The richness of Ophioglypha is particularly remarkable in the depths visited by the Scotia. Of the sixteen new species reported, this genus alone contains ten of them.

The littoral ophiuroids have twelve species, which are:

\begin{tabular}{|c|c|c|}
\hline & Localities. & Depths in fathoms. \\
\hline Amphilepis antarctica, nov. sp. & South Orkneys & $9-10$ \\
\hline Ophiactis asperula, (Philippi) & Burdwood Bank & 56 \\
\hline Amphiura Mortenseni, nov. sp. ... & South Orkneys & $9-10$ \\
\hline$" \quad$ tomentosa, Lyman ................. & South Orkneys & $9-10$ \\
\hline “ magellanica, Lyman & Gough Island & 75 \\
\hline “ squamata (Delle Chiaje) & Gough Island & 75 \\
\hline Ophiacantha vivipara, Ljungmann & Burdwood Bank & 56 \\
\hline “ Valenciennesi, Lyman ..... & Gough Island & 100 \\
\hline 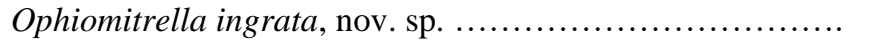 & Gough Island & 100 \\
\hline Ophiomyxa vivipara, Studer ............................... & Burdwood Bank & 56 \\
\hline Astrotoma Agassizi, Lyman & Burdwood Bank & 56 \\
\hline 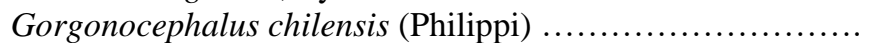 & Burdwood Bank & 56 \\
\hline
\end{tabular}

Only three of these species are new. Among the others, two are cosmopolitan. These are Amphiura squamata and Ophiacantha Valenciennesi. Amphiura magellanica, found at Gough Island, was known at the Strait of Magellan. As for Amphiura tomentosa, it was known at Kerguelen. The specimens found by the Scotia do not completely conform to the type. The perhaps represent a variety. The other species are sub-Antarctic. 


\section{ECHINOIDS.}

The echinoids are less numerous. They contain only ten species in all. Only four are abayssal. They are:

\begin{tabular}{|c|c|c|c|}
\hline & Lat. $\mathrm{S}$ & Long. W. & Depth in fathoms \\
\hline & $\circ$ & $\circ$ & \\
\hline Stereocidaris Mortenseni (Koehler) & $71 \quad 22$ & $16 \quad 34$ & 1410 \\
\hline Pourtalesia carinata, Agassiz & 6640 & $40 \quad 35$ & 2425 \\
\hline & $69 \quad 33$ & 1519 & 2620 \\
\hline Delopatagus Brucei, nov. gen., nov. sp. & 6640 & $40 \quad 35$ & 2425 \\
\hline Urechinus fragilis, nov. sp. & 7122 & 1634 & 1410 \\
\hline
\end{tabular}

The two last species are new. One forms the type of a new genus. Stereocidaris Mortenseni has already been recognized by the Belgica between $70^{\circ}$ and $71^{\circ}$ lat. S., but at a much shallower depth (100 to 600 meters). Pourtalesia carinata was dredged by the Challenger in several southern stations of the Indian and Pacific Oceans.

The littoral species number six:

\begin{tabular}{|c|c|c|}
\hline & Localities. & Depths in fathoms. \\
\hline 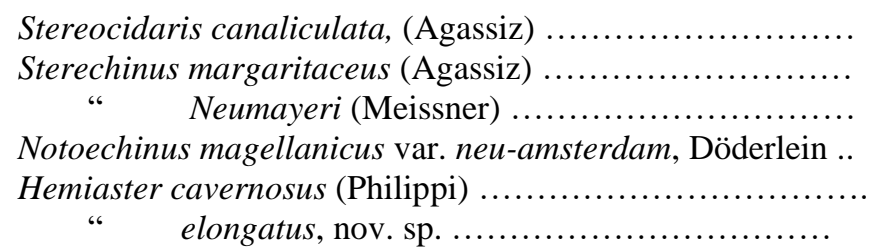 & $\begin{array}{l}\text { Falkland Islands. } \\
\text { Burdwood Bank. } \\
\text { South Orkneys. } \\
\text { Gough Island. } \\
\text { South Orkneys. } \\
\text { South Orkneys. }\end{array}$ & $\begin{array}{c}0-5 \\
56 \\
6-10 \\
100 \\
6-10 \\
6-10\end{array}$ \\
\hline
\end{tabular}

All these species, except the last that is new, have already been encountered in areas near those where the Scotia collected them. The variety neu-amsterdami of Notoechinus magellanicus from Amsterdam Island, which is found at the same latitude as Gough Island.

It seems to me absolutely useless to consider here the comparison of the echinoderm faunas of the arctic and Antarctic to show, once again, using the information furnished by the explorations of the Scotia, that these faunas are completely different from each other. The question was settled a long time ago. But there is another fact that results from this comparison and that seems to me without contest. It is that the Antarctic fauna is much richer than the arctic fauna. I shall add that it also less uniform. It is richer because the number of Antarctic species presently known is greater than the number of arctic species. However, while the boreal regions have been the object of numerous explorations and that the new species there have become rarer and rarer, the Antarctic regions, on the contrary, have hardly been explored and have already furnished a large number of species that will probably grow with future explorations. We know, in fact, the uniformity of the arctic fauna, which is easily explained by the continuity of the continents in the boreal region. This continuity contrasts with the isolated state of the southern lands. As far as we can judge at the present, the faunas of Patagonia, Kerguelen and New Zealand are quite different. However, we 
have scarcely explored up until now, in the Antarctic, in the part south of Cape Horn. It is possible that the investigations that will be done in the future, at other longitudes, will make known still other forms.

\section{ASTEROIDS.}

Dystaster felix, nov.sp. (Pl. I. fig. 1 to 3)

18 March $1904,71^{\circ} 22^{\prime}$ lat. S., $16^{\circ} 34^{\prime}$ long. W.; depth 1410 fathoms. Two specimens.

In the large specimen $\mathrm{R}=72$ and $\mathrm{r}=14 \mathrm{~mm}$. This specimen is not in very good condition. Four arms are broken toward the end and the disk is more or less damaged. The small specimen is better preserved. Its dimensions are: $\mathrm{R}=40 \mathrm{~mm}, \mathrm{r}=10 \mathrm{~mm}$.

The disk is rather large. The arms are rather narrow at the base where their width attains 18 to $29 \mathrm{~mm}$. They taper gradually to the end that is fine and pointed. The dorsal surface is covered with very dense paxillae, a little unequal and irregularly rounded. They are very small, especially in the central region of the disk. They largest ones do not pass 0.7 to $0.8 \mathrm{~mm}$. They have some central granules, to the number of two to six, surrounded by aa circle of smaller peripheral granules. In general, one of these granules, or even sometimes two, are elevated on the paxillae of the central region of the disk into a small, short spine, rounded at the end and recumbent. The arrangement of the paxillae becomes a little more regular in the area of the interradial corners where they have a tendency to be arranged in parallel rows. The madreporite is very large, oval, elongated in the radial direction. Its external edge is separated by approximately five $\mathrm{mm}$ from the dorsal marginal plates.

On the arms, the median paxillae are arranged without order. They do not differ from those of the disk. The lateral paxillae form small, rather regular transverse rows, each having six to seven paxillae. These lateral paxillae, although smaller than the median ones, nearly all have their single central granule raised into a small blunt cone while in the middle of the arm, the papillae, which are a little larger and which have several central granules, do not have any that are raised.

The paxillar area of the arms is very wide. The dorsal marginal plates are comparatively very narrow. These are a little wider than long, but when we look at them from above, the part that appears with the dorsal surface of the arms is a little longer then wide. They are well separated from each other, as well as the ventral marginals that correspond exactly to them. They are covered with dense granules, rounded, becoming simply a little smaller toward the edges. There is never a marginal row that is distinguished from other granules, either by size or by regularity.

The latero-ventral plates cover a rather narrow space. The rows that they form are not easy to distinguish on the large specimen because of the spines and pedicellariae they have. In the small specimen, these rows are better defined. The first interradial row contains six plates. All the plates have short spines, conical, dense, rather large on the ventral surface of the plate, becoming smaller and finer and inclining obliquely on the sides. Most of these plates have a group of three spines transformed into a large tridactyl pedicellariae whose valves are thick, elongated and sometimes 
arched. These pedicellariae are very apparent. I find them on the small specimen. They are continuous on the arms. I still observe them opposite the tenth ventral marginal plate.

The small ventral marginal plates correspond to the dorsals. They are a little wider than long in the interbrachial corner. Then they become nearly as wide as long. They are covered with dense granules that are a little elongated. In the interbrachial corner, one of these granules is elevated toward the middle of the external surface of the plate into a small conical spine with a blunt point. It progressively approaches the distal edge of the plate. Not all these plates have this spine. I do not see it after half the length of the arm. Perhaps this absence is accidental. Above this spine and toward the upper edge of the plate, i.e., toward the interval that separates it from the corresponding dorsal marginal plate, I often see a tridactyl pedicellaria at the beginning of the arm, identical to that of the ventral plates. These pedicellariae occur also on the small specimen.

The ambulacral tubes are contracted with a very small terminal sucker. The groove is not very large except toward the middle of the arm.

The adambulacral plates have, in the groove, a first row of eight to ten elongated spines arranged regularly in the form of a comb. The median ones are a little longer than the other. Outside come two irregular rows of larger spines, three to six per row. These spines are lanceolate and pointed. Some adambulacral plates also have a pedicellaria.

The teeth have on their edges, numerous, very dense spines that extend inward. On the ventral surface, we see an external row of small granules. Inside are to irregular rows of granules.

Similarities and Differences.-D. felix is separated from all known Dytaster . It is especially notable by the number of pedicellariae of the ventral surface and by the presence of thee pedicellariae on the dorsal edge of the ventral marginal plates as well as on the adambulacral plates. By its general form, it is to D. nobilis Sladen that D. felix is most similar, but it is distinguished from it by the absence of spines on the dorsal marginal plates and by its pedicellariae.

$$
\text { Psilasteropsis facetus, nov. sp. (P1. II, fig. } 16 \text { to18). }
$$

13 April 1904, 48 6' lat. S., $10^{\circ} 5^{\prime}$ long. W.; depth 1742 fathoms. Two specimens.

In the large individual, $\mathrm{R}=93$ and $\mathrm{r}=22 \mathrm{~mm}$; in the other, $\mathrm{R}=75$ and $\mathrm{r}=20 \mathrm{kk} /$

These specimens are unfortunately in rather bad condition. In the larger, whose two arms are broken toward the end, the dorsal surface is not too deteriorated, but the dorsal marginal plates have lost their covering. As for the ventral surface, it has greatly suffered. Most of the spines of the ventral plates, of the marginal plates, of the teeth and of the adambulacral plates have been torn off. The other individual has broken arms and the dorsal surface is very damaged, while the ventral surface is, at least in some areas, less deteriorated than in the large individual.

The disk is large and even comparatively more developed in the small specimen. The arms are strong and thick, rather wide at the base. They taper very regularly to the end that is very pointed. the dorsal surface is flat. The ventral surface is convex. The lateral surfaces of the disk and the arms are high and vertical.

The dorsal surface of the disk is covered with extremely small and dense paxillae in the central region where they are irregularly arranged. Their diameter is only 0.2 to $0.3 \mathrm{~mm}$. Then they rapidly become larger and arranged in regular radial rows. On the arms, we see a median band of very small paxilllae that continue the small central paxillae and form five or six irregularly longitudinal 
rows. On each side of this band leave transverse rows, oblique and very regular of larger paxillae, about ten per row at the base of the arms. It is especially in the intervals of these rows that the papulae are found. Under the microscope, these paxillae are seen constituted of vertically upright spinules, containing a central group, variable in number, surrounded by a peripheral circle of the same dimensions. The madreporite is small. It is located nearer the edge than the center. There is a very small central anus surrounded by some circles of extremely reduced paxillae.

The dorsal marginal plates, about forty, are wide, thick and prominent. Their external surface is convex. These plates are very high. They are nearly two thirds the height of the arms. They are separated by very marked grooves. They are covered with rather large granules, wide and flat, that abruptly become small toward the sutural border. We see thus three or four rows of the small granules. The adjacent plate has similar rows, but these granules are never elongated. They have no tendency to form fasciculate pedicellariae. Toward the middle of its external edge, each plate has an elongated spine, flat and pointed. We can even sometimes see two superposed into the interbrachial arch, but in general these spines are torn off. They are nearly all missing in the large specimen and better preserved in the small.

The ventral marginal plates, which correspond to the dorsals, are also wide but less high than the latter. They are covered with flat, dense granules and have, in addition, a row of rather large spines, strong, flat and pointed, in the form of a saber blade and recumbent on the plate. In the interbrachial arch, we count four or five spines on each plate. This number then falls to three. The internal spine is the smallest. Its length increases up to the most external and nearly equals the article. Toward the sutural border, the granules become smaller and have the same arrangement as the dorsal plates.

The ventral lateral plates form transverse rows going from the adambulacrals to the ventral marginals. The first interradial row has six plates. Then the number rapidly decreases. There are approximately ten rows, of which the latter have only two plates and finally only one. These plates have very short spines, erect, dense, with a rounded end that rather resembles elongated granules.

The ambulacral grooves are wide. The ambulacral tubes are large, pointed, with a rudimentary sucker. It is nearly impossible to recognize the characters of the adambulacral spines because of the state of the specimens. I see an internal row with approximately six to eight spines forming a vertical comb. Outside are two ventral, more or less regular rows. But I cannot distinguish the number or the exact disposition of the spines.

The armature of the teeth is likewise removed in large part. I distinguish, however, on the free edge of each tooth a row of strong spines, erect, very tiight against each other. On the ventral surface, they seem to have only a single row of very short spines, forming rather large flat granules arranged parallel to the external row.

Similarities and Differences.-I have placed this asteroid in the genus Psilasteropsis because it has a great exterior resemblance to Ps. patagiatus (Sladen). But it differs from this species, like Ps. cingulata W. K. Fisher, by the presence of spines on the dorsal marginal plates. From this point of view, Ps. facetus is near Ps. humilis that I recently described in which the dorsal marginal plates are also armed. A precise generic determination could be made only with the possibility of observing the characters of the teeth and adambulacral spines. I have unfortunately been unable to do this. Our asteroid recalls also Persephonaster. This genus is, moreover, extremely close to the genus Psilasteropsis. 


\section{Ripaster Charcoti, Koehler.}

Koehler, Expédition Antarctique française du Dr. Charcot: Echinodermes, p. 4, pl. III., dif. 20, 21, 31 and 32.

18 March 1903, $62^{\circ} 10$ lat. S., 412 20' long. W.; depth 1775 fathoms. Three specimens.

These specimens are in a deplorable state. The disk and the arms are bent, broken, deformed, denuded. The debris is scarcely recognizable. They obviously belong to the genus Ripsater as I defined it and I cannot distinguish them for Ripaster Charcoti, that then descends to a depth much greater than that where the Français collected it.

\section{Odontaster validus, Koehler.}

Koehler, Expédition Antarctique française du Dr. Charcot: Echinodermes, p. 6, pl. III, fig. 22-26/

March-November 1903. Scotia Bay, South Orkneys; depth 5-10 fathoms. Several specimens.

June 1903. South Orkneys; depth 9-10 fathoms. Three specimens, of which two have four arms.

31 January 1904, Falkland Islands; depth 5-20 fathoms. Several specimens.

All these individuals conform very well to the type that I have described and figured, but they are very different in size. Here are some measurements that I took from some specimens:

\begin{tabular}{|c|c|c|c|}
\hline $\mathrm{R}=\underset{47}{50 \mathrm{~mm}}$. & $\mathrm{r}=\underset{25}{25 \mathrm{~mm}}$. & $\mathrm{R}=32 \mathrm{~mm}$ & $\mathrm{r}=\underset{14}{15 \mathrm{~mm}}$. \\
\hline 42 ، & 17 ، & 24 ، & 10 \\
\hline 35 “ & 17 ، & 21 " & $10.5^{\text {، }}$ \\
\hline
\end{tabular}

Odontaster Grayi (Bell).

See for the bibliography:

Ludwig, "Asterien und Ophiuren der schwedischen Expedition nach den Magalhaenslandern. 1895-1897." Zeit. für wiss. Zool., Bd. lxxxii, p. 44.

$1^{\text {st }}$ December 1903, Burdwood Bank, 54 $25^{\prime}$ lat. S., $57^{\circ} 32^{\prime}$ W.; depth 57 fathoms. One specimen. $\mathrm{R}=32 \mathrm{~mm}$.

The specimen conforms well to the figure that Perrier has given under the name Asterodon pedicellaris, according to an individual coming from Cape Horn. This species is widely distributed in the Antarctic regions. It gave rise to a fairly complicated synonymy that has been unraveled by Ludwig.

Odontaster pusillus, nov. sp. (P1. 1. fig. 10 and 11)

13 April 1904, $48^{\circ}$ 6' lat. S., $10^{\circ}$ 5' long. W.; 1742 fathoms. A single specimen. $\mathrm{R}=13 \mathrm{~mm}$; $=7 \mathrm{~mm}$. 
The disk and the arms are very flat and only $2 \mathrm{~mm}$ thick. The body is polygonal, with the sides strongly excavated. The pointed and triangular arms are well separated from the disk.

The dorsal surface has very distinct plates, small, convex and separated by deep grooves that have papulae. They have seven or eight spines arranged as paxillae. In the central part, these plates are arranged without order. But on the arms, we recognize a median row and, on each side, one or two other rows. They become smaller toward the dorsal marginal plates and then form small transverse rows. The paxillar area becomes very narrow toward the end of the arm but it continues up to this end. Each paxilla has a central spine surrounded by a peripheral circle of divergent spines. These spines are cylindrical, a little swollen at the end that has some very fine and very short spinules.

The madreporite, located equal distance between the center and the marginal plates, is small. It has only a small number of grooves.

There are ten dorsal marginal plates on each side and an unpaired plate. This is large, wider inside than outside, but not triangular. The three or four following are rectangular, wider than long. Then the other become a little shorter. The last is very small and triangular. The terminal plate is small, triangular, with an obtuse proximal corner and a very convex distal edge. The covering of these plates is nearly lost. We recognize, however, on the surface, elongated granules, dense and rugose. On the external edge of the plates, they elongate into true spines, flat and a little enlarged at the end. They have fine denticulations on their edges. The dorsal marginal plates remain separated from each other up to the end of the arms.

The ventral surface of the disk has nearly square plates, arranged in regular longitudinal and oblique rows. The first row, contiguous with the adambulacrals, has plates nearly as large as the latter and, in general, two corresponding to three adambulacrals. Each plate has four or five elongated spines, cylindrical and rugose at the end that is obtuse. These spines decrease in length toward the ventral marginal plates. All these spines form a rather dense covering that prevents distinguishing the contours of underlying plates.

The ventral marginal plates correspond to the dorsals. Like these latter, they have spines that, on their lower surface, are in the form of elongated granules. Toward their external edge, they develop greatly, elongating at the same time that they enlarge and flatten at the end. Thus, they constitute spines with very fine denticulation as on the dorsal plates.

The adambulacral plates have, in the groove, three flat spines, obtuse and rugose at the end. They are arranged in a way to form a small comb. On their ventral surface, the adambulacral plates have some spines that generally are arranged in two rows.

The teeth have on their free edge, about six spines identical to the adambulacral spines. On their ventral surface, we find two larger spines and, finally, lying on the median suture, a large conical spine that ends in a hyaline extremity that characterizes the genus Odontaster.

I have not seen pedicellariae on either the dorsal or ventral surface.

Similarities and Differences. - The single specimen collected by the Scotia is without doubt a young individual, but it cannot be related to any known species. O. pusillus is near $O$. Grayi (in the sense that LUDWIG gave to this species). It differs from it by its arms that are truly distinct and by the great development the spines take on the free edge of the dorsal and ventral marginal plates. It is distinguished easily from $O$. cremeus Ludwig, which has much more numerous marginal plates covered with simple granules. We cannot confuse $O$ pusillus with $O$. penicillatus. I have compared the specimen of the Scotia to a specimen from the museum of Hamburg, identified by MEISSNER and in which $\mathrm{R}=12.5 \mathrm{~mm}$. There are nine marginal plates. The animal is infinitely 
more robust. It is thicker. Its height attains approximately $3 \mathrm{~mm}$. The arms are thicker and much wider. Finally, the adambulacral spines, must larger and stronger, have a different arrangement. O. elongatus is also very different. The other near southern forms belong to the genus Asterodon.

Chitonaster Johanna, nov. sp. (P1. IV. Fig. 32 to 37.)

18 March 1903, 62 10’ lat. S., 41²0’ long. W.; depth 1775 fathoms. Four specimens.

The respective dimensions of the specimens are the following:

$$
\begin{aligned}
& \mathrm{R}=31 \mathrm{~mm} . ; \mathrm{r}=11 \mathrm{~mm} . \quad \mathrm{R}=12 \mathrm{~mm} . ; \mathrm{r}=5 \mathrm{~mm} \text {. } \\
& 23 \text { “ } 10 \text { “ } \\
& 10 \text { “ } 4 \text { “ }
\end{aligned}
$$

The individuals are unfortunately not intact, except for the smallest. The next one has only two arms, the other has three and the largest has preserved four arms out of five.

The whole animal has a very robust and very solid structure. The plates form a true rigid carapace. The disk, which is large, is very high. Its height attains $10 \mathrm{~mm}$. in the large specimen. The arms are very wide at the base. Their end is obtuse. Their dorsal surface is also very convex.

The dorsal surface is covered with irregularly polygonal and unequal plates, with rounded corners. These plates are very separated and very distinct in the two small specimens. They are still rather distinct in the middle one, but their contours are hardly visible in the largest where they appear fused together. These plates have large, elongated granules, robust and thick, resembling rather small, very short spines with a rounded end They are unequal in size and height. In the large individual, there are three to six granules per plate. In the others, this number varies between two and five The plates, as well as their granules, are arranged without order in the two large specimens. In the small ones they form concentric, more or less distinct circles. On the arms, the plates form transverse rows, more apparent in the large specimens than in the small. In the two latter, the granules are less numerous than in the large.

We are absolutely surprised to encounter, on some of the plates, large valvular pedicellariae whose length can attain $2 \mathrm{~mm}$ in the large individual. They occupy a rather large region of the plate, leaving place for two or three small granules on the sides. On the large specimen, I count seven pedicellariae, occupying all the interradial position, but arranged in a completely irregular manner. Most are found on the edge of the disk. Only one is located near the center. The middle specimen has five pedicellariae, a little smaller and always arranged without order. The two small individuals do not have pedicellariae on the dorsal surface. However, I note on one plate of the specimen in which $\mathrm{R}=12 \mathrm{~mm}$, two elongated and contiguous thickenings that appear very well to correspond to a pedicellaria in the process of development (as I shall say later, this same specimen has on the ventral surface perfectly developed pedicellariae).

The madreporite is rather small, rounded, with grooves that leave the center, irregularly radiating. It is located a little nearer the edge than the center of the disk.

There are eighteen to nineteen dorsal marginal plates in the large specimen. The plates have a very regular arrangement of their granules forming a transverse row of four that is perpendicular to the axis of the arm. Moreover, we find in general a small accessory granule. The apical granule is very apparent. It is rounded, a little wider than long. It does not occupy the entire width of the arm in the two large specimens. It is comparatively larger in the two small ones where it occupies all the end of the arm. It has some small granules on its surface. 
The latero-ventral plates are not numerous. Their contours are hidden by the integument. In the large specimen, the row parallel to the adambulacrals has five or six plates. Outside, two or three plates complete the ventral surface. In principle, each plate appears to have a small cylindrical and obtuse spine with two or three granules. But the spine can be missing and the granules alone are seen. Moreover, the order is sometimes modified by the transformation of spines into pedicellariae. In the large specimen, we can see a pedicellariae in each interradius. Four of these pedicellariae are found immediately outside the teeth. The fifth is a little separated. I note in addition that in three interradii, the pedicellaria is placed longitudinally and in the two others transversally in relation to the interradial axis. These five pedicellariae are the only ones in this species. We see that their arrangement is fairly regular. In the middle specimen, the pedicellariae are much more irregularly placed and occur anywhere on the ventral surface. Only two or three are definitively formed. The others consist of an elongated granule and it is still not split. Finally, some adambulacral plates also have a pedicellaria. In the specimen in which $\mathrm{R}=12 \mathrm{~mm}$, I note a pedicellaria on one of the latero-ventral plates, another on the ventral marginal plate and three on the adambulacrals. The smallest individual totally lacks pedicellariae.

The ventral marginal plates correspond to the dorsals. In the large specimen, their armature is generally arranged in the following manner; below, an elongated granule; in the middle, a larger and longer granule forming a true spine; above, two smaller granules. On some plates, however, I see only three granules, of which the middle one is larger. This arrangement is the rule in the middle specimen. In the two smaller ones, there are generally four of them per plate: one lower, one in the middle and two above.

The ambulacral grooves are rather narrow. The ambulacral tubes are very regularly biserial and end in a larger sucker.

Each adambulacral plate has, in the groove, two unequal spines; the proximal spine is elongated, cylindrical and obtuse at the end, the other is shorter and resembles rather an elongated granule; sometimes, we see a supplementary granule in front of the spine. On the ventral surface of the plate is an erect cylindrical and obtuse spine. In the small specimens, the two spines of the groove are subequal and smaller than the ventral spine. We have already seen above that the adambulacral plates themselves can have pedicellariae. There are not numerous.

The color of the specimens is yellowish-gray.

Similarities and Differences.-The discovery of a new species of the genus Chitonaster is very interesting because the genus has, until now, been represented by a single species, itself created after a single specimen. The presence of valvular pedicellariae in the species collected by the Scotia, pedicellariae that do not exist in Ch. Cataphractus, allows fixing in a definitive manner, the position of this genera in the family of pentagonasterides, where SLADEN had placed it with some doubt.

The type of the Challenger comes from southern seas. As it has been collected at $62^{\circ} 26^{\prime}$ lat. S. and $95^{\circ} 44^{\prime}$ long. E., we see that the two species are not encountered at the same latitude but, in contrast, are found in localities very narrow in longitude.

Ch. cataphractus was described by SLADEN after an individual whose dimensions were: $\mathrm{R}=$ $16.5 \mathrm{~mm}$ and $\mathrm{r}=5 \mathrm{~mm}$. These are thus intermediary, in size, between the second and third specimens of the Scotia. The most important difference between the two species is the presence of valvular pedicellariae that are completely absent in Ch. cataphractus. This difference cannot be attributed to a difference in age because the pedicellariae occur in a specimen of Ch. Johannse in which $\mathrm{R}$ is only $12 \mathrm{~mm}$. Moreover, the arrangement of the adambulacral spines and the armature 
of the dorsal and ventral marginal plates differs in the two species. Finally, the dorsal surface of the disk and the arms in Ch. Johannsei has granules and not true spines.

\section{Marcelaster, nov. gen.}

The genus Marcelaster is near the genus Pararchaster, It has the general appearance and the narrow marginal plates. But does not have the unpaired marginal plate. Instead of it, we see in the interbrachial arch a group of latero-dorsal plates with a tuft of large spines that cover the first dorsal marginal plate of each side. This plate is a little smaller than the following. The dorsal plates of the disk and arms are covered with spines arranged as paxillae. We see on the dorsal surface of the disk some plates larger than the other, each with a large central spine. These plates appear arranged in a certain order. There is a central plate and radial and interradial plates. There are no latero-ventral plates (at least on the individuals I have studied). The dorsal and ventral marginal plates each have a large and strong spine, surrounded by some other smaller ones. The adambulacral plates have, on their ventral surface, one or two large spines.

Marcelaster antarcticus, nov. sp. (Pl. III. fig. 22 to 25.)

18 March 1903, 62 ${ }^{\circ} 10^{\prime}$ lat. S.., $41^{\circ} 20^{\prime}$ long. W.; depth 1775 fathoms. Three specimens that are intact and in excellent condition. One another, a little smaller, is incomplete. The latter is very small.

In the large individual, $\mathrm{R}=33 \mathrm{~mm}$ and $\mathrm{r}=8.5 \mathrm{~mm}$. In the smallest, $\mathrm{R}=10 \mathrm{~mm}$.

The disk is of medium size and low. The arms are flat and thin. They measure approximately $7 \mathrm{~mm}$ in width at their origin. Then they taper gradually to the end that is blunt.

The dorsal surface of the disk and the arms is covered with round plates, a little unequal, with oblique and divergent spines that represent paxillae. The largest of these paxillae is formed of seven or eight spines, arranged or not around a central spine. The smallest paxillae, along the edge of the disk or on the arms, have only four, three or even two spines. These are elongated, cylindrical, obtuse and slightly rugose at the end. The plates are completely hidden by these spines that crisscross and entangle from one paxilla to another. Their limits appear only when the spines are removed. Even these limits are not always very precise because the plates are united at their base by a common calcified tissue. In the central region of the disc, some plates larger than the others have, in the center of the spines that form the paxilla, a large spine, strong, cylindrical, stocky, obtuse at the end, and at least $2 \mathrm{~mm}$ in length. The large specimen has a dozen of these spines, among which we can distinguish a central spine and at least two spines per radius and interradius. The regular arrangement of these spines is better marked in the individual in bad condition. In the small specimen that I shall describe below, we clearly recognize a centro-dorsal plate and, separated from it by two or three rows of small plates, five interradial plates nearly as large as it and five smaller radial plates (P1. III, fig. 25).

The madreporite, near the interbrachial arch, is small and has some grooves. The anus has the form of a very small opening, located beside the central paxilla.

Toward each interbrachial arch, some dorsal plates each has a group of elongated spines, generally arranged in three rows on each plate: four rather short dorsals, scarcely longer than those 
that form adjacent paxillae, four longer medians and finally three or four much longer externals. All these spines crisscross and constitute, as a whole, a dense tuft that covers the base of the interbrachial arch. When we remove these spines, we see that the plates that supported them number seven: three on each side of the interradial angle and one unpaired located exactly above the suture that separates the first dorsal plate from its counterpart (fig. 24).

The dorsal marginal plates number eighteen. There is no unpaired plate as in Parachaster, but the first plate of each series is smaller than the following. These plates are long but very thin. They are not very separated from each other because their very thin lateral surfaces are more or less confluent. They form rather, as an ensemble, a kind or border having thickenings from place to place. Each marginal plate has a large oblique principal spine, cylindrical and obtuse, with a rugose surface, surrounded at the base by a circle of seven or eight much smaller spines. The first marginal plate, which is smaller, does not have in general the principal spine, but by a group of five or six elongated spines.

There are no latero-ventral plates. The ventral marginal plates are followed immediately by the adambulacrals. These plates correspond to the dorsals. Each of them has in its middle, a large spine more developed than the corresponding spine of the dorsal plates and surrounded by a circle of much smaller spines. On the first plates each series, we note that one or two of these small spines is elongated, especially the spine located immediately inside the principal spine.

The adambulacral plates have, in the groove, three spines, elongated and cylindrical, the median longer than the two others. On the ventral surface, we note one, and sometimes two large spines, elongated and very wide, larger than the spines of the groove, and also some smaller spines of which one is often pointed inside, which brings to four the number of spines in the groove. The ambulacral grooves are of medium width. The ambulacral tubes are arranged in two very regular rows and end in a convex sucker as wide as the diameter of the tube.

The teeth have on their free edge, a row of eight to ten spines, smaller than the ambulacral spines and, on their ventral surface, a row of three or four large spines.

The small specimen, that still has not acquired the characters of the adult, has some particularities that it is interesting to note (Pl. III, fig. 25). The dorsal surface of the disk and the arms is covered with small plates, rounded or irregularly polygonal. We do not distinguish a carinal row, but only eleven very apparent primary plates. There is a large centro-dorsal, five smaller radials located in the middle of the base of the arm, and five larger interradials. Each of these eleven plates has a large spine surrounded by some other smaller ones. The other plates have groups of three to five small spines. The dorsal marginal plates number eight. Each of them has a large spine and some other smaller ones. The first plate is a little smaller than the following. These plates are narrow and touch by their thin edges. There is not the least indication of an unpaired plate. The dorsal plates that are near the interradial angle do not differ from the adjacent ones. The terminal plate is large and swollen. It is notched on its proximal edge for the last dorsal plate of the arm. Toward its free edge, it has two large divergent lateral spines and some other smaller ones. The ventral marginal plates have each a large spine and other smaller ones. The adambulacrals have three spines in the groove, and, on their ventral surface, two large spines and some other smaller ones. At some distance from the base of the arms, we can distinguish only one principal spine. 
Ganeria attenuata, nov. sp. (Pl. III. fig. 26 and 27.)

18 March $1903,62^{\circ} 10^{\prime}$ lat. S., $41^{\circ} 20^{\prime}$ long. W.; depth 1775 fathoms. A single specimen.

$\mathrm{R}=35$ to $38 \mathrm{~mm} ; \mathrm{r}=11$ to $12 \mathrm{~mm}$.

The specimen was very strongly contorted and folded on itself. I have succeeded, by drying it, to straighten it and give it the form that I have photographed.

The dorsal surface is convex and the ventral surface concave. But it is certain that this form is due to the defective attitude taken by the preserved specimen that, in the living state, must be flat and very thin.

The dorsal surface of the disk and arms is covered with small plates with irregular contours, each of which has a short spine, obtuse and rugose at the end, and sometimes even with two or three very short spines. The base of the spine is widened but the rest is cylindrical. There are sometimes two spines per plate. The plates, as well as the spines, are arranged without order and do not form series. The anus is central and small, over which are folded some spines. The madreporite is small, located near the center. It is a little protruding and has on its surface some rugose and very flat granules. On the edges of the arms, the plates are extended into a rather regular marginal row. They each generally have a small comb of three spines, but these are ordinarily broken and, in any case, lying down and mixed with each other so that it is very difficult to distinguish them.

The plates of the ventral surface do not have distinct contours. They have rather strong spines, elongated, cylindrical, with an obtuse end and arranged without order. The ventral marginal plates are very thin. Each has two spines identical to other ventral spines and that are more or less confused with them as well as with the spines of the dorsal marginal plates.

The ambulacral groove is of medium width. The ambulacral tubes are biserial. The adambulacral plates have an oblique spine in the groove and, on their ventral surface, two strong and cylindrical spines, the inner one larger than the other.

The teeth have on their free edge four or five spines identical to the adambulacral spines that they continue. On their ventral surface are some spines forming an irregular row that is continuous with the other spines of the ventral surface of the body.

Similarities and Differences. - G. attenuata is distinguished from the other species of the genus by it dorsal plates that have a single spine.

Scotiaster, nov. gen.

The genus Scotiaster is near the genus Ganeria, from which it differs by the little development of the dorsal skeleton. The dorsal surface remains rather soft, and the calcareous plates, hidden under the integument are not apparent. They are without doubt rudimentary. We have observed on this surface, only spaced small tubercles or granules that, on the sides of the arms are arranged in small transverse rows. These granules, little developed, appear only across a thin integument. The dorsal and ventral marginal plates are little apparent. The dorsals are not even visible except at the end of the arms. The ventral plates have indistinct contours and have elongated spines. 
Although the genus Scotiaster is very near the genus Ganeria, it appears to me necessary to separate it because of the character of the dorsal surface that is nearly deprived of all covering and has only some granules. We can only suppose that this surface had in the living animal some formations such as spines or others that were accidentally lost. In fact, the single specimen that has been given to me appears in excellent condition and the dorsal surface has a thin integument that covers the granules. The papulae are well preserved and very apparent.

The genus Scotiaster is thus characterized by an obvious reduction of the skeleton and spines of the dorsal surface. The spines of the ventral surface themselves are soft.

Scotiaster inornatus, nov. sp. (Pl. IV. fig. 38 et 39.)

9 April 1904, 51 $7^{\prime}$ lat. S., 9 31' long. W.; depth 2103 fathoms. A single specimen.

$\mathrm{R}=38$ to $40 \mathrm{~mm} ; \mathrm{r}=15 \mathrm{~mm}$.

The disk is large. The triangular arms are inserted on the disk by a wide base that taper rapidly to the end that is obtuse. The animal is without rigidity and the arms can be turned back on themselves.

The dorsal surface of the disk is soft and can be easily depressed. It has a thin integument, under which appears small tubercles, inconspicuous, sparse, arranged without order, widely separated from each other. On the arms, however, these tubercles become denser and they are arranged in small transverse row, rather close together, and extend in an irregular median band to the dorsal marginal plates. These latter are not apparent, neither the interbrachial arch nor at the beginning of the arm. They are scarcely visible until the second half. They are in the form of slight elevations that become more marked toward the end of the arm. They correspond to the ventral marginals that are better marked. Each plate has one or two granules identical to those we see on the dorsal surface. Between the granules are elongated papulae that are numerous but isolated. The madreporite, located nearly at equal distance between the center and the edge, is small and rounded. It has grooves that radiate from the center.

The contours of the latero-ventral plates are absolutely indistinct. These plates are covered with a thin integument. It has elongated spines, very wide at the base, conical, pointed and very close together. These spines are not rigid. They are often a little incurved. Their end is soft. Under the microscope, they are seen constituted of a calcareous stem covered with a rather thick integumentary sheath. They form rows parallel to the adambulacrals and other more apparent rows joining, in a radial direction, the ventral marginals. These spines become smaller as they approach the latter. It is possible that each of them corresponds to a plate. To be assured of that, it would be necessary to treat with potassium a part of the ventral surface. But I did not dare to do that, the specimen being very soft and could be greatly damaged by this treatment.

The contours of the ventral marginal plates are not very distinct. Each of them has a small transverse row of two or three very short spines. It is the latter that make the marginal plates apparent.

The ambulacral groove is wide. The ambulacral tubes are irregularly biserial, sometimes triserial. They stand out clearly by their deep brown color on the ventral surface, that is very pale and yellowish-white. The adambulacral plates have in the groove, two spines. We find two others on the ventral surface. These spines are large, conical. They resemble the spines on the rest of the ventral surface. 
The teeth have on their free edge, three spines, of which the proximal is more elongated and larger. On their ventral surface is a large spine directed obliquely forward, under the terminal spine.

The general color is yellowish-white, with the ambulacral tubes very dark, as I have said above.

Retaster verrucosus, Sladen.

Sladen, Reports of the "Challenger": Asteroidea, p. 478, pl. lxxvi., fig. 1-2, and lxxvii., fig. 9-10.

$1^{\text {st }}$ December 1903, Burdwood Bank, 54 $25^{\prime}$ lat. S., 57 32' long. W.; depth 56 fathoms. One specimen.

$\mathrm{R}=38$ to $40 \mathrm{~mm} ; \mathrm{r}=25$ to $28 \mathrm{~mm}$.

The arms are shorter and the interbrachial spaces less excavated than in the type described by SLADEN. But I do not believe I can separate it on this one character that can vary. The dorsal tent is very thick and folded. We cannot distinguish bundles of fibers there. SLADEN says this happens in adult individuals.

The type of the species comes from the entrance to the Strait of Magellan, Atlantic side, at 55 fathoms depth.

Hymenaster campanulatus, nov. sp. (P1. I. fig. 8 and 9; Pl. II. fig. 19 to 21.)

18 March 1904, $71^{\circ} 22^{\prime}$ lat. S., 16³ 34' long. W.; depth 1410 fathoms. A single specimen.

$\mathrm{R}=11$ to $12 \mathrm{~mm} ; \mathrm{r}=7 \mathrm{~mm}$.

The body is remarkably high. Its form can be compared very exactly to that of a bell whose base is extended into five triangular lobes, ended in obtuse points corresponding to the arms. The total height, measured from the end of the arms, is $12 \mathrm{~mm}$. The ventral surface is very deeply concave. The edge of the body is not fringed.

The dorsal covering is fine and transparent. The fibers appear very weakly developed. The spines of the paxillae raise it into strong prominences, conical, rugose and fairly regularly arranged. We count five to eight per paxillae. The spiracles, round or oval, and limited by a very slightly protruding circle, are arranged rather regularly between the prominences of the dorsal surface, sometimes in a single row, sometimes in two according to their size. The oscular opening is small. The valves are formed of five or six large and strong spines, free in the terminal part. The two external spines are very small, the longer median ones are nearly equal.

The ambulacral grooves widen up to the end of the arm without reaching, however, a great width, then they narrow rapidly. The three ambulacral spines form a slightly oblique comb. They are thin and pointed. The internal one is directed toward the groove, the external one, slightly longer, is directed obliquely downward. Finally, the median one, that is the longest, is directed obliquely inward. In some places, these spines are united by a very clear membrane. The papillae of the segmental openings have a form that we rarely see in the genus Hymenaster. It recalls that of $H$. procoquis Sladen. It is a small oval plate that is free only on its distal edge and that is adherent to the other side, leaving free only a narrow and arched opening. 
The teeth are small and united in a plate nearly as long as wide or a little wider than long, in the middle of which is an ovoid protuberance (Pl. II, fig. 21). Each of them ends in a large spine, very strong and thick, cylindrical, obtuse at the end, whose length equals at least twice the length of the tooth. This spine is directed obliquely and forms with its counterpart a fork, but whose two branches are less divergent. These two spines appear to be the only ones that have teeth. I cannot find lateral dental spines. To be sure of their absence, it would be necessary to dissect the specimen. Thus constituted, the teeth have a very particular physiognomy.

The spines of the ventral surface are rather strong. The first seven or eight spines of each row converge or touch toward the median interradial line. Their length increases progressively. Afterwards come about fifteen spines whose length decreases little by little and become very short. Their obtuse end slightly extends past the edge of the body.

The general color is yellowish-white.

Similarities and Differences.-H. campanulatus is obviously near H. procoquis Sladen, with which it shares the particular form of segmental papillae and it has, like it, three adambulacral spines. But it is distinguished from it by its general form that is completely different and by the structure of its dental system.

SLADEN had wondered if it would be appropriate to place $H$. pracoquis into a separate genus because of the special form of the segmental papillae. Finally, he decided to leave it in the genus Hymenaster. I do not believe that there is any inconvenience in placing $H$. campanulatus in this genus, but it is certain that these two species form a separate section in the hymenasters.

Hymenaster edax, nov. sp. (Pl. II. fig. 12 to 15.$)$

18 March 1903, 62 10’ lat. S., 41²0’ long. W.; depth 1775 fathoms. Three specimens.

$\mathrm{R}=10$ to $11 \mathrm{~mm} ; \mathrm{r}=6 \mathrm{~mm}$.

The form of the body is pentagonal, with sides excavated in a way to form short, triangular arms whose base exceeds the length, with a very obtuse end. The dorsal and ventral surfaces are both convex, with thin, sharp edges. They have a very narrow fringe crossed by the ends of the spines.

The thin dorsal tent is supported by the spines of the paxillae in conical eminences that are nearly all the same dimensions on the disk, where they are irregularly arranged. They have, however, a tendency to form groups of four to six. They become more numerous, denser and small on the arms where the form sometimes more or less apparent oblique rows. The fibers are rather distinct and they divide a little like $H$. coccinatus Sladen, but the spiracles are much more numerous than in this latter species. These spiracles are sometimes large, unequal, circular or oval, with a slightly prominent contour. They generally form a more or less regular circle at the base of each eminence. We find others in the intervals. The ossicle is small. The five valves that limit it are each formed of five or six large, striated spines that become free in the external half.

The first four or five spines of the ventral surface touch or at least are very near each other at the median interradial line. They lengthen rapidly from the first to the sixth, then they decrease progressively. There are approximately eighteen in all. The ends of the spines after the fifth are free and form a very slight protuberance outside. 
The ambulacral groove is wide and a little petaloid.

The first adambulacral plate has three spines. The three or four following have four. This number falls to three on the others. These spines are elongated, strong, pointed, divergent. They form an oblique comb in which the external spine is the longest.

The papillae that cover the segmentary openings are elongated, lanceolate. Their form recalls that SLADEN indicated in $H$. coccinatus, but they have only one median side and two laterals.

The teeth are little developed. They join into a small prominence that serves, in the end, only to support three spines, very strong and very large, elongated, cylindrical, obtuse with some rugosities at the end. There is, on the side of the tooth, a spine directed backwards and, at the end, two superposed spines directed forward.

The general coloration is gray.

Similarities and Differences.-H. edax is especially near $H$. coccinatus Slaten, but it differs from it by the arrangement of the adambulacral spines and by the very small teeth with three considerably developed spines. It also recalls $H$. campanulatus that I have described above. But it is separated immediately by its flat form and by the number of adambulacral spines.

Hymenaster fucatus, nov. sp. (Pl. III. fig. 28 to 31.)

18 March $1904,71^{\circ} 22^{\prime}$ lat. S., $16^{\circ} 34^{\prime}$ long. W; depth 1410 fathoms. Two specimens,

The two individuals have nearly the same dimensions: $\mathrm{R}=24 \mathrm{~mm} ; \mathrm{r}=15 \mathrm{~mm}$.

One of the two specimens is in good condition. It is uniformly gray in color. The other is covered with mud on the dorsal surface and in the ambulacral grooves that it has been impossible to remove completely. Its dorsal surface is deep gray in color from the mud while the ventral surface is reddish.

The body is pentagonal with more or less excavated sides. In the specimen in good condition, the arms are not in general very distinct, while they are much better marked in the other individual. The dorsal surface is nearly flat and the ventral surface, a little convex. The body is limited by a thin fringe that the spines slightly exceed.

The dorsal tent extends uniformly on the spinules of the paxillae that raise it from place to place in small conical eminences irregularly distributed and crossed by the end of the spinules. We see leave from the eminences small fibers that are soon lost in the intervals that remain flat. At some places, especially on the dorsal surface of the arms, these spinules form groups of three to five. The spiracles are small, irregularly arranged between the eminences of the tent. They are not numerous and not dense and limited by a slightly thickened rim. The osculum is wide. The valves are formed each by seven or eight long parallel spines. The two external ones are a little shorter than the others.

The first seven or eight spines of the ventral surface converge toward the area of the interradial medial line generally without touching each other. Their length increases regularly from the first to the sixth. The other spines that decrease progressively, number about fifteen. All these spines are thick and strong, cylindrical and rather spaced.

The adambulacral plates generally have three spines, rather large and elongated and obtuse at the end. They are united by a membrane and arranged in an oblique comb. The internal one is a 
little smaller. The first adambulacral plate has only two spines. This is the number that we often see beyond the second half of the arm.

The segmentary openings are covered with well-developed papillae, sometimes simply oval in the better preserved specimen, although in the other it is clearly fusiform and extended into a blunt point as in $H$. coccinatus Sladen. We encounter, moreover, in the first specimen papillae having this form. These papillae have on their surface, more or less sharp sides. We can distinguish a stronger median side and two lateral sides, as SLADEN described in his H. coccinatus. It is the median side that is extended into a more or less marked point. The first papilla is much larger than the following.

The teeth are not very developed. They form by meeting on the median line, a protruding and rounded keel, ending in a free point at the two ends and directed obliquely. On each side of the keel, we find two large spines located one behind the other and, on the edge of the lateral processes, a row of five small spines, unequal or slightly decreasing in length and size from the first proximal spine to the last.

Similarities and Differences.-H. fucatus is near H. latebrosus Sladen, from which it differs by the eminences of the dorsal tent, less strong, more apart and separated by large intervals where the few spiracles are found; by the more protruding teeth with a marginal row of five small spines, by unequal adambulacral spines and by the more developed first pair of segmentary papillae.

Hymenaster densus, nov. sp. (P1. I. fig. 4 to 7.)

21 March 1904, 69 33' lat. S., 15 19' long. W.; depth 2620 fathoms. Two specimens that, despite their external appearance, are not in very bad condition. The adambulacral and dentary spines notably are nearly all broken.

In the larger specimen, the general form is ovoid and the body is elongated in a direction so that the rays are very unequal. In measuring the larger dimensions, $\mathrm{I}$ find $\mathrm{R}=25$ to $26 \mathrm{~mm}$ and $\mathrm{r}=$ 12 to $14 \mathrm{~mm}$. In the smaller, whose bod is regularly pentagonal, $\mathrm{R}=12 \mathrm{~mm}$ and $\mathrm{r}=8 \mathrm{~mm}$.

I shall first describe the large individual.

The dorsal surface is a little swollen. The ventral surface is, on the contrary, convex and strongly swollen. The arms are strongly curved and folded over the dorsal surface of the disk. They are elongated and end in an obtuse point.

The dorsal tent is rather thick and opaque. The paxillae, dense and close together, end in five of six spines, smooth, elongated, rather robust, with an obtuse and nearly horizontal end. At the center of each group is a shorter central spine. In some places, these groups are very distinct as it undoubtably is in the living animal. But, in general, they are more or less entangled. The fibers are indistinct. The spiracles are not numerous, small and sparse. The osculum is small. The very reduced valves are lying on top of each other and I cannot distinguish the spines that form them.

The ambulacral grooves are wide. They widen up to the points where the arms roll up to fall back on the dorsal surface. The adambulacral spines are greatly damaged and it is very difficult to count them. In general, I recognize four of them. The internal one is small and conical. The others are elongated, slender and pointed. Nearly all are broken. 
The teeth are elongated, thin, protruding. They are united to form a prominence in the form of a very developed crest that has no spine. On the lateral extension and against the crest are two elongated spines. The internal one is longer. Its length is nearly equal to that of the tooth. Three other spines, finer and shorter, occur on the free edge.

The segmentary papillae are small and oval and terminate at their free end by two or three small extensions.

The first five or six ventral spines converge, with the exception of those of the first pair, toward the middle of the interbrachial arch. Following are five or six spines whose length decreases rapidly. Then the arms are raised on the dorsal surface and the very small spines become difficult to count. On the ventral surface, each spine is fairly often accompanied by a small accessory spine, much slenderer.

The small specimen has arms much less raised than the large one. The paxillae are very dense. The spines that form then are rugose. I distinguish, in the valves of the osculum, distinct spines, but the valves are so strongly folded over one another that it is impossible to count the spines in each of them. The adambulacral spines appear to be united by a membrane but they are not better preserved than in the large specimen. It is the same with the teeth.

Similarities and Differences.-Although I have not been able to study in a complete way the characters of the adambulacral spines and the teeth, it is obvious that $H$. densus cannot be related to any already known species having more than three adambulacral spines.

\section{Cribrella Pagenstecheri, Studer.}

See for the bibliography:

LeITPOLDT, "Asteroidea der Vettor Pisani Expédition," Zeit.f. wiss. Zool., Bd. lix., pp. 578-584

(C. Pagenstecheri).

MEISSNER, Hamburger Magalhaensische Sammelreeise: Asteroideen, p. 13.

LuDWIG, "Asterien und Ophiuren der schwedischen Expedition," Zeit.f. wiss. Zool., Bd. 1xxxii., p. 68.

$1^{\text {st }}$ December 1903, Burdwood Bank, 54² $25^{\prime}$ lat. S., $57^{\circ} 32^{\prime}$ long. W.; depth 56 fathoms. Two specimens

21 April 1904, Gough Island; depth 25 fathoms. A single specimen.

The authors who have recently studied Antarctic cribrellids believe that the numerous species that have been created should be united. LEITPOLDT and MEISSNER think that Cribrella Pagenstecheri, Hyadesi, Studeri and obesa do not differ from C. prastans and simplex of Kerguelen, and that all these forms constitute a single species while LUDWIG is inclined to consider the two last species as distinct from the preceding.

While waiting for a revision that is to be imposed absolutely on all the Antarctic cribellids, it appears evident now that the different forms of Patagonia and adjacent regions belong to the same species to which the name of Pagenstecheri should be applied, and that has variations similar to those that we know in $C$. occulta from the boreal Atlantic. 
The specimens of the Scotia rather recall the form Hyadesi described by FERMER. In one of the individuals from the Burdwood Bank, $\mathrm{R}=33 \mathrm{~mm}$ and $\mathrm{r}=8.5$. The arms are relatively wide at the base and measure 9 to $9.5 \mathrm{~mm}$. This individual differs, in the regard, from the type of PERRIER, that has arms longer and narrower at the base. But by the other characters, it absolutely conforms to it, notably in what concerns the arrangement of the adambulacral spines and the latero-ventral plates as well as the armature of these latter.

In the second individual, $\mathrm{R}=40 \mathrm{~mm}$ and $\mathrm{r}=8 \mathrm{~mm}$. The arms are $8 \mathrm{~mm}$ wide at the base. The dorsal surface recalls well $C$. Hyadesi and the adambulacral spines are also arranged as in this latter, but the latero-ventral plates are more numerous and denser.

In the third individual that comes from Gough Island, $\mathrm{R}=44 \mathrm{~mm}$ and $\mathrm{r}=8 \mathrm{~mm}$. The adambulacral spines and the latero-ventral plates are still arranged as in C. Hyadesi, but the granules that cover the latter tend to be elongated into small spines. This tendency is accentuated on the dorsal surface that comes to have the structure indicated by PERRIER in $C$. studeri, i.e., this surface is form of very dense ossicles have spines very close to each other and arranged in a brush.

\section{Cycethra verrucosa (Philippi).}

See for the bibliography:

MEISSNER, Hamburger Magalhaensische Satnmelreise: Asteroideen, p. 14. LORIOL Notes pour servir à l'histoire des Echinodermes, $2^{\circ}$ série, fnscicule 2, p. 21.

LUDWIG, "Asterien und Ophiuren der schwedischen Expedition nach den Magalhaensländern,"' Zeit.f. wiss. Zool., Bd. lxxxii., p. 53, pl. vi. fig. 2-3.

$1^{\text {st }}$ December 1903, Burdwood Bank, 54 $25^{\prime}$ lat.S., $57^{\circ} 32^{\prime}$ long. W.; depth 56 fathoms. Two specimens.

31 January 1904. Falkland Islands; depth 5-20 m. One specimen.

Following the example of MEISSNER and LUDWIG, I consider Cycethra verrucosa to be a very polymorphic species of which there is no reason to separate different forms that have been distinguished under the names of $C$. electilis, simplex, etc.

The two specimens of Burdwood Bank recall the form electilis Sladen. The whole body is robust. The arms are thick, wide. They thin gradually up to the end that is round. The ventral plates are very clearly arranged in longitudinally and transverse rows. They have spines a little more numerous than SLADEN indicated. There are eight to ten per plate.

In the larger individual, $\mathrm{R}=52 \mathrm{~mm}$ and $\mathrm{r}=18 \mathrm{~mm}$.

The specimen from the Falkland Islands corresponds very exactly to the figure and description that BELL has given of $C$. simplex. It is a ganéroïde form, following the expression of PERRIER, with distinct marginal plates.

Lophaster abbreviatus, nov. sp. (Pl. IV. fig. 42 et 43.)

18 March 1903, 62 10’ lat. S., 41²0’ long. W.; depth 1775 fathoms. A single specimen. 
$\mathrm{R}=11 \mathrm{~mm} ; \mathrm{r}=5 \mathrm{~mm}$.

The disk is flat and swollen. The arms, very wide at the base, are rather short, stocky, and triangular with an obtuse end. The dorsal surface is convex, the ventral surface is flat.

The dorsal surface of the disk and the arms is covered with scattered paxillae, irregularly dispersed except on the arms where we can recognize more or less apparent rows. Each paxilla has a short stalk, thick and stocky with a few spinules, only six to eight. These spinules ae longer than the stalk. They are erect or slightly divergent and unequal. Their end is rugose or even with some denticulations. They specimen that was sent to me being dry, I cannot distinguish papullae between the paxillae.

The madreporite is small, indistinct, and brown.

The paxillae of the dorsal marginal plate are more developed than the others. Their stalk is longer and thicker. The spinules are also more elongated. There are nine or ten marginal plates on each side. The ventral marginal plates correspond to the dorsals. They have, like them, well developed paxillae and form a very apparent row. The two paxillae in the interradial angle are smaller than the following ones.

The ventral surface, reduced to a very narrow space between the ventral marginals and the adambulacrals, is naked.

The wide adambulacral plates have in the groove three divergent spines, united by a membrane. The number falls to two at some distance from the base. These spines are elongated, cylindrical and thin. Seen under the microscope, they show fine denticulations on their surface. On their ventral surface, the adambulacral plates have a group of two spines, ordinarily parallel, elongated and strong that show, under the microscope, rather marked denticulations.

The teeth are strong, prominent and elongated. On their free edge they have seven or eight rather short and conical spines, except the internal one that is elongated and cylindrical. I do not see any on their ventral surface.

The dorsal surface has a yellow-brown coloration. The ventral surface is paler.

Similarities and Differences.-Obviously the single individual collected by the Scotia is young. It is however well characterized and cannot be confused with any known species. It is near L. stellans Sladen, from which it differs especially by the adambulacral spines. L. abbreviatus has three elongated spines, while L. stellans has four short and stocky spines. The two ventral spines of the first species are also longer. Finally, the teeth do not have spines on their ventral surface. I have been able to compare my specimen with a L. stellans collected by the Belgica that has been extremely kindly sent me by Professor VAN BENKDEN, and I am confident the two species are very different.

Solaster Lorioli, nov. sp. (Pl. IV. fig. 40 et 41.)

7 March 1903, 67 33' lat. S., 36 35' long. W., depth 2500 fathoms. One specimen. $\mathrm{R}=22 \mathrm{~mm} ; \mathrm{r}=5 \mathrm{~mm}$. 
The disk is rounded, a little convex. The arms are narrow at the base and rather distinct from the disk. They are elongated, thin, and taper progressively to the end that is obtuse.

The dorsal surface of the disk and arms have isolated paxillae composed of a very short stalk supporting six to eight elongated spinules, thin, cylindrical, a little rugose and ending in an irregular and denticulated point. The madreporite is indistinct. The papullae are not numerous. On the disk, the paxillae are arrranged without order. On the arms, they become smaller and form some poorly defined longitudinal rows.

On the edge of arms is a single marginal row of large and strong paxillae that differ notably in their size from the other dorsal paxillae. The stalk is elongated, thick and cylindrical. It has a bunch of twelve divergent spinules. These paxillae are spaced. There are not more than eleven or twelve of them along each arm. The first paxilla of each row is a little smaller. Under the microscope, the spinules of these paxillae scarcely show one or two denticulations toward the end. This end itself sometimes has one or two very fine teeth.

The ventral surface is reduced to a triangular space, triangular and naked.

The ambulacral grooves a rather wide. The tubes are regularly biserial.

The ambulacral plates have, in the groove, three elongated spines, cylindrical and thin. This number then falls to two. The ventral surface of these plates constitutes a prominence in the form of a blunt tubercle with four and sometimes five divergent spinules arranged in a transverse comb. This number then falls to three. All these spines have denticulations toward their ends.

The teeth have, on their free edge, about a half-dozen spines that resemble the admbulacral spines. But as they are nearly all broken, it is impossible to estimate their length. I have not seen any on the ventral surface.

Similarities and Differences. - S. Lorioli is easily distinguished from all known species. Perhaps the single specimen collected by the Scotia is not adult, but it is nevertheless very well characterized. In another species of Solaster with five arms that has been found by the Valdivia at Bouvet Island at a depth of 457 meters. They species still has not been described but the figure that CHuN gives shows that it is very different from $S$. Lorioli.

\section{Solaster australis (Perrier).}

Crossaster australis, Perrier, Mission du Cap Horn : Stéllérides, p. 113, pl. x. fig. 1.

Solaster australis, Ludwig, "Asterien und Ophiuren der schwedischen Expedition," Zeit.f. wiss. Zool., Bd. lxxxii., p. 65.

$1^{\text {st }}$ December 1903, Burdwood Bank, 54 $25^{\prime}$ lat. S., $57^{\circ} 32^{\prime}$ long. W.; depth 56 fathoms. Three specimens.

The three specimens are of small size. The length of their large ray varies between 25 and 32 $\mathrm{mm}$. They are thus smaller than the type of PERRIER to which they conform very well however. One of the individuals has eight arms and the two others have nine. 


\section{Crossaster penicillatus, Sladen.}

SLADEN, Reports of the "Challenger": Asteroidea, p. 446, pl. lxx. fig. 5, and lxxii. fig. 9-10.

21 April 1904, Gough Island; depth 25 fathoms. One specimen.

$\mathrm{R}=15 \mathrm{~mm}$.

The individual is thus larger than the type of SLADEN. It is in rather bad condition, very soft and macerated. The paxillae of the dorsal surface are torn off. They are preserved only at the end of the arms and on their edges. Part of the dorsal surface is even completely torn off. The ventral surface is better preserved. There are nine arms.

This individual conforms well to the type of SLADEN that came from Tristan d'Acunha at a depth of 110 fathoms.

Styracaster robustus, nov. sp. (Pl. IV. fig. 44 and 45.)

9 April $1904,51^{\circ} 7^{\prime}$ lat. S., $9^{\circ} 31^{\prime}$ long. W.; depth 2103 fathoms. A single specimen in rather good state of preservation but, however, deformed and a little flattened.

$\mathrm{R}=$ approximately $45 \mathrm{~mm} ; \mathrm{r}=15 \mathrm{~mm}$. These numbers are approximate. The exact dimensions cannot be evaluated because of the deformation of the specimen.

The whole is very robust. The disk is high and thick. The ventral surface is flat with protruding teeth. The dorsal surface is folded, which prevents recognition of its exact form. The sides of the body are more or less deeply excavated. The arms are very wide at the base and taper very rapidly while always remaining thick and strong. They are cylindrical and end in an obtuse point.

The dorsal surface of the disk is covered with numerous small paxillae, rounded, unequal, formed of three or four rounded and very distinct granules. There are rarely five. The madreporite is rather large, very close to the edge from which it is separated by three rows of paxillae. It has divergent grooves on its surface.

The lateral surfaces of the disk are high and vertical. They have eleven cribriform organs, large and whose striated part is a little wider than the intercalary spaces. The two end ones are smaller than the others. These each contain a dozen rows of scales. The spaces that separate these organs have two or three rows of small granules, rounded and spaced.

There are seventeen dorsal marginal plates in each arm. Six form the sides of the disk. The other eleven limit the arms. The seventh is a little wider than the following ones. All are higher than wide. The last plate, located between penultimate one and the apical plate is small and triangular. The plates of the arm are smooth and do not have granules like those that limit the disk. At the point of union of the seventh and ninth pairs are two strong and conical spines. The first, always more developed than the second, attains $5 \mathrm{~mm}$ in height. Its base is very widened. It is compressed laterally and slightly curved. The following spine is shorter and simply conical. These two spines constantly occur on the five arms. There are no others.

The ventral marginal plates are the same number as the dorsals. On the disk, they exactly continue the latter. They also have on their surface the same granulation that are narrower than high. On the arms, their vertical limits do not always correspond exactly to those of the dorsal 
plates but are sometimes a little nearer the disk. They are nearly square and lack granules. The apical plate is little developed and short. It ends in a large spine, on each side of which is a much smaller spine.

The ventral surface of the disk is covered with a thick integument, under which we cannot distinguish any plate. It has on its surface round granules that are not very apparent in the proximal region but are more numerous and more apparent toward the edge of the disk. The ambulacral grooves are rather narrow inside the disk and widen on the arms. The adambulacral plates are invisible and hidden under the same integument that covers the rest of the ventral surface. We do not perceive even, in the groove, a continuous row of adambulacral spines. We see only, in the intervals of the ambulacral tubes, small groups of two to four elongated granules protruding into the groove. In the second half of the arms, however, the granules become longer and then form rather distinct combs of four or five spines. On the ventral surface of the adambulacral plates, outside the groove, are barely seen some granules that do not differ from other granules of the ventral surface.

The protruding teeth have on their free edge eight or nine small spines, short and conical, that resemble the granules of the ambulacral groove except the last two that are extended and become stronger, especially the latter. On the surface of the teeth are several irregular rows of granules that become a little stronger inside, toward the proximal end of the tooth.

Similarities and Differences.-St. robustus is distinguished from other species of the genus by its very short arms and the higher number of cribriform organs, as well as by the characters of the armature of the adambulacral plates. The species of Styracaster that have numerous cribriform organs (seven to nine) have very long arms, like St. horridus Sladen and elongatus Koehler, while those with short arms have less numerous cribriform organs. Recently, LUDWIG described several new species of Styracaster coming from the dredges of the Valdivia, but none of them are related to St. robustus.

Hyphalaster Scotia, nov. sp. (P1. VII. fig. 71 et 72).

18 March 1904, $71^{\circ} 22^{\prime}$ lat. S., 16³4' long. W.; depth 1410 fathoms. Two specimens.

In the larger individual, $R=20 \mathrm{~mm}, \mathrm{r}=10 \mathrm{~mm}$; in the smaller, $\mathrm{R}=1515 \mathrm{~mm}, \mathrm{r}=8 \mathrm{~mm}$.

The general structure is rather robust. The disk is thick and the dorsal surface is strongly swollen in the large specimen. The ventral surface is a little convex. The arms are short, but thick and strong. A small epiproctal cone is seen in the middle of the disk in the two specimens. It is relatively more developed in the small one.

The disk is large with the sides nearly vertical.

The dorsal surface of the disk is covered with fine paxillae, small and dense, often oval. Each of them is formed by a single spine surrounded by a peripheral border of six to seven spines.

The madreporite is small, oval, with divergent grooves. Its external edge is separated from the dorsal marginal plates by a single row of granules. 
The dorsal marginal plates number eight including the last. Four of them are found on the sides of the disk. They are higher than wide and smooth. The others limit the sides of the arms and are contiguous on the dorsal median line. The first is large and wide. The two following are smaller. Finally, the last is extremely reduced and triangular. Beyond the cribriform organs, the plates have rather large round granules, flat and spaced.

The ventral surface of the disk is covered with thin imbricated plates, forming transverse rows that become narrower toward the edge of the disk. There are approximately ten rows of these plates. Each of them has some small spines, short, conical, with a blunt point that form, all together, transverse rows, naturally denser in the peripheral region of the disk than in the central region.

The ventral marginal plates have the same number as the dorsals to which they correspond, except the two that follow the cribriform organ and that are a little shorter. The last plate is quadrangular and larger than the corresponding dorsal.

The apical plate is rather short, but wide and swollen on the dorsal side. It has a terminal spine that is not very developed, on each side a smaller lateral spine, and another less important spine also on the dorsal surface.

There are five cribriform organs, three wider medians and two narrower others. The median organ contains a dozen rows of scales.

The ambulacral grooves are rather narrow, sometimes a little widened in their median region. The adambulacral plates have each, in the groove, three rather strong spines, conical and pointed. On their ventral surface, we see two spines having nearly the same characters as the preceding, but a little stronger and shorter.

The teeth have on their external edge a row of about a half-dozen spines identical to the adambulacrals. The last proximal spine is stronger. Toward the sutural border is a row of three or four shorter spines. Outside them, we can still see two or three smaller and inconstant spines. The teeth form, leaning back, a very marked protuberance. After meeting medially, they separate to form an oval space, then they meet again and then diverge enough to receive the odontophore. This is small and triangular with an acute and elongated proximal corner, two slightly concave lateral edges and a straight or slightly convex distal edge.

On one of the arms, we see that one of the dorsal marginal plates takes an ovoid form and determines a rather marked protuberance. Thus, the regular order of the plates is a little disrupted on this side. This anomaly is perhaps caused by the presence of a parasite.

Smilarities and Differences.-H. Scotice is distinguished from other species of the genus by its short arms and the number of cribriform organs. $H$. diadematus Sladen, dredged between Valparaiso and Juan Fernandez, which has only five cribriform organs does not have contiguous dorsal marginal plates.

\section{Hyphalaster Scotia, Juv. (Pl. VI. fig. 60.)}

I believe it is necessary to report with $H$. Scotice a very young specimen of porcelanasterid collected with the two adult individuals described above. This specimen has some peculiarities and it will not be useless to give a description of them. The size is very small: $R=6$ and $r=4.5$ $\mathrm{mm}$.

The disk is pentagonal, with the sides slightly concave. The dorsal surface and the ventral surfaces are flat. The lateral sides are vertical. The very short arms end in a large apical plate, wide 
and thin, cordiform, wide than long and notched on its proximal edge. This plate has a large dorsal side toward its distal end and two lateral spines. We see moreover, toward its lateral edge, two small spines that quite resemble a conical granule.

Toward the end of one of the arms, the specimen has an outgrowth that greatly resembles a tumor produced by a parasite and recalls those provoked by myzostomes in crinoids. To be certain of this origin, it would be necessary to dissect the specimen, which I did not dare do because it would destroy it. This tumor resembles that I have reported above in one of the adult $H$. Scotisae, but it is more conspicuous. It measures approximately one or two $\mathrm{mm}$. It is located obliquely on both sides of the arm immediately behind the apical plate whose development it has hampered. It has also caused anomalies on the two sides of the arm, which I shall indicate below, in the marginal plates and the cribriform organs.

The dorsal surface has in its middle a small epiproctal cone. It is covered with large granules. These plates are arranged without order in the central region of the disk. On the arms, they become smaller and tend to be arranged in radial rows.

The ventral surface of the disk is covered with plates arranged in transverse rows, of which the size decreases toward the ventral marginal plates. We can distinguish, outside the teeth, a first proximal rose of three plates, of which the median is larges and square, then a second row of five plates, and finally two successive rows of smaller plates. This arrangement is not absolutely constant. The peripheral plates have three conical and pointed granules. They are generally missing on the proximal plates.

The dorsal and ventral marginal plates correspond exactly. There are three of them on each side, or six dorsal marginal plates and as many ventrals on each arch between the apical plates. The width decreases rapidly from the first to the third. Seen by the dorsal surface, the first marginal plate is longer than wide, the second is as long as wide and the last is wider than long. This latter is wider inside than outside. It is not contiguous with its congener, but is separated from it by two or three rows of dorsal plates. All the marginal plates are very finely granular.

The three cribriform organs on the sides of the body. This seems to be the normal number. They are reduced to two rows of papillae located opposite each other. Each row contains sixteen to eighteen granules.

I have said above that one of the arms has immediately inside the apical plate a tumor directed obliquely. This tumor has not only affected the development of the apical plate that is atrophied on this side, but we must also attribute to its presence the modifications in the arrangement of the cribriform organs and the marginal plates on the two side of this arm. On one side, there are four cribriform organs constituted normally and a supplementary marginal plate. This is nearly intact on the ventral surface, but on the dorsal side it is divided into two fragments. On the other side, there is a supplementary ventral marginal plate near the apical plate. The second marginal plate on the same side is divided into two superposed plates. The cribriform organs have the following arrangement: one median, normal, that extends to the ventral surface; outside is an organ that results evidently from the fusion of two others and that takes the form of a $U$ bypassing the sides of the second marginal plate and separating, by its horizontal branch, this one and the ventral marginal. The third, located below the preceding, has a horizontal direction and separates the two halves of the ventral marginal plate that has split.

The seven adambulacral plates are two times longer than wide. The first has four large spines, wide and flat, with a blunt point. The following have three of them, then only two. Toward their external edge, the plates have one or two conical granules. 
The teeth are large, long, strong and rise obliquely up to their sutural border that is prominent. They are separated from each other only toward their distal end to receive the odontophore that is triangular and extremely reduced. On their free edge, the teeth have six spines that continue the adambulacral spines to which they are identical, except the last proximal that is much longer. Toward their sutural border we find, in addition, two are three rounded granules.

This young Hyphalaster greatly recalls by its appearance, its characters and its size, Pseudaster cordifer that PERRIER has described earlier as a new genus and that LUDWIG has shown to be a young Thoracaster. I have also found, in the collections of the Princesse Alice, a young Thoracaster scarcely different from the specimen described by Perrier. We can note that, in the specimen of the Scotia, there is no unpaired marginal plate and that these plates number 3 on each side of the arm, while the young Toracaster cited above has the characteristic unpaired marginal plate.

Granaster biseriatus, Koehler. (Pl. V. fig. 48 et 49.)

KoEHLer, Expédition Antarctique française du Dr. Charcot: Échinodermes, p. 11, pl. i. fig. 6, pl. iv. fig. 42.

November 1903, MacDougall Bay, South Orkneys; depth 5 fathoms. Several specimens.

6 December 1903, Scotia Bay, South Orkneys; depth 0-2 fathoms. Several specimens.

2 February, Scotia Bay, South Orkneys; depth 0-2 fathoms. Three specimens.

All the specimens correspond well to the type of the species that I established according to the individuals collected by the Expédition Charcot. The arms are always elongated and fairly separated from the disk. The ambulacral tubes form two very regular rows, sometimes with a slight alternation. The ambulacral groove is narrow. The adambulacral spines are sometimes arranged in three rows, but this arrangement appears rare and not constant.

Examination of the rather numerous specimens collected by the Scotia thus confirms my opinion that I expressed in my memoir on the echinoderms of the Charcot expedition, namely that Gr. biseriatus was more than a simple variety of Gr. nutrix and had to be raised to the rank of species.

I have not been able to find, in the specimens of the Scotia, the least trace of spawning, nor the least indication of incubation habits. I have opened a half-dozen individuals and I have seen that the gonads are little developed. In some, however, I have recognized eggs.

STUDER has reported in Gr. nutrix straight pedicellaria in the ambulacral groove and crossed pedicellariae in the midst of the granules of the dorsal surface, especially on the arms. I have found straight pedicellariae in the groove that are not very dense. I note that their valves, that end in a hook, have denticulations toward the end, as STUDER said. But these pedicellariae have a contour different from that STUDER has represented in Gr. nutrix (Pl. V, fig.48).

As for the tridactyl pedicellariae of the dorsal surface, they are always isolated in the midst of the granules. They are relatively very large. The diameter attains half that of the granules. They are $0.25 \mathrm{~mm}$ in diameter and the pedicellariae can have 0.10 to $0.15 \mathrm{~mm}$. The valves are finely denticulated on their edge and very wide. We distinguish these pedicellariae in the form of clear points in the midst of large granules in fig. 49. 


\section{Zoroaster tenuis Sladen.}

Reports of the "Challenger": Asteroidea, p. 421, pl. lxvii. fig. 1 and 2; pl. lxviii. fig. 7 et 8.

13 April 1904, 48 06’ lat. S., 05’ long. W.; depth 1742 fathoms. A single specimen.

$\mathrm{R}=19 \mathrm{~mm} ; \mathrm{r}=4 \mathrm{~mm} /$

The single specimen collected by the Scotia is obviously young. It is a little larger than the type of the Challenger in which $\mathrm{R}=15.5 \mathrm{~mm}$ and $\mathrm{r}=2.5 \mathrm{~mm}$. It does not absolutely conform to the description of SLADEN, but the differences do not appear to me important enough to require a specific separation. Thus, the large spines of the dorsal and ventral marginal plates are less developed and those of the dorsal marginal plates are not much larger than the other spines, while in the figure of SLADEN these spines are larger. Most of the adambulacral plates have only two spines instead of three, except the first. Finally, the apical plate appears larger in my specimen. I also see a row of latero-dorsals and latero-ventrals that do not exist in the specimen of SLADEN. This is without due to it is less developed. These differences, as we see it, are not very great.

The type of the Challenger came from the area of New Guinea at a depth of 1070 fathoms.

Anasterias cupulifera, nov. sp. (Pl. V. fig. 52; Pl. VI. fig. 58 and 59.)

April 1903, Scotia Bay, South Orkneys; depth 10 fathoms. One specimen.

$\mathrm{R}=60$ to $65 \mathrm{~mm} ; \mathrm{r}=11$.

The disk is small. The arms are about $15 \mathrm{~mm}$ in width at the base. Their dimensions scarcely change in their first half. Beyond, they decrease progressively to the end that is rather pointed.

We perceive, on the dorsal surface of the disk, a pentagon whose sides are depressed and corners from which leave the interradial depressions that continue to the interbrachial angles. These depressions correspond without doubt to the calcareous ring and to the interradial branches that represent the rudimentary dorsal skeleton characteristic of Anasterias.

I am unfortunately unable to give any information on the structure of this skeleton, whose study would require sacrifice of the only specimen I have at my disposal. However, the reduction of the dorsal skeleton and, consequently, the place of this asteroid in the genus Anasterias, cannot be doubted. The integument of the dorsal surface, which is very thin and transparent, does not show the slightest trace of the skeleton in the intervals between the special pustules covering this surface. Moreover, microscopic examination of a fragment of the skin shows no trace of calcareous ossicles. The integument is very soft and is very easily depressed, but it returns to its original position afterwards, which indicates a certain elasticity.

The integument is covered with very special formations that correspond to the pustules of other species of Anasterias, but which have very different characters. In order to understand their origin well, we are going to first consider the ventral surface of the animal, outside the adambulacral spines. Immediately outside these spines, we find a double row of spines arranged in a fairly regular manner and that are exactly opposite in each row. Every two spines correspond sometimes to two, sometimes to four adambulacral spines. These spines, short and rather thick and cylindrical are, as usual, surrounded by a sheath containing crossed pedicellariae. But these, instead of 
constituting a pad, produce a row of small lobes in which each encloses a pedicellaria. It covers the base of the spine, forming a kind of cupule with irregular and fringed edges. From its center emerges the spine. This is always very short and little apparent. In general, the number of pedicellariae that each sheath encloses is not high. There are approximately ten or fifteen and never more than twenty.

At some distance above the external row, we find on the lateral surface of the arms. another row of spines, but much less apparent, less regular and less continuous than the preceding. This lateral row appears only at some distance from the base of the arm. Its spines are also rather short.

In summary, the arrangements recall those that we see in other species of Asterias, notably those I have described in A. tenera. Suppose now that, on the rest of the body of the asteroid, the spines come to atrophy but the sheaths persist while becoming smaller and closer together. We have thus the formations that cover the disk of our asteroid, between the rows of spines that I just mentioned that that have processes of very diverse form and variable dimensions (Pl. VI, fig. 59). These processes are often made prismatic by their reciprocal pressure and have three or four surfaces. Their widened free end is irregularly lobed. It is often depressed in its middle, especially in the large ones. This depression can be quite accentuated for the process to take the form of a cupule. Finally, in the large cupules, we see emerge from the center a small spine that does not pass the edges of the cupule and that, most often, is scarcely apparent. The largest cupules are on the dorsal median line of the arms where they form one or two irregular rows. The large cupules are distinguished, then, only by a smaller size than those that surround the marginal spines that I shall describe soon. They are one $\mathrm{mm}$ in diameter. On the disk itself, we do not distinguish processes larger than on the sides of the arms. Although these processes are very near each other, we can easily recognize, by separating them, the thin and transparent integument on which they are implanted. I do not see papulae in these intervals. All these processes remain short and their height, which does not exceed one mm, is nearly constant. Also, they give, to touch, the sensation of coarse velvet.

In one of the interradii, we note a very narrow space with the processes missing and which indicates the location of the madreporite.

Under the microscope, the processes allow to be recognized a tissue formed of very dense connective fibers that contains some crossed pedicellariae whose number is reduced to only one in the smallest and to two or three in the median ones. These pedicellariae measure $0.4 \mathrm{~mm}$ in length on average. In the largest cupules that contain a small central spine, the pedicellariae are a little more numerous. Moreover, we find at the base of the cupules, some isolated reticulated calcareous plates.

The ambulacral grooves are very wide. The rather slender ambulacral tubules are arranged in four rows. The lateral surfaces of the grooves have a row of rather regular straight pedicellariae. These pedicellariae have no particular character and measure 0.6 to $0.8 \mathrm{~mm}$ in height.

The adambulacral spines are arranged in a single regular row. They are small, elongated, cylindrical, obtuse at the end and covered with an integumentary sheath that is often folded and appears lobed at the end. They frequently take a prismatic form because of their reciprocal pressure.

The teeth are ended by a large spine directed obliquely. Moreover, their ventral surface has a spine identical to the adambulacral spines.

The general color is yellowish. There is not the least trace of spawning in the single specimen I have. 
Similarities and differences.-A. cupulifera is easily distinguished from other known Anasterias by the form of the cutaneous processes that uniformly cover the integument and are numerous, dense and often in the form of cupules.

\section{Anasterias tenera, Koehler.}

KoEHLER, Expédition Antarctique française, du Dr. Charcot: Échinodermes, p. 12, pl. ii. fig. 11 to 16, pl. iii. fig. 27 and 28, pl. iv. fig. 41.

Scotia Bay and Brown Bay, South Orkneys; depth, 10-20 fathoms. Four specimens.

These specimens are identical to the type that I have described and figured. They are only smaller. In the largest, $R=50 \mathrm{~mm}$. In the others, they scarcely exceed $30 \mathrm{~mm}$. These specimens have, above the two marginal rows of large spines, a lateral row of smaller and inconstant spines that I have reported. But, curiously, this row is better marked and more constant in the small individuals than in the large ones.

The dorsal skeleton of the disk and the arms is arranged exactly as I have described. It differs from that of A. Belgica Ludwig, the species with which A. tenera has the most similarity. I have been able to examine the three species of Anasterias collected by the Belgica, thanks to the extreme amiability of PROF. VAN BENEDEN who kindly sent them to me. But I naturally have not been able to compare the skeleton of A. tenera with A. Belgica because it would have been necessary to dry and degrade the specimen. Moreover, the description of LUDWIG is so complete and clear that is suffices amply for all comparisons.

Stolasterias Brucei, nov. sp. (Pl. V. fig. 46 and 47.)

July 1903, Scotia Bay, South Orkneys; depth, 10 fathoms. Three specimens.

The respective dimensions of the three specimens collected are the following:-

$$
\begin{aligned}
& \mathrm{R}=65 \mathrm{~mm} ; \mathrm{r}=13 \mathrm{~mm} \\
& \mathrm{R}=85{ }^{\prime \prime} ; \mathrm{r}=16 \text { “ } \\
& \mathrm{R}=125 \text { “ } ; \mathrm{r}=25 \text { “ }
\end{aligned}
$$

The dimensions of the largest individual are only approximate, this individual being fixed in the incubating posture. In fact, it has a spawn, but not abundant, consisting only of a dozen individuals that are simply hidden in the proximal part of the ambulacral groove and not attached to the mother by any special production.

The two other specimens had extended arms. I have taken as type the average individual that is represented in Pl. V., fig. 46 and 47. It is in it that the specific characters appear better marked.

The integument is thick and pieces of the skeleton forms under it a network comparable to that we see in St. glacialis. The disk is small. The arms are slightly narrowed at their base that measures 14 or $15 \mathrm{~mm}$. Then they widen a little to attain the maximum width of $20 \mathrm{~mm}$ (including the marginal spines). They decrease then very progressively to the end that is an obtuse point. The 
disk is not prominent. The dorsal surface of the arms is nearly flat, with the carinal line slightly raised. Their narrow lateral surfaces are vertical.

Toward the periphery, the disk has a circle of about fifteen spines, short, cylindrical and obtuse, surrounded at their base by a sheath enclosing crossed pedicellariae. these sheaths are low, wide and contiguous at their edges. They thus limit a central spaced enclosing an internal circle of about a dozen spines, plus a central spine. All these spines are small. They are surrounded by a flat sheath, much lower than that of the external spines. Numerous papulae appear between the sheaths.

Leaving the exterior circle, the median line of each arm has a carinal row of plates, each surmounted by a spine, short and obtuse, surrounded by a sheath contiguous with the adjacent ones. Also, these sheaths are usually square or rectangular. This carinal line extends to the end of the arms. It is not absolutely straight but has slight sinuosities that are also seen in the two other specimens. I count forty-two to forty-three spines in each line. The edges of the arms have a dorsal marginal line of spines identical to the preceding but, sometimes, a little protruding. Their sheaths, a little higher also, are always exactly contiguous by their edges. The spines of this marginal row are nearly the same number as the carinal row. Between these two series, the dorsal surface of the arms has small, very short spines each surrounded by a very low sheath with irregular contours, smaller than on the marginal and carinal rows. We can recognize two or three longitudinal rows, moreover very irregular of these sheaths. These are separated by papulae. In addition, we note that they do not reach the marginal row, at least at the base of the arms. There remains, between this row and the sheaths, a band approximately $2 \mathrm{~mm}$ in thickness that only has papulae.

The small specimen has the same arrangements that I just descried. In the large one, the disk does not have at its periphery, the distinct circle of spines. All its surface is uniformly covered with spines surrounded by contiguous sheaths that attain 3 or $4 \mathrm{~mm}$ in diameter. These spines are continuous with those of the dorsal surface of the arms, but the carinal row is less distinct and the sinuosities are less marked than on the two other individuals. The spines are scarcely longer than the other spines of the dorsal surface and the sheaths are very flat. On each side of this carinal row, we find three or four very irregular lateral rows and, at the base of the arms, there is always between the most external row and the marginal row, an elongated triangular space exclusively filled with papulae. In contrast, the spines of the dorsal marginal row are notably larger and stronger than the others and the sheaths are very developed.

The lateral surfaces of the arms, which are vertical, have first in their dorsal region, a band whose height attains $3 \mathrm{~mm}$ in the medium specimen and 4 in the large one, and that is exclusively occupied by papulae arranged in four or five rows. In the median specimen, these papulae are elongated and very dense, while in the large one, they are contracted and resemble large granules that are distributed in groups of eight to twelve, each corresponding to a marginal plate. After this space comes a double row of superposed plates, the lower of which limits the sides of the ventral surface. Each plate has a large spine, wide and flat, with an obtuse end, surrounded by a wide and thick sheath filled with crossed pedicellariae. The spines of the two series correspond exactly and, moreover, correspond to the spines of the dorsal marginal row. The ventral series is very near the adambulacral spines. It is hardly possible to distinguish, at the base of the arms, a narrow interval occupied by some papulae. The spines of this series are in general at little smaller than those of the upper series. This difference, which is already appreciable at the base of the arms, accentuates progressively. The spines become shorter, their sheaths lower and narrower, and finally, they disappear toward the posterior quarter of the arm. In the large specimen, the spines of the two ventral series are particularly thick. They have more or less deep grooves on their surface that appear sometimes to divide into a bundle of three or four fused spines. 
The adambulacral grooves are comparatively wider in the two small specimens that in the large one. The adambulacral plates are armed with a double row of large and strong spines, flat, obtuse at the end and covered with an integument that makes their contours a little irregular. These spines are relatively very developed in the large specimen where they are flat, at least two times wider than thick. Each group of three or four adambulacral spines corresponds to a marginal plate.

The teeth end in two spines that scarcely differ from the adambulacral spines.

The adambulacral grooves have on their walls, some straight pedicellariae supported by a stalk exceeding their length. These pedicellariae are not very numerous. They are covered with a more or less thick integumentary sheath. It is this that is extended in a way to form the stalk. The length of these pedicellariae is $1 \mathrm{~mm}$ in the middle specimen and 1.5 in the large one.

The color of the middle specimens is pale yellow-brown. The two others are brownish-gray.

St. Brucei is an incubator. I have said above that the large specimen has a spawn reduced to a dozen individuals. These young, whose diameter varies from 5.5 to $6 \mathrm{~mm}$, are at a stage extremely close to that I have observed in Anasterias tenera reported by the Charcot expedition. They are scarcely more advanced. They are simply placed into the ambulacral groove near the mouth of the mother to which they are not attached by any umbilical cord. Moreover, they are easily detached from the mother. Some remain in place in the groove. The others fall to the bottom of the flask.

Similarities and Differences.-St. Brucei is easily distinguished from the other Antarctic asteroids belonging to the genus Stolasterias and that number only two. St. eustyla Sladen, found by the Challenger at Tristan d'Acunha at 100 to 150 fathoms depth, has on the ventral marginal plates, an oblique row of three species that St. Brucei does not have. The type of SLADEN in near in its dimensions to the small specimen collected by the Scotia, but it is very different. It has only one row of latero-ventral plates; the dorsal marginal spines are more accentuated and there is only a single row of plates between the dorsal marginal row and the carinal row. Finally, SLADEN did not find straight pedicellariaes in his species. The other species is St. candicans Ludwig collected by the Belgica. Thanks to the indulgence of Prof. VAN BENEDEN, I have been able to examine the original specimen. It is smaller than the smallest specimen collected by the Scotia. I have seen it differs completely from it. The spines of the different series are fine, conical, pointed and widely disengaged from their sheath. The adambulacral spines are also thin and pointed and the dental spines are very elongated and thin

Diplasterias Brandti, J. Bell. (Pl. V. fig. 50 and 51.)

See for the bibliography:

MEISSNER, Hamburger Magalhaensische Sammelreise: Asteroideen, p. 7.

"Shore kelp," Falkland Islands. A single individual fixed in the incubating position with the disk very strongly domed and the arms rolled up at their end. The brood is dissociated and none of the young remains attached to the mother. These are found isolated in the bottle that contains some of them.

$1^{\text {st }}$ December, 1903. Burdwood Bank, 54 $25^{\prime}$ lat. S.; $57^{\circ} 32^{\prime}$ long. W.; depth 56 fathoms. One specimen whose dimensions are: $\mathrm{R}=45 \mathrm{~mm}, \mathrm{r}=12 \mathrm{~mm}$. 
MEISSNER has given, in the work cited above, the synonymy of this species to which several Diplasterias from the southern tip of South America relate and had been considered by authors as constituting distinct species. I think that we should also unite to D. Brandti, at least two Diplasterias from the mission of Cape Horn described by PERRIER: D. Lovent and D. Lütkeni. I have been able to study the specimens of the first species that are found in the Jardin des Plantes. Its identity with $D$. Brandti is without any doubt to me. As far the numerous specimens of $D$. Lükeni that the mission of Cape Horn has collected, it has been impossible, despite the investigation that Prof. JOUBIN was kind enough to do in the collections of the Museum, to find a single specimen. Accord to PERRIER who created this species, it is very close to D. Lovent. In comparing its description to the of different species that must be united to D. Brandti, I do not see the character that really permits separating it from this obviously polymorphic species.

Concerning D. spinosa that also comes from the mission of Cape Horn, I could not be as affirmative. It is certain that it has an appearance fairly different from the specimens of $D$. Brandti that I have been able to examine. Its characters have been well indicated by PERRIER. But, in summary, I have not been able to see, in the original specimen, characters important enough that permit separating it clearly from D. Brandti. However, I do not dare decide on this matter because the number of specimens of this latter species that I have had in hand is too few for me to be able to make an exact idea on the value of the variations they can have.

I do not have to return here to the characters of $D$. Brandti, of which there exist sufficient good descriptions and figures, either under the name of D. Brandti or under those of D. Belli Studer, glomerata Sladen, and neglecta Bell. I content myself with representing there the individual that had is brood (Pl. V. fig. 50). But it appears to me useful to describe the characters of these young.

As I said above, none of these were in place and all were found on the bottom of the jar containing their mother. But, when they were alive, they were certainly fixed as PERRIER represented in A. spirabilis (A. antarctica) and as LUDWIG and I have seen in various Anasterias. All the young show, in fact, in one of the interradii of the ventral surface, the end of a short, broken stalk, nearly all are isolated, except a dozen that form a small group attached to a common cord.

As usual, these young individuals are all in the same stage of development. They are of very small size. The total diameter does not pass $2 \mathrm{~mm}$ (Pl. V. fig. 51). The body has the form of a pentagon with slightly concave and arms still little marked. The height is nearly equal to the diameter because the dorsal surface is strongly swollen. The body is in fact filled with a compact mass of yolk. The presence so much yolk leaves us to suppose that the young receive from their mother only a small part of the material that is necessary for the formation of its tissue and that the umbilical cord serves only as an organ of suspension.

I have studied these young specimens with the aid of sections that show nothing new and with the aid of preparations in toto obtained by clearing them in cedar oil and Canada balm. Because of the thickness of the tissues and the opacity of the yolk, these preparations are never very transparent except at the edges. They permit, however, seeing the arrangement of the calcareous plates that are still at a very young stage and that have thin reticulated plates that are always isolated from each other.

In examining one of these young asteroids from the ventral side (Pl. V. fig. 51), we see leave at some distance from the center and in the direction of each arm, a double row of very thin and reticulated plates. The plates of each row correspond exactly and thus form pairs. We note that the plates of the first two pairs are more separated than the following that continue to the end of the arm. The proximal plates are larger than the others, whose dimensions decrease progressively. The 
last four or five are particularly thin. I count a dozen plates in each row. The last two or three are located on each side of the terminal plate of the arm. These plates obviously represent the ambulacra. Much further out and near the edge of the arm, we can see another row of plates, one behind the other and rather well aligned, but irregular in size. These plates do not yet correspond to the preceding. They represent without doubt the adambulacral plates.

Finally, at the end of each arm, is a large plate, round and very distinct. This is the terminal plate.

On the dorsal sides, we distinguish in the central region of the disk, only a few plates, arranged without any order and at some distance from the center. Their number varies from one to four.

The state of preservation of the tissues does not permit undertaking more in-depth studies on the structure of these young asteroids.

\section{Diplasterias Turqueti, Koehler.}

Koehler, Expédition Antarctique française du Dr. Charcot: Échinodermes, p. 19, pl. ii. fig. 17, pl. iv. fig. 39.

June 1903, Scotia Bay, South Orkneys; depth 18-20 fathoms. Two specimens.

April and December 1903, Scotia Bay and Brown Bay, South Orkneys; depth 9-10 fathoms. Five specimens.

All these individuals are smaller than the type that I described: in the largest, $\mathrm{R}=57 \mathrm{~mm}$, and in the smallest, $\mathrm{R}=25 \mathrm{~mm}$.

In the largest specimen, the dorsal surface of the arms has more numerous spines than the others and in the specimens collected by Dr. CHARCOT. These spines tend to form very irregular longitudinal rows. We can distinguish a median row and two lateral rows. Outside the latter are some isolated spines.

In the smallest specimen, the two ventral marginal rows of spines do not always exist. In some places, we can distinguish only one row.

\section{Diplasterias induta, nov. sp. (Pl. VIL fig. 68 to 70.)}

June 1903, Scotia Bay, South Orkneys; depth 10-20 fathoms. A single specimen.

$\mathrm{R}=12 \mathrm{~mm} . \mathrm{r}=9 \mathrm{~mm}$. The arms measure approximately $10 \mathrm{~mm}$ in width at the base, without counting the marginal spines and 13 in counting these spines. They taper very slowly in the first third, and a little more rapidly in the second third to the end that terminates in an obtuse point. The disk is of medium size.

The sides of the arms are limited on the dorsal surface by a row of twenty-five to thirty-eight flat spines, ended in a round extremity and protruding approximately $0.5 \mathrm{~mm}$ outside a sheath that recalls sometimes the form of a cone surrounding the base of the spine and enclosing some cross pedicellariae. All the rest of the dorsal surface of the disk and the arms is covered with vertical processes, resembling those I have described above in Anasterias cupulifera, but in general finer, 
denser and having less frequently and less clearly the form of cones than in the latter species. These processes are moreover very unequal and that are often flattened by reciprocal pressure. In some places, especially on the disk, these processes are connected to each other by trabeculae in a way to form a kind of spongy tissue or to constitute a meandering ensemble (Pl. VII. fig. 70). It is rare to find, in the midst of these processes, a small spine. They are very dense and the interstices that they leave between them are filled with papulae. The ensemble gives to touch the sensation of a slightly coarse velvet. The underlying integument is very rigid and cannot be depressed. In examining under the microscope a portion of the dorsal surface, we see by transparency under the integument, a calcareous network formed of small ossicles two or three times longer than wide and limiting irregular meshes.

In one of the interradii, and very near the edge of the disk, we recognize a round space that is filled with the madreporite. This is nude and has on is surface divergent grooves that leave the center. It is not surrounded by any particular formation. Toward the center of the disk, we distinguish another nude space, in the midst of which opens the anus that is very small and looks like a very fine pore.

The sides of the arms, on the ventral surface, have a double row of plates that each has a spine surrounded by an integumentary process enclosing several crossed pedicellariae. The spines of the upper row correspond exactly to the spines of the lower row. This double row corresponds itself to a latero-dorsal row on the sides of the dorsal surface of the arms. Only the first are stronger, wider and longer than the latero-dorsal spines. Between the two rows of latero-dorsal spines on the sides of the arms is a narrow space scarcely measuring $2 \mathrm{~mm}$ in width at the base of the arms. This space is especially filled with papulae, with some very thin cutaneous processes.

The adambulacral spines are very regularly arranged in two equal rows. They are of medium length, flat, with an obtuse end and surrounded by a thin integument that makes their contours very irregular.

The ambulacral groove is very wide. The ambulacral tubes are thin and very regularly quadriserial. On the edges of the groove, we see, on each side, a row of straight pedicellariae that have nothing in particular.

Each tooth is ended by a spine that scarcely differs from the adambulacral spines.

Similarities and Differences. - D. induta is near D. Turqueti Koehler, which it approaches by the absence of spines on the dorsal surface of the disk and the arms. But here the cutaneous processes, instead of constituting the low and wide pustules, are raised, thin, often widened, compressed by reciprocal pressure, of variable size and sometimes in the form of cones.

By its external appearance, D. induta recalls absolutely Anasterias cupulifera described above. It is very curious to see that some species of Antarctic Anasterias and Diplasterias have absolutely the same exterior shape although the two genera have a very different internal structure. I have already reported that Diplasterias turqueti and Anasterias tenera, both discovered by the Charcot expedition, have identical surfaces. We see now that Diplasterias induta has the same external appearance as Anasterias cupulifera. These two species have, moreover, been captured by the Scotia at the same station. 


\section{Asterias antarctica (Lùtken).}

See for the bibliography:

LeITPOLDT, "Asteroidea der Vettor-Pisani Expedition," Zeit.f. wiss. Zool., Bd. lix., p. 70 (Asterias rugispina). MEISSNER, Hamburger Magaltaensische Sammelreise : Asteroideen, p. 10.

LORIOL, Notes pour servir à l'histoire des Échinodermes, $2^{\mathrm{e}}$ série, fasc. 2, p. 36.

LuDWIG, "Asterien und Ophiuren der schwedischen Expedition," Zeit.f. wiss. Zool., Bd. lxxxii., p. 70.

Fifteen specimens collected in different locations of the Falkland Islands at depths not exceeding 6 fathoms.

Authors have already indicated the differences that can occur in the development of the dorsal skeleton of the disk and the arms, as well as the spines and these differences have led to the creation of several species that cannot be maintained. In the work cited above, MEISSNER has represented the two extreme forms that we can observe. One with very developed dorsal skeleton and spines and the other with a very reduced skeleton.

The specimens of the Scotia are related to this latter form. Their skeleton is more or less reduced and the spines are always very short, little or not at all visible exteriorly and sparse. The dorsal surface of the arms is soft and many specimens resemble Anasterias. But desiccation or a very delicate treatment with potash always permits recognition of the calcareous mesh of the dorsal network.

Asterias pedicellaris, nov. sp. (Pl. VII. fig. 61 to 67; Pl. VIII. fig. 74 to 78. )

18 March $1904,71^{\circ} 22^{\prime}$ lat. S., $16^{\circ} 34^{\prime}$ W.; depth 1410 fathoms. Five specimens.

In the largest specimen, $R=40 \mathrm{~mm}$ and $\mathrm{r}=7 \mathrm{~mm}$. In two others, the length of $\mathrm{R}$ varies from 25 to $28 \mathrm{~mm}$. Finally, three others are much smaller. Their large rays measure respectively 15, 12 and $7 \mathrm{~mm}$. There are in addition some isolated arms. I shall describe the largest individual.

The arms are subequal, but one of them is broken toward the middle. the disk is small, rather swollen on the dorsal surface. The elongated arms are narrow at the base that measures approximately $5 \mathrm{~mm}$ in width and decreases little by little up to the end that is rather pointed. Their dorsal surface is convex.

The dorsal skeleton of the arms forms three longitudinal rows of rather regular plates united by transverse bands in a way to leave between them large rectangular meshes a little wider than long. The median row forms a rather marked protrusion. The two others limit the lateral edges of the dorsal surface of the arm. At the point of union of the plates are elongated spines, thin, conical and pointed. These spines are always isolated. It has been absolutely impossible for me to find at the base of these spines the least indication of a sheath of pedicellariae. Sometimes, as I note on one of the arms of an individual of average size, the median row of plates is split for some length and we see at the same time two rows of spines. The papulae are sparse and isolated. 
On the disk, the plates form an irregular circle of about a dozen plates, each with a spine. We ordinarily see five radial spines and five other interradial spines, a little smaller. Inside this circle, we find a network of plates bearing four or five spines. The madreporite is small and indistinct.

In some places of the dorsal surface of the arms, we note some crossed pedicellariae, truly enormous, whose length can exceed $2 \mathrm{~mm}$ by 1 of width. Their presence gives the dorsal surface of $A$. pedicellaris a particular appearance. These pedicellariae do not appear constant, neither in number nor in location. They are scattered in a variable number on the dorsal surface of the arms, but always isolated and sparse. They are sometimes more frequent toward the end of the arms and can also occur on the disk. I had already encountered them on small individuals that have two or three on each arm. In summary, these isolated and enormous pedicellariae replace the crossed pedicellariae that are grouped in a sheath at the base of each spine in the genu Asterias and that are missing here. These pedicellariae have the same structure as those that are found at the base of the ventral spines. I shall return to this below.

The ventral surface of the arms is limited by a lateral row of plates that correspond exactly to the latero-dorsal plates. Each plate has a spine identical to those of the dorsal surface, but this spine has at its base a small group of six to ten crossed pedicellariae that together form a sheath similar to that we know in other Asterias.

The narrow space that remains free between the ventral marginal plates and the adambulacrals has no distinct plates, but only some crossed pedicellariae identical to those of the dorsal surface, but they are much small. The attain only 0.5 to $0.6 \mathrm{~mm}$ in length

The adambulacral spines, arranged in a single row, are very long, cylindrical, slightly swollen at the base and ended in an obtuse extremity.

The ambulacral grooves are rather wide. the ambulacral tubes form four rows, but they are often alternate on each side. We note on the edges some rather rare straight pedicellariae whose structure has nothing in particular.

The crossed pedicellariae of the ventral surface and the much larger pedicellariae that are disseminated on the dorsal surface have, in their structure, some particularities (Pl. VII. fig. 62 to 66; P1. VIII. Fig.75 to 78). Their valves taper up to the end in a stronger and more apparent hook on the small pedicellariae of the ventral spines than on those of the dorsal surface. A thin integument covers these pedicellariae.

The general color of the specimens is yellowish-gray.

Similarities and Differences.-A. pedicellaris is distinct from all the other known species by the size and particular characters of the crossed pedicellariae on the dorsal surface that are isolated and few on this surface.

Freyella Giardi, nov. sp. (P1. VI. fig. 53 to 57.)

7 March 1903, $67^{\circ} 33$ lat. S.; $36^{\circ} 35^{\prime}$ long. W.; depth 2500 fathoms. A disk without arms and another disk with a single adherent arm, plus some separated arms.

21 March 1904, 69 33' lat. S., 153 19' long. W.; depth 2620 fathoms. Two specimens of which one has preserved three complete arms and the other four. There are in addition some detached arms. 
Most of the arms are contorted and folded. The marginal spines are ordinarily broken. The specimens appear to have been strongly compressed and damaged by the dredging apparatus and Faubert's tangles.

The diameter of the disk varies according to the individual, from 8 to $9 \mathrm{~mm}$. The arms are extremely long and they could have been up to $15 \mathrm{~cm}$ in length, which makes the ratio $\mathrm{R} / \mathrm{r}$ to have the value of 15 or 20 .

The disk is round, slightly depressed on the dorsal surface and a little excavated between the bases of the arms. There are six arms. They are inserted on the disk by a narrow base, then wide and swell for a length of 2 to $4 \mathrm{~cm}$. It is impossible to fix exactly the length of this genital region that is continuous with the rest of arms without a definite line of demarcation. The maximum length of this genital region is $4.5 \mathrm{~mm}$. Beyond, the width of the arms is $3 \mathrm{~mm}$, then the number falls to $2.5,2$ and 1.5.

The dorsal surface of the disk is covered with unequal plates, polygonal or rounded, contiguous by their edges and without the least trace of imbrication. Each of them has a strong spine, conical, elongated and pointed, whose length exceeds the width of the plate. It is rare to find two spines on the same plate. Many of these spines are broken. On most of them, we recognize a corona of crossed pedicellariae, ordinarily located at some distance from the base. This corona does not occur on all the pedicellariae, but it is possible that they have been detached accidentally because, as I said above, the specimens are strongly damaged. In addition, the plates of the disk have on their surface some isolated pedicellariae that are not numerous.

On the lateral surfaces of the disk, and in each interradial space, we see an unpaired oval plate, elongated vertically and whose surface is finely granulose. This piece separates below the distal ends of the two teeth of each pair. It has the same ratios as in F. sexradiata Perrier and Belgicella racovitzana Ludwig.

The anus, slightly eccentric, is very small. The madreporite, very large, is located very near the edge of the disk and has a sinuous groove, limited by two very prominent and most often broken lips.

The dorsal plates of the disk are continuous on the arms. But they become much larger while keeping the same characters. They are polygonal, contiguous, unequal and arranged without order. There are nearly six or seven on a same transverse line. On the sides of the arms, the lower plates rest on the adambulacral pieces. The free edge even extends onto these pieces without adhering to them. Each plate has, in its center, a long spine, elongated, conical and pointed, often broken and having, at some distance from its base, a wide and rather loose corona of crossed pedicellariae. In addition, the plates have on their surface some isolated pedicellariae.

The genital region has thus, on its dorsal surface, a well-developed and compact skeleton. But this skeleton is not limited to this region. It continues well beyond on the narrow part of the arms. Only the plates become progressively smaller. Four or five $\mathrm{cm}$ beyond the enlarged portion, the plates that had remained contiguous, begin to separate from each other and, at the same time, they disappear on the sides of the arms. We can often distinguish four irregular rows of unequal plates, two on each side of the median line and two lateral ones. Then the plates disappear little by little and only the spine persists. However, we can find plates up to the area of the end of the arm.

The adambulacral plates are elongated, very strongly excavated in their median region by the corresponding ambulacral pores. They are enlarged at the ends and articulate with the other by wide facets, flat and slightly oblique. The anterior facet is nearly flat, while the posterior facet has an internal apophysis directed obliquely inward. It bypasses the anterior facet of the following 
plate. I have not been able to discover spines on these plates in the ambulacral groove except on some plates of the genital region in the specimens whose three arms have been preserved. Everywhere else these spines are missing. But it is evident that they existed and that they were torn off. Toward the middle of their ventral surface, the adambulacral plates have a large strong spine, thick and pointed, whose length nearly reaches that of the adambulacral plate. the insertion of this spines is more or less near the distal end. These sub-ambulacral spines are covered with a sheath of pedicellariae that covers nearly all their length. At the base of the arms, the first adambulacral plate has in addition, toward the distal edge, another spine similar to the preceding, conical and directed obliquely inward.

The adambulacral plates have in addition, on the external surface and toward their distal edge, a large spine directed outward and that appears toward the third or fourth plate, inserted above the sub-ambulacral spine. This spine generally occurs every two articles but with some irregularity. At some distance from the base of the arm, we can see it on nearly all the articles. It becomes longer than the article. It is surrounded, as usual, by a sheath of crossed pedicellariae. ${ }^{1}$ The spine articulates on a large mamelon supported by the lateral surface of the adambulacral plate. It corresponds evidently to the marginal spine of other brisingids. It is ordinarily supported by the initial one of the arches. But here, there is not the least trace of arches or of the initial ones of the arches and the spine is inserted directly on the plate.

The terminal plate of the arms is longer than wide. It has at its end two lateral spines and a slightly larger median spine.

The teeth are elongated, widely separated from each other They have on their proximal or buccal edge, which is straight, two spines, the large internal, strong and elongated and the external, finer and shorter. On the external edge, each tooth has two spines. All these spines are surrounded by an integumentary sheath beaded with pedicellariae.

The gonads extend 2 or $3 \mathrm{~cm}$ beyond the genital region. At the base of the swelling, we find beside the gonadal tubes, two intestinal caeca approximately $1 \mathrm{~cm}$ in length.

The general color is pale gray.

Similarities and Differences.-F. Giardi is near F. sexradiata Perrier. It differs from it by the presence on the dorsal surface of the arms of plates forming a continuous covering that passes much of the genital region. The arms are also very developed and without doubt much longer than in $F$. sexradiata. As for the armature of the adambulacral plates, I cannot use to separate the two species the absence of spines in the groove in F. Giardi because I am not sure that these spines that I have seen on some proximal articles do not exist further on.

Belgicella racovitzana, Ludwig. (P1. VII. fig. 73.)

Résultats du Voyaye du S. Y. " Belgica": Ludwig, "Die Seesterne," p. 59, pl. iv. fig. 40-44, pl. v. fig. 45-51.

18 March $1904,7^{\circ} 22^{\prime}$ lat. S., $16^{\circ} 34^{\prime}$ long. W.; depth 1410 fathoms. Two specimens.

In one of the specimens, the disk has a diameter of $10 \mathrm{~mm}$. Four arms adhere to the disk. One of them, very short, is in the process of regenerating. Its length does not reach $1 \mathrm{~cm}$. The relatively small terminal plate is quadrangular. Its distal edge has three fine, equal spines.

\footnotetext{
${ }^{1}$ This sheath is not shown in fig. 54, 55 and 56 made from dried specimens.
} 
In another specimen, the diameter is $11 \mathrm{~mm}$ and four arms are preserved. These arms are approximately $5 \mathrm{~mm}$ wide at the base. Then, three or four $\mathrm{mm}$ beyond their insertion, they begin to widen and rapidly reach $6.5 \mathrm{~mm}$, then they decrease slowly in width. The length of the genital region, measured from the base of the arm is approximately $25 \mathrm{~mm}$. The arms should not be very long. One of them measures $8 \mathrm{~cm}$. I have represented the enlarged dorsal surface of this specimen.

Thanks to the kindness of Prof. VAN BENKDEN, who has very willingly sent it to me, I can compare the original specimen of the Belgica to the specimens of the Scotia. I see that they are identical. I have little to add to the so complete description of LUDWIG. I note only on one of my specimens, the centro-dorsal plate is a little smaller than the interradials and that they are nearer the edge of the disk than the figure of LUDWIG. Moreover, they clearly flex on the dorsal surfaces of the disk. I have moreover been able to observe on the type of the Belgica that the plates are nearer the periphery than indicated by LUDWIG. THEY are also a little oval, while they are circular in the type. Finally, the ambulacral spines of the first four or five pairs are not ended in a point, but they are slightly swollen at the end. They have some lobes separated by striations more accentuated than on the rest of the spine. Then the spines become progressively pointed. LUDWIG has not indicated this arrangement that I have observed in the type, of which many of the proximal spines are broken.

\section{OPHIURES.}

Ophioglypha Brucei, nov. sp. (P1. VIII. fig. 81 and 82.)

10 March 1903, 66 40' lat. S., 40 35' long. W.; depth 2425 fathoms. One specimen

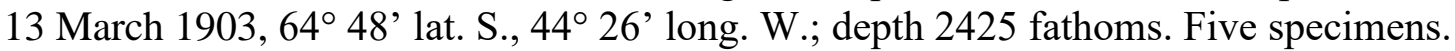
21 March 1904, 69 48' lat. S., 15 19' long. W.; depth 2620 fathoms. Two specimens.

In the largest specimen, the diameter of the disk is $14 \mathrm{~mm}$ and the arms are $38 \mathrm{~mm}$ long. In two others, the diameter of the disk attains respectively 13 and $11 \mathrm{~mm}$. The other individuals are smaller. The diameter of their disk varies between 9 and $4 \mathrm{~mm}$.

The disk is thin and flat with a pentagonal contour. The arms are fine and slender.

The contours of the dorsal plates of the disk are a little obscured by the integument. They are polygonal-rounded and unequal. We recognize a rosette of six primary plates, large and rounded, the centro-dorsal of the same size as the radials and separated from them by one or two rows of small plates. There is, in general, in the interradial spaces, two plates larger than the nearby ones, of which the last occupies the edge of the disk. Between these different plates, the rest of the disk is filled with smaller plates, irregular and polygonal. The radial shields are very large, triangular, longer than wide and separated on all their length by a row of rectangular of square plates, of which the last is sometimes rather large. They are divergent. Their length is greater than a third of the 
radius of the disk. Outside the radial shield, on each side of the base of the arms, there are some small, rounded plates. But we cannot find the least trace of radial papillae.

The ventral surface has very unequal, polygonal-rounded plates. The genital plates are elongated and thin. The genital slits are extremely narrow and short, little apparent. They are limited to the sides of the first lateral brachial plate. They have the form of very narrow slits, limited by two parallel edges very close together without the least trace of papillae.

The buccal shields are rather large, a little wider than long, triangular or rather trifoliate. The proximal region forms a rounded, obtuse lobe. The sides are slightly concave and continue by a rounded edge with the distal edge that is nearly straight or sometimes slightly convex. The adoral plates are elongated, widened in the middle region that is molded to the concavity of the buccal shields and narrows toward their ends, especially outside. They are contiguous inside. The oral plates are triangular, large and high. The lateral buccal papillae are small, low and rectangular. They form a nearly continuous edge in which it is rather difficult to distinguish the line of separation. The unpaired terminal papilla is conical and a little larger. It is to be noted that the papillae of each edge are exactly contiguous to those of the opposite edge so that the mouth is absolutely closed. In general, the buccal pieces have contours more or less obscured by the integument.

The dorsal brachial plates are of medium size. The first is rectangular, wider than long, with a convex distal edge. The second is as wide as long, with the proximal side narrower, the distal edge wide and rounded and the sides divergent. The following ones are triangular, a little longer than wide, with the distal edge very convex. This edge ends by splitting into two sides meeting in an obtuse corner so that the plates become lozenge-shaped and wider than long. They are separated after the second.

The first ventral brachial plate is large, triangular and a little longer than wide, with a rounded proximal corner and sides a little convex joined by rounded corners at the distal edge that is convex. This is sometimes split into two sides that are joined by an obtuse corner. The second plate is still large, triangular, with a convex distal edge. It is as long as wide. Beyond, the plates become smaller with a very obtuse proximal corner and a convex distal edge. They are much wider than long. They are at first triangular. Then they become lozenge-shaped by the splitting of their distal end into two sides. They are separated after the first.

The lateral plates, little developed, have three and sometimes four very reduced and papilliform spines. The dorsal one is generally a little separated from the two or three others.

It is to be noted that the arms are sensibly wider inside the disk than beyond.

The tentacular pores are extremely reduced. Those of the first pair are small and separated at the bottom of the buccal slits into which they do not open. They are limited by an edge in which it is impossible to distinguish the limits of papillae or scales. The pores of the second and third pair are reduced to small, rounded openings on each side of the corresponding ventral plate. Beyond, the pores cease to exist.

Similarities and Differences.-O Brucei is near $O$. abyssorum Lyman. It is distinguished by a different arrangement of the dorsal and ventral plates of the disk that are also smaller and more numerous, by the tentacular pores still more reduced, by the extremely slender arms and by the presence of some brachial spines. 
Ophioglypha intégra, nov. sp. (Pl. VIII. fig. 79 and 80.)

18 March $1903,62^{\circ} 10^{\prime}$ lat. S., $41^{\circ} 20^{\prime}$ long. W.; depth 1775 fathoms. Six specimens.

The diameter of the disk can attain 17 to $18 \mathrm{~mm}$ in the largest individuals. The arms are broken several centimeters from their base. They are of medium size.

The disk is pentagonal, rather thin. The edges are sharp.

The dorsal surface is covered with extremely numerous and dense plates, small, with a shallow notch at the base of the arms. There is a central rosette of primary plates, distinct, rather small and rounded, the centro-dorsal a little larger than the other. These plates are widely separated from each other by several rows of plates. The plates of the disk are especially small in the central region. They become a little larger toward the periphery. We distinguish, toward the middle of each interradial space, a rounded plate, a little larger than the adjacent ones, and, at the periphery of the disk, another plate widened transversely. The radial shields are rather large, triangular, one and a half times longer than wide, divergent and widely separated by several rows of plates. There is a radial comb formed of papillae, low, obtuse, square and small. These papillae are continuous along all the length of the genital slit.

The ventral surface of the disk is covered with numerous small plates, irregularly polygonal or rounded, unequal and not imbricated. The genital plates are very elongated and very narrow. The genital slits are also very narrow and elongated.

The buccal shields, of medium size, are a little wider than long. They are pentagonal with an obtuse proximal corner limited by two straight sides, two lateral edges, short and rounded connecting by equally rounded corners to the distal edge that is convex. The adoral plates are very long, thin, four or five times longer than wide. The oral plates are rather large and wide, two times longer than wide. The lateral buccal papillae number eight at least. They are low and obtuse, nearly square, except the most internal that is elongated and conical. The unpaired terminal papilla is stronger and conical.

The first two or three dorsal brachial plates in the notch of the disk are wide and very short, rectangular and a little irregular. The following are also rectangular, wider than long, with the distal edge wide and rounded, the proximal edge narrower and the sides divergent. They are all contiguous.

The first ventral brachial plate is rather large, widened transversally, often octagonal. The two following are larger, triangular, much wider than long, with an obtuse proximal corner that is truncated on the first plate, very pointed lateral corners and a wide distal edge having a small lobe in its middle. The following ones become much shorter. They are always triangular, with a very obtuse proximal corner and a strongly convex distal edge. They are separated after the second. The lateral parts of the second and third plates are separated from the rest by an oblique groove.

The lateral plates have three small spines, short and papilliform, near the ventral border.

The tentacular pores of the first pair, very elongated and opening into the buccal slits, have six scales on each side. The pores of the second pair have five external scales and three or four internal ones. Those of the fifth pair have only three or four proximal scales. Then the number falls to two and finally to one on the following ones.

Similarities and Differences.-O. integra is near O. Loveni Lyman, orbiculata Lyman, concreta Koehler and mundata Koehler. It differs from the first by its larger radial shields, by the longer dorsal and ventral plates and by the three very small brachial spines. It differs from $O$. 
orbiculata by the presence of a rosette of primary plates and by the larger radial shiels. It differs from $O$. concreta by its primary rosette, by the larger radial shields and by the three brachial spines that are close together. It is separated more from $O$. mundata by the very thin dorsal plates of the disk, by the large and wider buccal shields, by the larger radial shields, by the larger dorsal brachial plates, etc.

Ophioghypha lenticularis, nov. sp. (Pl. X. fig. 90 and 91.)

9 April 1904, 51ำ ' lat. S., 9 31' long. W.; depth 2103 fathoms. One specimen.

Diameter of the disk, $32 \mathrm{~mm}$. The arms are broken near the base. The detached pieces that are preserved show that their length should scarcely pass $60 \mathrm{~mm}$. They are rather thin and their dorsal surface is swollen but not keeled. The disk is thick, convex on the dorsal surface as well as on the ventral surface, very thin on the edges and in the form of a lentil.

The dorsal surface of the disk is covered by extremely small plates, thin and imbricated, becoming a little larger toward the periphery of the radial shields. These plates recall more those of Amphiura than of Ophioglypha. There is a central rosette of distinct but small primary plates. The centro-dorsal is rounded. The radials are a little widened transversally, separated from each other as well as the centro-dorsal by several rows of small plates. We distinguish in addition, in the radius, two plates a little larger than the adjacent ones and, in the interradius, a first plate between the center and the edge, and another plate a little larger located at the periphery of the disk and slightly widened transversally. The radial shields are very small, irregularly triangular, with the edges and the corners rounded and separated by several rows of plates. They are divergent and scarcely longer than wide. The length is equal to a sixth or a seventh of the radius of the disk. Outside the radial shields, we distinguish a row of radial papillae, low and obtuse, that pass to the ventral surface and extend the entire length of the genital slit where they are very low and rectangular.

The ventral surface is uniformly covered with small and unequal plates, a little imbricated. The genital plates are extremely narrow. The genital slits extend the entire length of the arms up to the buccal shields.

The buccal shields are rather small, nearly as long as wide, pentagonal, with a rather pointed and elongated proximal corner, limited by two sides a little concave, two straight, rather short lateral edges connecting to the distal edge, which is rounded, by equally rounded corners. The adoral plates are very thin, elongated, narrowed outside by the tentacular pores of the first pair, approximately five times longer than wide. The oral plates are a little wider, but shorter and number approximately eight. They are small, a little conical. The most internal is a little longer than the adjacent ones. The unpaired terminal papilla is a little stronger.

The dorsal brachial plates are very large, rectangular, much wider than long, with the distal edge very wide and convex, the proximal edge narrow and the sides divergent. It is only at a great distance from the base of the arm that they become as long as wide, and further on, a little longer than wide.

The first ventral brachial plate is small, triangular or trapezoidal, widened transversely with the distal edge convex. The second is quadrangular, as long as wide, with the proximal edge narrow and slightly concave. The wider and convex distal edge and the divergent sides, slightly excavated 
by the tentacular pores of the second pair. The following ones become much wider than long and triangular, with a proximal obtuse corner, a convex distal edge and pointed lateral corners that, from the fourth to the eighth, are often separated from the rest of the plate by an oblique groove. They are separated only toward the tenth or the twelfth.

The lateral plates are large with a convex distal edge. They have five spines, conical, pointed and elongate, longer than half the article. the last dorsal is a little separated from the others and the first ventral is a little shorter. On some articles, we can even find accidentally six spines.

The tentacular pores of the first pair open into the buccal slits. They are very elongated. They have a half dozen scales on each side. The internal scales are generally arranged in a slightly irregular manner. The pores of the second and third pair have six external scales and four or five internal. The number of scales decreases up to the sixteenth pair, which has three or four external or proximal scales and two internal or distal scales. The following pores have no more than three then two proximal scales.

Similarities and Differences.-O. lenticulatus is absolutely remarkable for its very large size. It recalls a little, by its appearance, O. figurata that is described below. But it is distinguished immediately by the form of the buccal shields and the dorsal and ventral brachial plates, as well as the number of spines. Among the species whose dorsal plates of the disk are thin and numerous, and the radial papillae low and obtuse, we can relate it to O. concreta Koehler, Loveni Lyman, orbiculata Lyman and tumulosa Lütken and Mortensen. But it is distinguished from all by the number of spines, the form of the brachial plates, the large size, etc.

Ophioglypha figurata, nov. sp. (Pl. IX. fig. 83 and 84.)

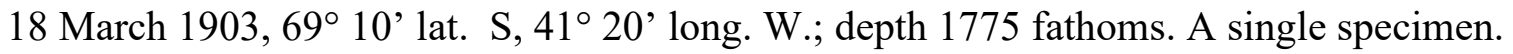

The diameter of the disk is $24 \mathrm{~mm}$. A single arm is preserved with a length of $55 \mathrm{~mm}$. The others are broken near the base. They are rather thin, nearly cylindrical, with a very slightly keeled dorsal surface.

The disk is pentagonal, thin at the edges. The dorsal surface is slightly convex. It has excessively small and numerous scales, very dense and imbricated, greatly recalling those of an Amphiura as in the preceding species. These scales become a little larger near the radial scales. We recognize, however, a rosette of primary plates. The centro-dorsal is rounded. The radials, nearly the same size as it, are widely separated from each other and the centro-dorsal by numerous rows of plates. We note, in addition, in each interradial space, a plate larger than the others, located toward the middle of the space, and a second, widened transversally, located at the periphery of the disk. The radial shields are small, triangular, with a rounded edge, a little longer than wide and widely separated by several rows of plates. Their length is equal to approximately a fifth of a disk radius. Outside the radial shields, we see a double irregular row of very small plates that do not pass the edge of the disk. They represent the radial papillae. They are continued above by a row of very regular and thin square papillae that extend along the entire length of the genital slit.

The ventral surface of the disk has small plates, imbricated and rather regular. The plates of the genital slits are narrow and very elongated. 
The buccal shields are rather small, triangular, a little wider than long, with a rather open proximal corner and straight sides joined by rounded corners at the convex distal edge. The adoral plates are elongated, a little irregular in the contour of their oral edge, swollen inside and continuous outside between the buccal shield and the first lateral brachial plate that they separate from each other. The oral plates are triangular, elongated, widened inside, narrowed outside. They continue in the form of a narrow lobe that goes around the widened part of the adoral plate. The lateral buccal papillae, generally nine in number, are square, obtuse and rather distinct. The internal papilla is a little elongated. The unpaired terminal papilla is a little stronger.

The dorsal brachial plates are large and very developed, rectangular, wider than long, with a narrow proximal edge, a very wide and convex distal edge and divergent sides. They are convex but not keeled.

The first three or four ventral brachial plates have some indication of fragmentation. The first is large, triangular, with an obtuse proximal corner limited by two rounded sides. The distal edge is convex or, better, fragmented into three small pieces. Moreover, it has a small rectangular distal lobe between the first two lateral plates that, on the five arms of the specimen I am examining is separated by a transverse line from the rest of the plate. Is this arrangement constant? The following two or three plates are large and triangular with a straight distal edge. They are wider than long and their lateral points are separated from the rest by an oblique suture. The following plates become much shorter with a very obtuse proximal corner, rounded lateral corners and a very convex distal edge. They are separate after the second.

The lateral plates, very large and very wide and rectangular, have three papilliform spines near the ventral edge. The dorsal plate is a little separated from the others.

The tentacular pores of the first pair, large and elongated, have five or six scales on each edge. The external scales continue with the buccal papillae. They open into the buccal slits. The second ones, smaller, have five or six scales outside and four inside. Those of the third pair have four or five external scales and two or three internal ones. The fourth pores have only three or four external and proximal scales, and two or three on the distal edge. The pores of the fifth pair have only three proximal scales, then the number of scales falls to two and finally one.

Similarities and Differences.- $-O$. figurata is easy to distinguish from other species by the very thin and imbricated plates of the dorsal disk, the absence of radial papillae on the dorsal surface of the disk on each side of the base of the arms, and by the three very small brachial spines. I have indicated, in describing $O$. lenticularis, the characters that distinguish it from this latter species.

Ophioglypha ossiculata, nov. sp. (Pl. IX. fig. 85 to 87.)

18 March 1904, 71²2’ S. lat., $1^{\circ}{ }^{\circ} 34^{\prime}$ long. W.; depth 1410 fathoms. Seven specimens.

The diameter of the disk is $19 \mathrm{~mm}$ in the largest specimen and 9 in the smallest. The arms are broken at one or two cm from the disk.

The disk is pentagonal, not very thick, with thin edges. The dorsal surface has, at the base of the arms, more or less marked notches to receive the first two or three dorsal brachial plates. It is covered with unequal plates, very thick, nearly all raised in obtuse prominences. These plates, while remaining well separated and distinct from each other, are united at their bases in a common 
calcified tissue. We distinguish a rounded centro-dorsal plate, rather large, having toward its edge a wide and prominent circular thickening and five rather large primary radials, widened transversely and having a thickening in the form of a semi-circle that occupies a good part of their surface. They are separated from the centro-dorsal by two or three rows of plates of which the internal ones, larger, form a rather constant pentagon. Among the other plates, we recognize one or two larger radials between the radial shields and, in the interradial spaces, a plate near the periphery of the disk. These different plates all have thickenings in the form of a semi-circle on their external edge. The other smaller plates that separate them are simply thickened and swollen. The radial shields are small, irregular in form and more or less triangular, as wide as long, divergent and very widely separated inside by three plates of which the middle one is generally larger than the other and cordiform. These shields have on their distal edge two thickenings. The external one is conical, the other internal, larger, thin and lamellar. A row of radial papillae, low and obtuse are outside. These papillae continue along the entire length of the genital slits where they become very small and flat.

The ventral surface of the disk is covered with unequal plates, irregularly polygonal and thick. The external plates have a conical prominence that disappears toward the buccal shields. The very thin genital slits extend up to the buccal shields. The genital plates are very narrow.

The buccal shields, of medium size, are triangular with the corners and edges rounded, except for the proximal corner that is obtuse. They are a little wider than long. The adoral plates are not very large. They are two times longer than wide and greatly tapered outside. The oral plates are a little wider, but shorter than the latter. The lateral buccal papillae number six. They are very distinct, obtuse and square. The internal one is a little elongated and conical. The unpaired terminal papilla is a little larger.

The first two or three dorsal brachial plates in the notch of the disk are rectangular, very short and wide. They then elongate and have a very wide distal edge, convex, a narrow proximal edge and divergent sides. The become as wide as long, then a little longer than wide. They are all contiguous.

The first ventral brachial plate is widened transversally, with the proximal edge wide and convex. The following one is trapezoidal with the proximal edge narrow, the distal edge very wide and the sides divergent, excavated by the tentacular pores. The following plates become triangular, much wider than long, with an obtuse proximal corner and a very convex distal edge. The second, third and fourth plates generally have an oblique line that separates the external corner of the plate from all the rest, as in O. lenticularis, figurata, etc. The ventral plates are separated after the fourth.

The lateral plates have, all along the length of their distal edge, a row of eight to nine small papilliform spines.

The tentacular pores of the first pair, very elongated, open into the buccal slits. They have six external scales and five internal ones. The second and third have nearly the same. Those of the fourth pair have four or five external and proximal scales and three or four distal ones. Those of the fifth pair have three or four proximal scale and two or three distal ones. After this, the pores have only three, then two proximal scales.

Differences and Similarities. - O ossiculata belongs to the Ophyoglypha with low and obtuse radial papilla and ventral brachial plates much wider than long. It is easily recognized by its disk covered with protruding and thickened plates and the number of brachial spines. I know no species that can approach it. 
Ophioglypha mimaria, nov. sp. (P1. IX. fig. 88 and 89).

18 March $1904,71^{\circ} 22^{\prime}$ lat. S., $16^{\circ} 34^{\prime}$ long. W.; depth 1410 fathoms. Several specimens.

In the largest individuals, the diameter of the disk is $11 \mathrm{~mm}$ and the arms are approximately $30 \mathrm{~mm}$ in length. But most of the specimens are small and their disk measures 5 to $8 \mathrm{~mm}$ in diameter.

$O$. mimaria has a great resemblance to $O$. ossiculata that I just described by the form of the dorsal and ventral brachial plates, as well as by the arrangement of the buccal pieces and the ventral plates of the disk that are flat and do not have the least trace of thickenings or prominences. Because of this important difference that is constant, I believe it necessary to separate them.

The disk is pentagonal. All the plates of the dorsal surface are flat and thin, irregularly rounded and unequal. We distinguish a rosette of primary plates, large and unequal, the rounded centrodorsal and the radials widened transversally. They are separated from each other by two or three rows of small plates. We distinguish, in the radial spaces, a large triangular plate separating the radial shields on the internal half and followed by another smaller one. In the interradial spaces are two successive plates, of which the latter, located at the edge of the disk, is widened transversally. The plates between the preceding are small, unequal and rounded. The radial shields, or medium size, are triangular with rounded corners and edges. They are not much longer than wide. Their length is less than a third of the disk radius. They are divergent and approach each other, in the large specimens, by their external corner, but without touching. The genital papillae stop at the lateral edges of the arms. We see only two or three on the dorsal surface of the disk.

The ventral surface is covered with rather small plates, polygonal or rounded and completely flat. The genital plates are narrow. The genital slits are elongated and edged with a row of very low and obtuse papillae.

The buccal shields are of medium size, triangular, as long as wide or a little wider than long. The other buccal pieces are arranged as in O. ossiculata.

The dorsal and ventral brachial plates have likewise the same arrangement as in this latter species. It is the same for the tentacular pores. The brachial spines number seven to eight.

In summary, there are important differences between $O$. ossiculata and O. mimaria only in the form and arrangement of the dorsal plates of the disk. However, I have carefully compared all the species of the two specimens that I have at my disposal, and I have not been about to find a transition of one form to the other. The small specimens of $O$. ossiculata whose disk is only 10 or $11 \mathrm{~mm}$ in diameter, compared to the largest individuals of $O$ mimaria in which the diameter of the disk attains nearly the same dimensions, always show the same differences. These latter do not have the least tendency to thicken the dorsal plate of the disk. In contrast, the smallest individuals of $O$. ossiculata, in which the diameter of the disk does not exceed 6 to $8 \mathrm{~mm}$, already have very marked thickenings. These are thus not the effect of size. They are always missing in $O$. mimaria and exists at all stages in $O$. ossiculata.

Is it necessary to see in $O$. mimaria a variety of $O$. ossiculata with smooth and thin plates or make it a distinct species? At first glance, the difference is so striking that it appears preferable to me to distinguish these two forms specifically. I think that we will adopt my opinion if we compare the figures that I have given, Pl. IX. fig. 87 and 88, that represents an O. ossiculata and an $O$. mimaria of nearly the same size. 
The question is all the more delicate as the two forms come from the same station and are even found together in the same jar. I have not, however, the least hesitation in sorting to separate the one from the other.

Ophioglypha anceps, nov. sp. (P1. X. fig. 92 and 93.)

18 March $1904,71^{\circ} 22^{\prime}$ lat. S., $16^{\circ} 34^{\prime}$ long. W.; depth 1410 fathoms. About fifteen specimens.

In the largest individuals, the diameter of the disk attains $15 \mathrm{~mm}$, and in the smallest, it is only 5 or $6 \mathrm{~mm}$. The arms are nearly all broken near the base and must be very short. In a specimen whose diameter of the disk of $14 \mathrm{~mm}$, it is scarcely $23 \mathrm{~mm}$ in length. They are rather thick and taper rapidly.

The disk is rounded or pentagonal. The dorsal surface has unequal plates, thick and rounded, rather large and not very numerous. This is a rosette of six primary plates, large and rounded, equal and separated by a row of small plates. In the radial spaces, a large plate separates the proximal halves of the radial shields. It is followed by one or two smaller plates occupying the triangular space that separates the distal region of these shields. In the interradial spaces, we distinguish two large successive rounded plates, of which the latter occupies the periphery of the disk. It is rather wide transversally. The rest of the disk is filled with very small plates. The radial shields are irregularly triangular, with the edges and corners rounded, as wide as long or a little longer than wide. Their length is equal to a third of the disk radius. They are a little divergent and separated along their entire length by the row of plates reported above.

All the plates of the dorsal surface of the disk are thick, prominent and separated by very accentuated and deep grooves. Moreover, they have thickenings that, on the large plates, generally form a semi-circle on their peripheral edge or make on each of them two distinct eminences. The centro-dorsal plate has a circular thickening constituted of five confluent prominences. As for the small intercalary plates, they are raised in cones. Finally, the radial shields have two well marked rounded prominences on their external edge.

On each side of the base of the arms and outside the radial shields, we see a border of two or three rows of small papillae, widened transversally, short and rather thick, that continue a little onto the ventral surface and penetrate between the genital plate and the third lateral brachial plate. These papillae disappear well before they have reached the genital slits. These are very small, very narrow and short. They are exactly limited to the sides of the first lateral brachial plate.

The ventral surface of the disk is little developed. It has, outside the buccal shield, only a single plate, very large, having the same width as the shield, but shorter, and, at the very edge of the disk, three small plates, a median one and two laterals. These have one or two conical eminences similar to those that we see on the dorsal plates of the disk. The large central plate also sometimes has similar prominences. The genital plates are elongated and rather narrow.

The buccal shields are large, longer than wide, with a pointed proximal corner, limited by two straight sides, two straight and parallel lateral edges and a straight distal side. The two edges of the proximal corner and the two lateral edges are not always very distinct from each other. The adoral plates are rather small, quite narrow, with parallel edges, two and a half times longer than wide. The oral plates are a little thicker than the adorals and shorter. The lateral buccal papillae form an extremely thin border. There are about five of them, very low. The unpaired terminal papilla is scarcely larger than the adjacent ones. 
The arms are moniliform because of considerable swelling of the distal edge of the lateral plates. The dorsal brachial plates are of medium size. The first two or three remain small, rectangular, wider than long, then they become longer than wide, with a wide and convex distal side, two divergent lateral edges and a proximal edge that rapidly becomes shorter and ends by disappearing. The plates then become triangular. They are slightly separated from each other. They all have a small conical prominence near their distal border.

The first ventral brachial plate is triangular, with straight sides and a rounded and truncated proximal corner. It is longer than wide. Sometimes the proximal corner is so truncated that the plate becomes rectangular. The second one is triangular with slightly rounded sides and a pointed proximal corner. It is a little longer than wide. The following ones are still triangular, but with an obtuse proximal corner. They become must wider than long, with a convex distal side and straight or slightly concave lateral sides. They are separated from the second.

The lateral brachial plates have, on the strongly thickened and prominent distal edge, two or three very small and papilliform spines.

There is hardly more than a single pair of tentacular pores that are limited to the sides of the oral plates and do not open into the buccal slits. These pores are small and narrow. We see two or three distinct scales on their interradial edge. Sometimes the radial edge has one or two smaller scales or is a simple rim without distinct scales. Beyond, the tentacular pores become nearly completely absent. On the large specimens, we distinguish, however, a very small pore without distinct scales on each side of the second ventral brachial plate and toward the middle of its lateral edge.

Similarities and Differences.-O anceps recalls absolutely by its appearance an Ophiomusium, but it certainly is an Ophioglypha that has, in truth, only one pair of normally formed tentacular pores It has some similarity with $O$. frigida Koehler that the Belgica collected in the Antarctic Ocean and that has, like O. anceps, thickened dorsal plates of the disk and arms and a single pair of tentacular pores. But it is distinguished by a different form of buccal shields and buccal pieces, as well as by the ventral plates of the disk and by the moniliform arms.

The small specimens greatly recall $O$. Martensi Studer that is also an Antarctic form. But they cannot be related to this species because they already have well marked the characteristic prominences of the dorsal plates of the disk and the arms that STUDER does not mention. The small individuals have a rather regular row of radial papillae to which, however, we already see added one or two rows of small scales whose number increases with age to give the arrangement we see in the adult.

Ophioglypha scissa, nov. sp. (Pl. XI. fig. 98 and 99; Pl. XII. fig. 112.)

18 March 1904, 71²2' lat. S., 16³ 34' long. W.; depth 1410 fathoms. Several specimens.

The disk is flat and rather thin. Its diameter measures $10 \mathrm{~mm}$. The arms ae sender and should attain approximately $25 \mathrm{~mm}$ in length. Their length cannot be indicated exactly because they are all broken at some distance from the base.

The disk is sub-pentagonal or pentagonal. The dorsal surface is covered with very unequal plates, among which we distinguish six large rounded primary plates nearly the same dimensions 
and separated from each other by a row of small irregular plates. The interradial spaces generally have two successive plates a little larger than the others. The latter, widened transversally, occupies the edge of the disk. All the rest of the dorsal surface is covered with small polygonal-rounded plates. The radial shields are triangular with rounded corners, hardly longer than wide. They are divergent and ordinarily separated outside. They are sometimes very close together but without touching, however. They often have in their midst a cleft more or less parallel to the edge of the disk. These is not the least trace of radial combs. All the large plates of the dorsal surface of the disk are finely granulose.

The ventral surface is covered with several polygonal plates in a space that is at least equal in length to the length of the buccal plate and often exceeds it. We frequently find in the midst of this surface a little larger plate around which the others are arranged. The genital plates are elongated. The genital slits are very small and often invisible They are limited to the sides of the first lateral brachial plate and do not reach the edge of the disk. Their edge does not have the least trace of papillae.

The buccal shields, of medium size, are pyriform or triangular, nearly as long as wide and often a little longer than wide. They have a pointed proximal corner, limited by two straight or slightly concave sides and a strongly convex dorsal edge. Most often, but not constantly, they are divided over all or on a part of their length by an interradial groove that sometimes passes the shield and divides one or two adjacent plates. The adoral plates are elongated, with parallel edges, two and a half times longer than wide. The oral plates are thicker. The lateral buccal papillae are low, rectangular, very short with indistinct contours. They number four or five. The unpaired terminal papilla is larger and conical.

The first dorsal brachial plate is rectangular, wider than long, with the distal edge rounded. The following ones are triangular, as wide as long, with the distal edge convex. They are separated after the second.

The first ventral brachial plate is rather large, triangular or pyriform, a little wider than long, with the distal edge convex and the distal corner obtuse. They are very widely separated.

The lateral plates have first four then three very small and papilliform spines, the dorsal one sometimes a little separated from the others.

The tentacular pores are very little developed. Those of the first pair generally do not open into the buccal slits. They have four or five external scales and three or four internal ones. The pores of the second pair are much smaller, with two or three external scales and one or two internal ones. Those of the third pair have only two or three proximal scales. Beyond that, the pores are no longer distinct.

As I have already seen in $O$. inornata, with which $O$ scissa has similarities, the grooves that divide the buccal shields have variations. In some individuals, they are completely lacking, while in others, one or several shields are divided in two by a groove that can continue onto the adjacent ventral plates. Finally, some shields are incompletely divided, the groove is only in their second half. Some similar variations are seen in the radial plates. The first five primary radial plates can also have grooves. As for the dorsal brachial plates, they are always undivided in O. scissa.

Similarities and Differences-O. scissa is near O. inornata Lyman, but it is distinguished by the absence of radial combs and by much smaller buccal shields. It has also some similarity to $O$. Bruce $i$ that I have described above, but it is separated by the arrangement of the dorsal plates of the disk, by the form of the buccal shields and by the divisions that affect some plates. 


\section{Ophioglypha partita, nov. sp. (Pl. X. fig. 94 and 95.)}

18 March 1903, 62 ${ }^{\circ} 10^{\prime}$ lat. S., $41^{\circ} 20$ long. W.; depth 1775 fathoms. A single individual that is unfortunately in very bad condition. The arms are broken very near their base.

The disk has a diameter of $10 \mathrm{~mm}$. It is pentagonal and rather thick. The dorsal surface is flat. It is covered with very unequal plates, rounded, very strongly granulose, rather prominent but united at their base in a compact calcareous tissue. We distinguish a rosette of six large primary plates, with nearly the same dimensions and separated by three or four rows of unequal plates. In the radial spaces, three or four rows of unequal and rounded plates separate the radial shields. One or two of them are larger than the others. The interradial spaces have only small unequal plates. The radial shields are large and elongated, triangular, nearly two times longer than wide, slightly divergent and widely separated. On each side of the base of the arms, we see some poorly defined granules that do not make a radial comb and that do not continue on the edge of the genital slit.

The ventral surface of the disk is covered with small plates, unequal and rounded. One rather large plate extends along the length of the arms, but the genital slits are exactly limited to a very narrow and very short gap between the first lateral central plate and a small plate placed in front of it. The buccal shields are all malformed, unequal. Their contours are irregular, without doubt because of the presence of a groove that crosses them in the interradial direction. Their form appears to be triangular, with a rather obtuse proximal corner and a convex distal edge. They are wider than long. The adoral plates are rather thick and short, two times longer than wide. In one of the interradii. They are in part aborted. The oral plates are large, high and wide. The six lateral buccal papillae are obtuse and poorly separated from each other. The unpaired terminal papilla is larger than the adjacent ones.

The dorsal brachial plates are large. The first two or three are rectangular, wider than long. They then become triangular with a rounded proximal corner and a convex distal edge. They are as long as wide or a little longer than wide. They are separated after the fifth. All these plates have a median very wide and rather deep groove that divides them into two equal halves.

The first ventral brachial plate is large, triangular, with an elongated proximal corner, a convex distal edge and sides a little concave. The second is pentagonal, with a narrow proximal corner limited by two small sides, two divergent lateral edges and excavated by the tentacular pores and a strongly convex distal side. It is a little longer than wide. The third is still pentagonal but shorter than the second and wider than long, with an obtuse proximal corner and a convex distal edge. The following ones become triangular with a very obtuse proximal corner and a strongly convex distal edge. They are separated from the first.

The lateral brachial plates, rather prominent, have on their straight distal edge three equally spaced spines, short and pointed.

The tentacular pores of the first pair, large, wide and short, have four external scales and three internal one. They do not open into the buccal slits. Those of the second pair have three external scales and two internal ones. The following ones have two external and proximal scales and only one distal scale. The pores of the fourth pair have only one distal scale. Beyond that, we cannot distinguish pores. 
Similarities and Differences.- $O$. partita is remarkable for the division of the buccal shields and the dorsal brachial plates. It shares this particularity with $O$. inornata Lyman $(O$. divisa Lütken and Mortensen), but it is very different from this species. It is distinguished from $O$. scissa that I have described above by its larger and divided dorsal brachial plates, as well as by the longer radial shields.

\section{Ophioglypha inops, nov. sp. (Pl. XL fig. 96 and 97.)}

18 March 1904, lat. $71^{\circ} 22^{\prime}$ S.; long. $16^{\circ} 34^{\prime}$ W.; depth 1410 fathoms. One specimen.

Diameter of the disk, $12 \mathrm{~mm}$. The arms are preserved for a length of $27 \mathrm{~mm}$ and could hardly be larger.

The disk is thick. The dorsal surface is a little convex. The edges are high and rounded. The arms are relatively thin.

The dorsal surface of the disk is covered with rather large plates, unequal and rounded, the smallest slightly imbricated. We distinguish a rosette of larger primary plates, the rounded centrodorsal, the radials a little widened transversely, separated from each other and the centro-dorsal by two rows of small plates. The rest of the disk is occupied by smaller plates, among which we recognize only one larger plate between the two radial shields of each plate. These are very small, triangular, elongated, widened outside, very narrow inside, nearly two times longer than wide. They are contiguous outside and separated inside by the large radial plate indicated above and to which is usually added a smaller plate located outside. Their length is a little larger than a third of the disk radius. A row of fine radial papillae, pointed and very close together, form a very apparent comb. These papillae continue the length of the genital slit where they are small, low and sparse.

The ventral surface of the disk has, apart from the small buccal shields, some rounded plates, subequal and a little imbricated. The genital plates are narrow and inconspicuous. The genital slits extend their entire length up to the buccal shield.

The buccal shields are small, triangular, a little longer than wide, with an elongated proximal corner and a slighted rounded distal edge. The adoral plates are very thin, elongated, narrowed in their middle by the tentacular pores of the pair and four or five times longer than wide. The oral plates are rather large, thick and strong, two times longer than wide. The lateral buccal papillae number five. The external ones are obtuse and the two internal ones are conical. All of them are small, except the internal one that is a little larger. The unpaired terminal papilla is a little larger than the adjacent ones.

The dorsal brachial plates are small. They are first rectangular, wider than long. The first two, between the radial shields, are very reduced. They elongate then and become triangular, nearly as long as wide. They are separated from each other toward the sixth or the seventh.

The first ventral plate is large, triangular, with the corners and the edges rounded. It is a little wider than long. The second one is rectangular, longer than wide, with sides excavated by the tentacular pores. The wide distal edge is very slightly rounded. The four or five following ones are rectangular, a little longer than wide. Then the proximal edge narrows and disappears. The plates than have a pointed proximal corner and thus becomes pentagonal. At the same time, they greatly elongate. They separate toward the tenth or twelfth. 
The lateral plates are prominent. They have on their convex distal edge a row of six equal spines regularly arranged along this edge. These spines are conical, rather strong and a little smaller than half the article. The number decreases at some distance from the disk.

The tentacular pores are large, widened, but short. Those of the first pair have five external scales and four internal ones. Despite their size, they do not open into the buccal slits in the single specimen that I have been able to study. The pores of the second, third and fourth pore pairs have four or five external scales and three or four internal ones. The following ones have three external and proximal scales and two distal scales. Finally, they have only two distal scales and only one afterwards.

Similarities and Differences.- $O$. inops has affinities with $O$. Lacazei and sculptilis described by LYMAN, which have square and contiguous ventral brachial plates, dorsal plates of the disk more or less numerous, and large and short tentacular pores. It is distinguished from them by the arrangement of the dorsal plates of the disk and the absence of larger plates in the interradial spaces at the edge of the disk, by the form of the dorsal brachial plates, by the number of spines, etc.

\section{Ophioglypha bullata, Wyville Thomson.}

See for the bibliography:

KOEHLER, Expéditions du "Travailleur" et du "Taliiman" : Ophiures, p. 259.

29 April 1904, 39 48' lat. S., 2 33' long. E.; depth 2645 fathoms. Several specimens.

Although these specimens do not rigorously conform to the description of LYMAN, I do not hesitate to relate them to $O$. bullata. There are principally rather notable variations in the relative dimensions of the dorsal plates of the disk. In some individuals, the six primary plates are very large and even contiguous, while in others, they are smaller and separated by two or three rows of small plates. The interradial plate that reaches the edge of the disk on the dorsal surface and that, in the figure of LYMAN, occupies all the interradial space, is always smaller and accompanied by one or two rows of small plates in the specimens where the primary plates are large. In the specimens where these primary plates are small, the interradial marginal plate itself is smaller and is accompanied by more numerous plates. The radial shields of each pair are separated, sometimes by a single row, sometimes by two of three rows of plates. They are sometimes brought together by their external border and slightly divergent.

In summary, the species is rather variable.

O. bullata has been encountered especially in the North Atlantic, but it is also found in the Southern Hemisphere. The Challenger found it at $35^{\circ}$ lat. S. and $20^{\circ}$ long. W. This station is rather near that where the Scotia dredged. 
Ophiocten Ludwigi, nov. sp. (PL XI. fig. 100 and 101.)

18 March $1903,62^{\circ} 10^{\prime}$ lat. S., $41^{\circ} 20^{\prime}$ long. W; depth 1775 fathoms. Three specimens in alcohol, but in bad state.

18 March 1904, $71^{\circ} 22^{\prime}$ lat. S., $16^{\circ} 34^{\prime}$ long. W.; depth 1410 fathoms. About a dozen specimens, dried but well preserved.

The disk is large. Its diameter reaches $12 \mathrm{~mm}$ in the largest specimens. It is thin and flexible. The arms are all broken at some distance from their base.

The disk is notched at the base of the arms. Its dorsal surface is covered with unequal plates, most of small size. Some are larger but they never become very large. The small plates do not form a circle around them. We distinguish, more or less clearly, a rosette of primary plates, rounded, small, and widely separated, then, in the radial and interradial spaces, four or five rounded plates in each space. The rest of the disk is covered by very small and thin plates, irregularly polygonal, becoming a little larger toward the edge of the disk and between the radial shields. These are small and irregularly triangular, as long as wide or a little longer than wide, a little divergent and widely separated by five or six rows of plates. We distinguish, outside each shield, a comb of small conical and pointed papillae, but that do not continue from one side of the arm to the other.

The ventral surface is covered with very small and imbricated plate. The genital slits are narrow.

The buccal shields are rather large, pentagonal, much wider than long, with a rather open proximal corner limited by two sides a little concave, and a convex distal edge. The adoral plates are large, elongated, thin especially outside and with a narrow lobe that separates the buccal shield from the first lateral brachial plate. They are five or six times longer than wide. The oral plates are rather large and wide, two and a half times longer than wide. the lateral buccal papillae generally number five. The two external ones are very low and rectangular, often mixed together. The others become progressively more conical and pointed. The unpaired terminal papilla is large and conical.

The dorsal brachial plates are large and quadrangular, except the first or the first two that are in the notch of the disk and very small. They are much wider than long, with a convex distal edge and divergent sides. At some distance from the disk, these plates become as wide as long and finally, longer than wide. They have, for the entire length of their distal edge, a row of dense papillae, excessively fine and resembling bristles. These papillae continue up to the twelfth plate and even beyond. Then they become less numerous and finally disappear. Perhaps on specimens better preserved, they would still be seen further. In the specimens of 18 March 1903, that are in less good state than the others, the papillae are very frequently missing and must have accidentally fallen off.

The first ventral brachial plate is large, trapezoidal, with a narrow and straight proximal edge, divergent sides and a distal edge wide and a little convex. The second is rather large, with a pointed proximal corner and a very convex distal edge. Then the proximal corner opens more and more to the point of disappearing nearly completely. At the same time, the plates become much smaller. They are separated from the first.

The lateral plates have three thin spines, pointed and elongated. Their length increases from the first ventral that is nearly equal to the article, up to the last dorsal that, on the first articles, comes to nearly equal two articles and then become shorter. 
The buccal tentacular pores have three of four small and obtuse scales. The pores of the second pair have one proximal scale and one distal scale. Then the distal scale disappears and there remains only the proximal scale that is small and conical.

Similarities and Differences.- $-O$. Ludwigi belongs to the section of Ophiocten whose primary plate are little apparent and whose large plates of the disk are little developed. It is especially near $O$. hastatum Lyman and pacificum Lyman, that it evidently represents in the Southern Seas. It is easily distinguished from these two species by the row of very fine papillae on the distal edge of the dorsal brachial plates and that continues on a number of articles.

Ophiernus quadrispinus, nov. sp. (Pl. XL fig. 102 and 103.)

18 March 1903. 62 10’ lat. S., $41^{\circ} 20^{\prime}$ long. W.; depth 1775 fathoms. Four specimens.

As nearly always happens with Ophiernus, the specimens collected by the Scotia are in a bad state. In three of them, all the arms are broken at the edge of the disk and the fourth has only kept some articles. The disk is more or less deformed, the radial shields are broken, etc. The specimen that has suffered the least is represented in Pl. XI. figs. 102 and 103. It is this that I shall describe below. The diameter of its disk is $13 \mathrm{~mm}$. In the others, this diameter reaches $18 \mathrm{~mm}$ in the largest and 11.5 in the smallest.

The disk is pentagonal, not concave in the interbrachial spaces. The dorsal surface has small plates, but very distinct, non-imbricated and becoming a little larger toward the radial shields and the edge of the disk. These plates have a few sparse, rounded granules that become denser toward the radial shields. In this specimen and in two others, the plates of the disk are equal and all very small. But in the fourth, we note some larger rounded plates that are surrounded by others much smaller than themselves as happens in Ophiocten. The radial shields are very large, oval, longer than wide and separated on the entire length by a few rows of plates.

The ventral surface has thin plates, equal, imbricated, becoming larger along the genital slit. These are narrow and elongated.

The buccal shields are rather large, as long as wide, with an obtuse and rounded proximal corner, lateral edges a little convex and a distal side with a more or less accentuated and prominent lobe in its middle in the interbrachial space. The adoral plates are very narrow, elongated, thin inside, but contiguous on the median line and very widened outside. They separate the first lateral brachial plate from the buccal plate. The oral plates are high and rather wide. There are five lateral buccal papillae, obtuse, a little unequal but with a very definite form, and an unpaired conical terminal papilla, larger than the adjacent ones.

The dorsal brachial plates that are preserved are quadrangular, much wider than long, with proximal and distal sides parallel and the lateral sides slightly divergent.

The first ventral plate is small and triangular. The following plates are large, quadrangular, with the proximal edge narrow and the distal edge wide and having a small median lobe. The lateral corners are pointed and the lateral edges, divergent, are widely excavated by the tentacular pores They are contiguous. 
The large lateral brachial plates have four spines on their distal edge, subequal and short. The number decreases without doubt on the following articles. The arms are not widened inside the disk.

The buccal tentacular pores, widely open into the mouth as usual, have three distal scales. The pores of the second pair also have three distal scales. The following pores have only two scales that move progressively to the external border, then to the proximal border.

Similarities and Differences.-O. quadrispinus differs from the other species of the genus especially by its brachial spines that number four at the base of the arms. It is likewise characterized by the larger and more distinct dorsal plates of the disk and by the less numerous granules than in the other species.

Amphilepis antarctica, nov. sp. (P1. XIII. fig. 113 and 114.)

August 1903, Scotia Bay, South Orkneys; depth 9-10 fathoms. A single specimen.

Diameter of the disk, $2.5 \mathrm{~mm}$. The arms are only $6 \mathrm{~mm}$ in length.

The disk is sub-pentagonal. The dorsal surface is covered with very large plates, few in number and polygonal, among which we do not see distinct primary plates. The radial shields are not larger than the largest plate of the disk. They are triangular, nearly as long as wide and separated their entire length by a row of two large plates.

The ventral surface is covered with unequal plates, polygonal-rounded, slightly or not imbricated. The genital slits are narrow but very distinct.

The buccal shields are rather small, triangular, with a rounded distal edge. They are nearly as long as wide. The adoral plates are elongated, very widened outside, narrowed inside and contiguous. The oral plates are rather thick and a little elongated. The external buccal papilla is wide and rectangular as in Amphipholis, the following one is small and conical. The unpaired papilla is a little larger.

The dorsal brachial plates are extremely large and wide. They occupy nearly all the dorsal surface of the arms to the exclusion of the lateral plates that are very small. They have a very obtuse proximal corner, an extremely convex distal end and rounded lateral corners.

The first ventral brachial plate is small, pentagonal, narrow in its distal part between the two adoral plates and much longer than wide. The following ones are pentagonal, larger, longer than wide, with an obtuse proximal corner, a nearly straight distal side. They separate toward the seventh or eighth.

The lateral brachial plates have three spines.

The opening of the buccal tentacular pore has a small conical scale with an obtuse point. The brachial pores have each a small conical and an obtuse point.

Similarities and Differences.-A. antarctica is distinguished from other species of the genus by its tentacular pores, all with a small scale, and by the size of the dorsal brachial plates. 
Amphiura magnifica, nov. sp. (Pl. XII. fig. 111; Pl. XIII. fig. 119.)

9 April $1904,51^{\circ} 7^{\prime}$ lat. S., $9^{\circ} 81^{\prime}$ long. W.; depth 2103 fathoms. One specimen of large size. 21 March 1904, 69 $33^{\circ}$ ' lat. S., $15^{\circ} 19^{\prime}$ long. W.; depth 2620 fathoms. One specimen.

This species attains a remarkable size for an Amphiura. In the largest specimen, the diameter of the disk is no less than $18 \mathrm{~mm}$. The arms are broken at some distance from their base. But they should reach about ten centimeters in length. In the other specimen, the disk, that is in bad condition, is smaller. Its diameter is only $15 \mathrm{~mm}$.

The disk is rounded. The dorsal surface is swollen. The ventral surface is flat. The edge is thick and rounded. The dorsal surface is covered with rather small plates, unequal and imbricated, becoming a little larger toward the radial shields and smaller toward the periphery of the disk. The primary plates form a distinct rosette. The centro-dorsal plate is rounded. The radials, that are separated from it by five or six rows of plates, are a little smaller and widened transversally. The radial shields are small, nearly semi-circular, one and a half times longer than wide, slightly or not divergent, and separated their entire length by a row of plates. Their length is equal to a fourth of the disk radius.

The ventral surface is covered with very small plates, thin and imbricate. The genital slits are narrow.

The buccal shields are small, a little longer than wide, triangular, with a convex distal edge and having in its midst a wide more or less marked prominence. The proximal corner is pointed. The lateral edges are straight. The adoral plates are wide and thick, triangular, with rounded corners and a proximal edge sightly irregular. The internal corners are not contiguous. The oral plates are very small. The lateral buccal papillae, four in number, are obtuse, square, and increase slightly in size from the external to the internal. The external is supported by the adoral plate. The following is generally found at the point of union of the oral plate and the adoral plate.

The dorsal brachial plates are extremely side and short, four times wider than long. They cover nearly all the dorsal surface of the arm. They have a distal corner so obtuse that it makes a nearly $180^{\circ}$ angle. The distal edge is convex and joins by a curved edge the sides of the proximal corner. These plates are separated by a slight gap at some distance from the base of the arm. They are sometimes divided by a longitudinal groove and even fragmented into two or three fragments. The first ventral brachial plate is rather small, square or trapezoidal, as long as wide. The following are pentagonal, with an obtuse proximal corner, truncated on the first two or three plates, straight lateral edges and a rounded distal side connected by equally rounded corners to the lateral edges. They are a little wider than long and all contiguous.

The lateral plates, slightly protruding, have three conical spines whose length is nearly equal to that of the article. The median is a little larger.

The tentacular scale, singe, is elongated. Its length nearly equals that of the sides of the ventral plate. Its edges are parallel and its end is obtuse.

Similarities and Difference.-A. magnifica belongs to the section of Amphioplus characterized by the presence of four buccal papillae. It is easily distinguished from the species of this section that have only one tentacular scale, because nearly all have more than three brachial spines, except $A$. dalea Lyman. But this latter species has larger radial shields, a different form of buccal papillae and the tentacular scale is supported by the ventral brachial plate. 
Amphiura Mortenseni, nov. sp. (Pl. XIV. fig. 121 and 122.)

April 1903, Scotia Bay, South Orkneys; depth 9-10 fathoms. Several specimens. 26 January 1904. Jessie Bay, South Orkneys. Three specimens.

Diameter of the disk, 5 to $6 \mathrm{~mm}$; length of arms, 25 to $30 \mathrm{~mm}$.

The disk is rounded, sub-pentagonal. The dorsal surface is covered with plates of medium size, among which we generally distinguish a rosette of larger primary plates. The centro-dorsal is rounded, the radials, as large as it, are rounded or widened transversally. They are separated from each other and the centro-dorsal by only a single row of small plates. We recognize, in addition, in the radial spaces, one or two larger plates. The latter is placed between the proximal ends of the radial shields. In the interradial spaces, we also see two larger plates, of which the latter stays at some distance from the edge of the disk. The other plates are small, imbricated and unequal. The radial shields are small, semi-circular, two times longer than wide, with a straight internal edge and a very convex external edge. They are divergent, close together outside but separated by a small plate. Inside, they are separated by two or three rows of plates. Their length is a little greater than a third of the disk radius.

The ventral surface is covered with imbricated plates, small and equal. The genital slits are narrow.

The buccal shields are a little longer than wide. They have a triangular principal part, with an obtuse and rounded proximal corner, limited by two convex sides and a wide, more or less protruding distal lobe in the interradial space. The adoral pates are elongated and very large, narrow inside and ending in a rounded corner that is contiguous to its counterpart. They are greatly widened outside. The oral plates are a little elongated and narrow. There is an external buccal papilla, short, strong, conical and pointed and an internal one, elongated, cylindrical, thick, with an obtuse point. Between the two, we can see, on an upper plane, a papilla, thinner, smaller and pointed.

The dorsal brachial plates are very large and wide, nearly biconvex, with a very short proximal edge that, at some distance from the base, disappears and is replaced with a very obtuse corner, small lateral edges, sometimes indistinct, and a strongly convex distal side. They are contiguous.

The first ventral brachial plate is small and narrowed in its distal region by the adoral plates that are adjacent to it. It has a convex proximal edge and two concave sides. The distal edge is very reduced. The following plates are large, pentagonal, with a very obtuse proximal corner, sometimes even reaching nearly $180^{\circ}$. This makes the plates nearly rectangular. A nearly straight distal side is connected by rounded corners to the lateral edges that are straight. They are nearly as long as wide and all contiguous.

The lateral plates have four unequal spines whose length attains that of the article. They are thick and strong, with an obtuse point.

The tentacular pores have two scales of medium size, slightly conical and arranged with a right angle.

Similarities and Differences.-A. Mortenseni belongs to the section Amphiura s. str. It is characterized easily by the form of the buccal shields with a prominent and well accentuated distal lobe. 
We cannot confuse it with other species of the same group that have the ventral surface covered with plates and two tentacular scales. A. Eugenice has three buccal papillae and must be in group Amphiodia. As for A. Studeri Lyman (A. antarctica Studer), it has pentagonal buccal shields, longer than wide.

Amphiura consors, nov. sp. (Pl. XIII. fig. 117 and 118.)

21 March 1904, 69 33' lat. S., 15 19’ long. W.; depth 2620 fathoms. Two specimens.

In the larger specimens, the diameter of the disk is $12 \mathrm{~mm}$. One of the arms, which is nearly entire, is $55 \mathrm{~mm}$ in length. In the other individual, the diameter of the disk is only $10 \mathrm{~mm}$. The disk is rounded, very slightly notched at the base of the arms. The dorsal surface is covered with small plates, nearly round, nearly as long as wide, imbricated only in the area of the edge of the disk. The three or four peripheral plates that are found immediately outside each radial shield are notably larger and longer than the others. At the periphery of the disk, the plates stop abruptly at a border that is constituted of much smaller plates. The radial shields, rather small, are one and a half times longer than wide, with a narrow distal border, a convex and slightly irregular edge and a straight internal side. They are slightly divergent and come together outside where they are separated only by a single plate, while inside they are separated by two or three plates. We distinguish a rosette of six very dissociated primary plates. The radials are a large distance from the centro-dorsal. These primary plates are very small in the large specimen. They are larger and closer together in the small one.i

The ventral surface of the disk is covered with very thin and imbricated plates. The genital slits are narrow.

The buccal shields are small, triangular, nearly as long as wide or a little wider than long. They have a very open proximal corner and straight sides and a slightly convex distal edge. The adoral plates, of medium size, are very widened outside. Their blunt internal summits barely touch. The oral plates are small, higher than wide. The lateral buccal papillae number four. They are small, obtuse and square. The external papilla is a little larger and more elongated than the others.

The dorsal brachial plates are extremely wide. The proximal corner is so obtuse that it nearly reaches $180^{\circ}$. The distal edge is convex. It joins, by two small lateral edges, the two sides of the proximal corner. These plates are four times longer than wide and even cover a little the lateral surfaces of the arm. They are very slightly separated from the base.

The first ventral brachial plate is extremely reduced. It is squeezed between the adoral plates. It is pentagonal. The following plates are large and pentagonal, with an obtuse proximal corner that is truncated on the first, large and straight lateral borders, and a convex distal side. They are a little longer than wide and all are contiguous.

The brachial spines number three. Their length is nearly equal to that of the article. The median spine is sometimes a little longer than the others. All are conical and pointed.

The tentacular pores are large and completely lacking in tentacular scales.

Similarities and Differences.-A. consors greatly recalls A. magnifica, that I described above, by the dorsal plates of the disk, by the form of the dorsal brachial plates and by the number of spines. but it is separated immediately by the absence of a tentacular scale and by the form of the buccal shields. 
The Amphiura of the section Amphioplus that have no tentacular scale at all are extremely few. I know among them only A. trepida Koehler and Verrillii Lyman, species with which A. consors cannot be confused.

\author{
Amphiura tomentosa, Lyman. \\ Lyman, Reports of the "Challenger": Ophiuroidea, 1882, p. 132, pl. xxix. fig. 10-12.
}

August 1903, Scotia Bay, South Orkneys; depth 9 to 10 fathoms. Two specimens.

The diameter of the disk varies between 3 and $2.5 \mathrm{~mm}$.

These specimens are not completely in conformity with the description of LYMAN, but I think that this is due to their young age, because the diameter of the disk in the type of LYMAN is 6.5 $\mathrm{mm}$. The external buccal papilla is protruding, conical and pointed instead of being short, and the radial shields are a little widened. Finally, the dorsal brachial plates are very developed, nearly as long as wide and longer than the type of LYMAN. It came from Kerguelen.

If these differences that I report between the individuals of the Orkneys and those of Kerguelen were to be found in the adult, there would be without doubt reason to consider the first as constituting a distinct variety of the type of LYMAN.

Amphiura magellanica, Ljungmann. (Pl. XI. fig. 104.)

See for the bibliography:

LUDWIG, "Ophiuroideen," Hamburger Magalhaensischen Sammelreise, 1899, p. 10.

LUDWIG, "Asterien und Ophiuren der schwedischen Expedition," Zeit.f. wiss. Zool., Bd. 1xxxii., 1905, p. 75.

23 April 1904, Gough Island; depth 75 fathoms. Two specimens.

Diameter of the disk, $2.5 \mathrm{~mm}$.

This species has never been represented. I give here a figure of the ventral surface, very characteristic because of the form of the first ventral spine that progressively elongates up to the seventh or eighth article.

\title{
Amphiura squamata (Delie Chiaje).
}

23 April 1904, Gough Island; depth 75 fathoms. One specimen of very small size. The diameter of the disk does not exceed $2 \mathrm{~mm}$. 
This specimen does not differ from the ordinary type of A. squamata, whose area of geographical dispersion is very vast, as we know (see LUDWIG, "Ophiuroideen," Hamburger Magalhaensische Sammelreise, p. 19).

\section{Ophiactis asperula (Philippi).}

See for the bibliography:

LuDwIG, "Die Ophiuren der Sammlung Plate," Zool. Jahrb., Suppl. Bd., 1898, p. 752.

LuDwIG, "Ophiuroideen," Hamburger Magalhaensische Sammelreise, 1899, p. 6.

LuDwIG, "Asterien und Ophiuren der schwedischen Expedition," Zeit.f. wiss. Zool., Bd. 1xxxii., 1905, p. 74.

KoEHLER, "Révision des Ophiures du Muséum," Bull. Scientif., 1907, p. 100.

$1^{\text {st }}$ December 1903, Burdwood Bank, 54 $25^{\prime}$ lat. S., $57^{\circ} 32^{\prime}$ long. W.; depth 56 fathoms. Several specimens.

\section{Ophiacantha Valenciennesi, Lyman.}

See for the bibilography.

KOEHLER, Ophiures de l'Expédition du "Siboga": Ophiures de mer profonde, 1904, p. 110.

fKoEHLER, Expéditions scientifiques du "Travailleur" et du "Talisman": Ophiures, 1906, p. 292.

23 April 1904, Gough Island; depth 100 fathoms. Two specimens.

In one of the individuals, the diameter of the disk is $11.5 \mathrm{~mm}$. The other is very small. The diameter of its disk does not exceed $5 \mathrm{~mm}$.

These two specimens conform well to the type of the species A single external buccal papilla is enlarged.

O. Valenciennesi has a very vast geographical distribution. The Challenger discovered it at $5^{\circ}$ $42^{\prime}$ lat. S. and $132^{\circ} 25^{\prime}$ long. E. The Siboga found it in the Sunda Islands. The Travailleur and the Princesse Alice found it in the North Atlantic. The observations of the Scotia show that this ophiuroid can decend toward $40^{\circ}$ lat. S.

\section{Ophiacantha frigida, nov. sp. (Pl. XIV. fig. 123 to 125.)}

18 March 1903, 62 ${ }^{\circ} 10^{\prime}$ lat. S., $41^{\circ} 20^{\prime}$ long. W.; depth 1775 fathoms. Three specimens.

18 March 1904, $71^{\circ} 22^{\prime}$ lat. S., $41^{\circ} 20^{\prime}$ long. W.; depth 1410 fathoms. Several specimens that arrived in a broken jar. The were found dried and at the same time covered with a very adherent mud. 
The diameter of the disk attains $13 \mathrm{~mm}$ in some very large individuals, but usually does not exceed 8 or $10 \mathrm{~mm}$. The arms are nearly all broken. The longest has a length of $45 \mathrm{~mm}$.

The disk is rounded or sub-pentagonal. The dorsal surface is completely covered with small spines, thin and cylindrical, having some rare denticulations on their edges and, at the end, two or three elongated spinules (fig. 125). These spines are very close together and we do perceive underlying scales, that are very fine, only in the places where they have fallen. The radial shields, which are completely covered with these spines, are not visible. They are small and widely separated.

The ventral surface is covered with spines identical to those of the dorsal surface, but they decrease toward the buccal shields. The genital slits are wide.

The buccal shields, of medium size, are widened and triangular, with a sharp proximal corner, lateral edges a little concave and a convex distal side having in its middle a more or less prominent lobe, whose presence often gives the shield a lozenge form. The adoral plates are rather strong and long, widened outside and forming a lobe that separates the first lateral brachial plate from the buccal shield. The oral plates are triangular, of medium size. The lateral buccal papillae number three. The internal one is conical. The second is a little stronger. The external one is still larger and very often thickened, at least at the base. The unpaired terminal papilla is large and conical.

The dorsal brachial plates are rather large, triangular, with the distal edge convex, slightly wider than long. They are separated from the first.

The first ventral brachial plate is small, pentagonal. The second is triangular with a truncated proximal corner. The following ones are large, triangular with a very obtuse proximal corner and a strongly convex distal edge. They are separated after the second.

The rather prominent lateral plates have eight plates that appear smooth to the naked eye but that, under the microscope are covered with very fine small rugosities. The spines of the first article are sometimes a little near the dorsal median line, but they never form a continuous row. The length increases after the first ventral, that is a little longer than the article, up to the seventh, whose length is nearly equal to three articles at the beginning of the arm. The eighth is a little shorter. On the following articles, the length decreases and the longest spine does not exceed two articles.

The tentacular pores of the first pair are large and sometimes have two conical scales. I have not seen these two scales on all the individuals, but I think that one of them has accidentally fallen or after the brushing I had to do to remove the mud that covered the specimens. The following pores have only one scale that is rather elongated and pointed.

Similarities and Differences.-O. frigida is near $O$. bidentata Retzius, from northern Seas, which it recalls by the thickening of external buccal papilla. It is stronger, however, in O. bidentata. It also differs from this species by the two scales on the tentacular pores of the first pair, by the larger dorsal brachial plates and finally by the presence of true spines on the disk.

$O$. frigida also has some similarities with $O$. cosmica Lyman, which the Scotia dredged further to the North. It differs from it by the notably smaller size, by the absence of spines on the first two dorsal brachial plates, by the absence of supplementary buccal papillae, by the longer spines of the dorsal surface of the disk, etc.

Ophiacantha opulenta, nov. sp. (Pl. XIV. fig. 128 and 129.)

18 March $1903.62^{\circ} 10^{\prime}$ lat. S., $41^{\circ} 20$ long. W.; depth 1775 fathoms. A single specimen. 
The specimen is nearly reduced to the disk, the seven arms all broken at their base. This circumstance is all the more regrettable as the species is very particular.

The disk is rather thick. Its diameter is $13 \mathrm{~mm}$. It is notched in the interradial spaces. The dorsal surface is swollen. It has seven pairs of protruding ribs, wide and very sharp that nearly reach the center of the disk toward which they converge. They are wider outside. We find toward the distal end, the radial shields that are thin and elongated, two and a half times longer than wide. The surface of the disk is covered with small rods, thick and rugose at the end that can even have very small spinules. We see clearly the slightly imbricated plates that have these rods and that are thin and rounded. Each plate has a rod. We find these same plates on the radial sides, but the rods are generally missing. They exist, however, because their scars are perfectly recognizable.

The ventral surface of the disk has rods identical to those of the dorsal surface, but shorter. The genital slits are narrow.

The buccal shields are triangular, with a proximal corner that is prolonged in a more or less sharp point, the sides a little concave and a convex distal edge having a small lobe in its middle. The dorsal plates are rather thick, short, with nearly parallel edges. They are two times longer than wide. They are contiguous inside and outside they do not separate the buccal shield from the first lateral brachial plate. The oral plates are high. The lateral buccal papillae generally number five. The four external ones are strong and obtuse. The internal one is more elongated, thinner and pointed, nearly two times longer than the others. The unpaired terminal papilla is likewise long, thin and pointed. It forms with its two neighbors a bundle that ends the jaws. It is directed toward the center of the mouth, give it a characteristic appearance. The arms are all broken near the disk. The first two or three dorsal brachial plates that are preserved are rectangular and wider than long.

The first ventral brachial plate is large, triangular with a convex distal edge that sometimes is separated into two sides limiting an obtuse corner. It is a little longer than wide. The following ones are triangular, with a very obtuse proximal corner and a strongly convex distal edge. They are separated from the second.

I see only two or three ventral spins on the preserved articles. These spines are shorter than the article, very thick, cylindrical, with an obtuse end. The dorsal spines have been removed

The tentacle scale is rather small, conical and obtuse.

Similarities and Differences.-O opulenta has a rather particular appearance. By its dorsal surface with protruding ribs, it resembles a Cladophiure. But it belongs to the genus Ophiacatha. It is easily distinguished from other species of this genus that have more than five arms by its very developed radial ribs and by the elongation of three proximal buccal papillae.

\section{Ophiacantha cosmica, Lyman.}

Ophiacantha cosmica, Lyman, Reports of the "Challenger": Ophiuroidea, p. 194, pl. xiii. fig. 13-15. Ophiacantha cosmica, Lütken and Mortensen, "The Ophiuridœ off the W. Coast of Mexico and off the Galapagos Islands," Mem. Mus. Comp. Zool., vol. xxiii., No. 2, 1899, p. 166, pl. xv. fig. 13.

10 March 1903, 66 $46^{\prime}$ ' lat. S., $40^{\circ} 35^{\prime}$ long. W.; depth 2425 fathoms. One specimen.

29 April 1904. 39 $48^{\prime}$ lat. S., $2^{\circ} 33^{\prime}$ long. E.; depth 2645 fathoms. Two specimens of large size. 
In the two largest specimens, the diameter of the disk is 16 and $17 \mathrm{~mm}$. The arms are $90 \mathrm{~mm}$ in the larger. These dimensions are near those LYMAN indicated. In one of the large individuals, the rods of the dorsal surface of the disk are very short, fine and spaced, while in the other, they are larger, stronger and more numerous and conform to the description of LYMAN. The supplementary buccal papillae are very irregular. In one specimen, I find, in a radius, up to four at the end of the oral plates, while in another, I see only one in all. The tentacular pores are sometimes very large. They often have two scales, the number indicated by LÜTKEN and MORTENSEN, while LYMAN mentioned only one.

LÜTKEN and MORTENSEN have completed or corrected the description of LYMAN on some points. The rods of the dorsal surface of the disk have the form they indicate, except for the individual mentioned above where the rods are small and sparse.

I see, in my specimens, that the ventral brachial plates are very large, with the distal edge convex. The dorsal plates are also wider than in the figures of LYMAN and the Danish authors. The first two dorsal brachial plates alone have spines that are found in nearly all toward the distal edge of the plate. There is also sometimes some on the plate itself. In summary, there are some variations as Lyman has already reported.

O. cosmica has a very large geographic distribution. The Challenger encountered it in localities between $2^{\circ}$ and $62^{\circ}$ lat. S. and longitudes of $45^{\circ}, 123^{\circ}, 144^{\circ} \mathrm{E}$. and $74^{\circ} \mathrm{W}$., at depths from 350 to 2225 fathoms. The Albatross found $O$. cosmica in the North Pacific between $6^{\circ}$ and $10^{\circ}$ lat. N. on one hand and $82^{\circ}-96^{\circ}$ long. W., at depths between 1672 and 2232 fathoms. We have seen above that the Scotia has encountered $O$. cosmica at two stations very separated from each other.

\section{Ophiacantha vivipara, Ljungmann.}

See for the bibliography:

LuDwIG, "Ophiuroideen," Hamburger Magalhaensische Sammelreise, 1899, p. 13.

Koehler, "Révision des Ophiures du Muséum," Bulletin Scientifique, 1907, p. 321.

$1^{\text {st }}$ December 1903. Burdwood Bank. 54 $25^{\prime}$ lat. S., $58^{\circ} 32^{\prime}$ long. W.; depth 56 fathoms. Six specimens, all with six arms and most carrying young.

Ophiotrema Alberti, Koehler.

See for the bibliography:

KOEHLER, Expéditions Scientifiques du "Travailleur " et du "Talisman ": Ophiures, 1906, p. 295.

9 April $1904.51^{\circ} 7^{\prime}$ lat. S., $9^{\circ} 31^{\prime}$ long. W.; depth 2103 fathoms. A single specimen in bad state.

Diameter of the disk, $17 \mathrm{~mm}$. A single arm is preserved with a length of $15 \mathrm{~mm}$. The others are broken at the base. The dorsal part of the disk is missing in large part. 
Apart from the very slight differences in the form of the dorsal brachial plate, which are exactly lozenge shaped, and the ventral plates that have slight notches on the distal edge, this specimen relates to the specimens from the North Atlantic that I have studied. The specimens of the Princesse Alice and of the Travailleu are themselves in rather bad state and as the Scotia has collected a single individual rather poorly preserved, comparisons are difficult. In any case, it is incontestable that this individual is extremely near the specimens found in the boreal Atlantic. Until there is proof to the contrary, I consider it as belonging to the same species.

Ophiomitrella ingrata. (Pl. XIV. fig. 126 and 127.)

23 April 1904, Gough Island; depth 100 fathoms. Several specimens.

All the specimens are of small size. The diameter of the disk does not exceed $4 \mathrm{~mm}$ in the largest. The arms are moniliform, more of less contorted, which means their exact length cannot be evaluated, but they are short.

The disk is rounded. The dorsal surface has large plates, irregularly polygonal or rounded, imbricated toward the edge of the disk. Each of them has in its center a large granule, elongated, rugose and rounded at the end. All the plates have this granule and, when it is missing, we can recognize the scar that indicates its insertion. The radial shields, of median size, are as long as wide, strongly divergent and contiguous or very near the outside. The ventral surface is covered with small plates as on the dorsal surface, imbricated and lacking granules. The genital slits are wide.

The buccal shields, of median size, are a littler wider than long and sometimes as long as wide. They are triangular or lozenge-shaped, depending whether their distal edge has in its middle a more or less prominent swelling. The proximal corner is rather open and limited by straight sides. The adoral plates are rather large, larger outside than inside. They separate the buccal shield from the first later brachial plate. The oral plates are triangular. The three lateral buccal papillae are large, cylindrical, with a rugose surface. Their obtuse end even has some small spinules. The unpaired terminal papilla is not much stronger than the others.

The first two or three dorsal brachial plates are quadrangular, widened transversally, much wider than long. The following ones are large, triangular, with the distal edge strongly convex. They are a little wider than long and widely separated.

The first ventral brachial plate is rather large and pentagonal or quadrangular, with a distal edge wide and rounded. The following ones are large, pentagonal, with an obtuse proximal corner, straight lateral sides and the distal side convex at first. Beyond the disk, this side has a slight notch in its middle.

The prominent lateral plates have five rather large spines, cylindrical, obtuse and covered with very fine denticulations. They are rather short. The first ventral scarcely equals the article and the last does not attain an article and a half. The dorsal rows are widely separated at the base of the arms

The tentacular scale is rather large, conical and pointed. 
Similarities and Differences.-O ingrata is near O. cordifera Koehler of the boreal Atlantic. It differs by the dorsal plates of the disk that are smaller and more numerous, each with a much smaller granule. The brachial spines also are less numerous, larger and obtuse at the end.

\section{Ophiomyxa vivipara, Studer.}

See for the bibliography:

LuDWIG, "Die Ophiuren der Sammlung Plate," Zool. Jahrb., Suppl. Bd. iv., 1898, p. 768.

LuDWIG, "Ophiuroideen," Hamburger Mayalhaens. Sammelreise, Hamburg, 1899, p. 9.

LuDwIG, " Asterien und Ophiuren der schwedischen Expedition," Zeit.f. wiss. Zool., Bd. 1xxxii. P. 76.

KOEHLER, "Révision des Ophiures du Muséum d'histoire naturelle," Bulletin scientifique, 1907, p. 341.

$1^{\text {st }}$ December 1903, Burdwood Bank, 54 $25^{\prime}$ lat. S., $57^{\circ} 32^{\prime}$ long. W.; depth 56 fathoms. Seven specimens.

In the largest, the diameter of the disk is $15 \mathrm{~mm}$. The others are smaller. Some individuals that I have opened have young in the genital pouches.

? Astrotoma Agassizi, Lyman. (Pl. XIII. fig. 120.)

See for the bibliography:

LYMAN, "Ophiuridae and Astrophytonidæ," Ill. Cat. Mus. Comp. Zool., No. 8, part 2, 1875, p.

24, pl. iv. fig. 57 and 58.

Lyman, Reports of the "Challenger": Ophiuroidea, p. 272.

$1^{\text {st }}$ December 1903, Burdwood Bank, 54² $25^{\prime}$ lat. S., $57^{\circ} 32^{\prime}$ long. W.; depth 56 fathoms. Two very young specimens.

It is with doubt that I relate these specimens to A. Agassizi, whose characters are still not clear enough to permit a precise determination. In the smallest, the diameter of the disk is only $4 \mathrm{~mm}$ and the arms are 20 to $25 \mathrm{~mm}$ in length. We still see the rosette of primary plates that is irregular. The dorsal surface of the disk and the arms is covered with large granules. In the other, which is a little larger and whose disk measures $6.5 \mathrm{~mm}$ in diameter, the primary plates are less distinct.

The madreporite is very apparent. The tentacular pores of the first pair do not have scales. All the following pores have two of them, as we see in A. Agassizi.

\section{Gorgonocephalus chilensis (Philippi).}

See for the bibliography. 
LuDWIG, "Ophiuroideen," Hamburger Magalhaevsische Sammelreise, 1899, p. 16.

KoeHLER, "Révision des Ophiures du Muséum," Bull, scient, du Nord, 1907, p. 100.

$1^{\text {st }}$ December 1903, Burdwood Bank, $54^{\circ} 25^{\prime}$ lat. S., $57^{\circ} 32^{\prime}$ long. W.; depth 56 fathoms. A small specimen.

\section{ECHINOIDS}

Stereocidaris canaliculatus (Agassiz).

See for the bibliography:

MEISSNER, Hamburger Magalhaensischen Sammelreise: Echinoideen, p. 3, 1900. The author places the species in the genus Cidaris and unites it with St. nutrix.

MorTEnSEn, The Danish Ingolf Expedition, vol. iv., part 1, 1903: Echinoidea, p. 25, pl. viii. fig. 6,8 et 32 .

January 1903, Port Stanley, Falkland Islands; depth 0-5 fathoms. About ten specimens.

$1^{\text {st }}$ December 1903, Burdwood Bank, 54 $4^{\circ} 25^{\prime}$ lat. S.; $57^{\circ} 32^{\prime}$ long. W.; depth 56 fathoms. Two specimens.

Authors have generally confused into one and the same species St. canaliculata Agassiz and nutrix (Wyville Thomson). MORTENSEN has shown that the two forms are very distinct and that the first was particular to the southern point of South America and the second to Kerguelen. The investigations of the Scotia confirm the opinion of the Danish naturalist and show that St. canaliiculata is found not only in the area of Tierra Fuego but descends much lower to the south.

St. canaliculata is susceptible to having variations that have already been indicated by AGASSIZ. Thus. some specimens of the Falkland Islands have short spines and others longer spines. The two individuals from the Burdwood Bank have elongated spines. I find in these different forms the same pedicellariae, identical to those that Mortensen has described and figured.

The individuals are all of rather small size. Their diameter is between 20 and $25 \mathrm{~mm}$, not including the spines. None of them are brooding, but I note that some specimens have the apical system strongly depressed. This results in the formation of a kind of pit, more or less deep that can evidently serve as an incubatory pouch. ${ }^{2}$

\footnotetext{
${ }^{2}$ While my memoir was in press, I received the important work of L. ClaRK on the Cidarida (Bull. Mus. Comp. Zool., vol. li, 1907, p. 7). This author places St. canaliculata and nutrix as well as Stereocidaris Mortenseni cited below, in a new genus to which he has given the name Austrocidaris that is characterized by the small number of tubercles on the apical system, the form of the secondary spines, etc. I have been able to see that by the arrangement of the ambulacral and interambulacral zones, the specimens of the Scotia belong to St. (Austrocidaris) canaliculata as understood by L. CLARK.
} 


\section{Stereocidaris Mortenseni (Koehler).}

Goniocidaris Mortenseni, Koehler, Résultats du Voyage de S. Y. "Belgica"; Échinides et Ophiures, 1901, p. 5, pl. i. fig. 1, pl. ii. 6g. 11, pl. iii. fig. 17, pl. iv. fig. 29, pl. v. fig. 30.

Stereocidaris Mortenseni, Mortensen, The Danish Ingolf Expedition: Echinoidea, part i., p. 27.

18 March $1904,71^{\circ} 22$ lat. S., $16^{\circ} 34^{\prime}$ long. W.; depth 1410 fathoms. One specimen in excellent condition.

The diameter of the disk is $30 \mathrm{~mm}$. All the spines are preserved. The largest attains up to 76 $\mathrm{mm}$ in length. The secondary spines are very developed, especially above the ambitus. They are elongated, cylindrical, and some a little swollen toward the end.

I have found in this specimen the globiferous pedicellaria described and figured by MORTENSEN.

The test and spines are a pale gray-brown. The spines are gray, slightly pink at the base.

The depth at which the Scotia dredged this echinoid is greater than that where the Belgica encountered it. ${ }^{3}$

Notechinus magellanicus, var. neu-amsterdami, Dôderlein.

See for the bibliography:

Dôderlein, Echinoideen der deutschen Tiefsee Expédition, 1906, p. 227, pl. xxvii. fig. 9, pl. xxviii. fig. 34, pl. xxxv. fig. 15, pl. xxxvii. fig. 5.

23 April 1904, Gough Island; depth 100 fathoms. Three specimens.

These specimens belong to the variety neu-amsterdami described by Dôderlein. They are of small size. Their diameter varies between 8 and $10 \mathrm{~mm}$.

Sterechinus Neumayeri (Meissner). (Pl. XVI. fig. 143 and 144.)

Echinus Neumayeri, Meissner, Hamburger Magalhaensischen Summelreise: Echinoideen, p. 12.

\footnotetext{
${ }^{3}$ In his work on the Cidarida, L. ClARK places Stereocidaris Mortenseni in his new genus Austrocidaris, but with some doubt because he did not know the form of the secondary spines. Now, as I have said above, these spines are cylindrical and very slightly swollen toward the end. The species thus could be perfectly placed in the genus Austrocidaris.
} 
Sterechinus Neumayeri, Mortensen, The Danish Ingolf Expédition; Echinoidea, p. 103, 106 et 107, pl. xix. fig. H, pl. xx. fig. 7 et 11 .

Echinus margaritaceus, Koehler, Expédition Antarctique française du Dr. Charcot: Echinodermes, 1906, p. 30, pl. i. fig. 9, pl. iii. fig. 29 and 30, pl. iv. fig. 40 and 43.

Sterechinus Neumayeri, Dôderlein, p. 219.

Scotia Bay, South Orkneys; depth 9 to 10 fathoms. Four specimens, of which the respective diameters are 28, 45, 50 and $57 \mathrm{~mm}$.

These specimens are absolutely identical to those I described under the name Echinus margaritaceus. I hasten to correct this error, that is rather excusable if we consider, on the one hand, that the single figure given by MEISSNER of Sterechinus neumayeei represent an abnormal apical system, and on the other hand, that the pedicellariae of the specimens that I had in hand having been attacked by formol, it was impossible for me to recognize their exact form, thus, as I explained it. Finally, Echinus margaritaceus had been described and figured only in a very imperfect way when I studied the collections of the Chacot Expedition.

The specimens of the Scotia, preserved in alcohol, show pedicellariae that competely conform to those that MORTENSEN indicates. This scholar has, moreover, very willingly examined one of my specimens so that this point of identification is now well established.

It is thus necessary to apply to Sterechinus Neumayeri the detailed description that I have published under the name of Echinus margaritaceus. The pedicellariae having already been described by MORTENSEN, I see nothing to add and I shall content myself to give here two figures, one representing a lateral view of the test with the spines partly removed and the second, an enlarged portion of the etc. I shall correct only a printing error which made me say, by a confusion of words between the ambulacral and interambulacral plates, that each ambulacrum had a primary tubercle (loc. cit., p. 31). In reality, the ambulacral tubercles are seen every two or even every three ambulacral plates.

Three of the specimens that have been sent to me are brown shading to purple. The fourth is pale gray.

\section{Sterechinus margaritaceus (Lamarck).}

See for the bibliography:

DöDERLEIN, Echinoideen der deutschen Tiefsee Expedition, p. 224, pl. xxix. fig. 1, pl. xxxv. fig. 12, pl. xlvii, fig. 9.

$1^{\text {st }}$ December 1903, Burdwood Bank, $54^{\circ} 25^{\prime}$ lat. S., $57^{\circ} 32^{\prime}$ long. S.; depth 56 fathoms Several specimens.

As I said above, the species that I described under the name Echinus margaritaceus in the Echinodermes de l'Expédition Antarctique française, is Sterehinus Neumayeri.

DöDERLEIN just described in a very complete manner the St. margaretaceus that was only very imperfectly known by the description and figures of AGASSIZ. It is thus to the memoir of the German naturalist scholar that it is necessary to refer for all that concerns this species that we can now easily recognize. 
The specimens of the Scotia conform well to the description of DöDERLEIN. They form a very interesting series, in which all the sizes are represented, from the largest individuals in which the diameter of the test measures $50 \mathrm{~mm}$ to the smallest that is only $23 \mathrm{~mm}$. They are in general very flat, as DöDERLEIN indicates, but some have a conical test. Then its height is a little greater than half the diameter.

The primary spines are nearly all missing. The general color of the specimens is pale gray.

St. margaritaceus is very near St. antarcticus that served me to establish the genus Sterechinus. There can be no question of placing these two species in two different genera.

As for St. Neumayeri, I believed it necessary, when I described it under the name $E$. margaritaceus, to emphasize some difficulties raised by its classification in the Sterechinus as I had established it. Now that the specific characters of St. antarcticus, margaritaceus and Neumayeri have been clearly established, it appears that St. Neumayeri do not differ sufficiently from the two other species for it be logical to place it in another genus. I thus renounce confining the genus Sterechinus to the limits that I assigned it and that MORTENSEN has enlarged. I follow the point of view of this scholar that has been likewise adopted by DôDERLEIN.

Hemiaster elongatus, nov. sp. (Pl. XVI. fig. 145 to 158.)

$1^{\text {st }}$ February 1904, Scotia Bay, South Orkneys; depth 6-10 fathoms, of which one is very young and some fragments of a fifth.

The small specimen is only $8 \mathrm{~mm}$ in length. The respective dimensions of the others are the following (including the spines).

$\begin{array}{llll}\text { Length, } & 45 \mathrm{~mm} & 37 \mathrm{~mm} & 30 \mathrm{~mm} \\ \text { Width, } & 35 \text { “ } & 30 \text { “ } & 21 \text { “ } \\ \text { Height, } & 23 \text { “ } & 21 \text { “ } & 17 \text { “ }\end{array}$

Seen from above, the perimeter of the test is irregularly ovoid, narrower behind than in front. It is widest at the level of the apical system that is a little nearer the anterior end than the posterior end. At the ambitus, the test does not have a regular curve, but is rather constituted of a series of nearly straight or slight curved lines united by very obtuse angles. Behind, the body is thinned. In front, the periphery of the test is not notched by the anterior groove that does not reach the edge but stops at the fasciole. This one passes some distance behind this border. Seen laterally, the test has a regular curve that goes up to the apical system. Then, behind this point, we see a slight gibbosity of the posterior interradius. This gibbosity, little accentuated and visible only in individuals whose spines have been removed, attenuates progressively behind in an oblique contour that is continuous with the posterior end. This is narrow and vertical. The ventral surface is a little swollen. It rises slightly behind, toward the end of the sternal plastron, in a small, very low conical prominence.

The apical system, rounded, is moved slightly forward. We see three gonopores, two to the left and only one to the right. This is located in the interradius posterior pair. These pores are small 
and oval. The two posterior ones are widely separated by the madreporite. The sutures of the plates are absolutely indistinct.

The unpaired anterior ambulacrum forms, on the dorsal surface of the test, a rather wide and shallow groove that weakens and disappears at the level of the fasciole without reaching the anterior edge of the test. The poriferous zones are straight and divergent. Each has seventeen to eighteen pairs of very fine pores, whose spacing increases progressively up to the fasciole. Beyond, the pores are very indistinct and much more separated. The anterior and posterior lateral ambulacra are not very deep. They have nearly the same length. The anterior ones are very strongly divergent and together form a very obtuse angle, while the posterior ones are much closer together and are separated only by the posterior interradial gibbosity. In the specimen represented in fig. 150, I count seventeen pairs of pores in the anterior ambulacra and eighteen in the posterior ones. The part of the test between each anterior lateral ambulacrum and the unpaired ambulacra is rather protruding. Between the two lateral ambulacra on each side, the test is less protruding.

The ventral surface is a little convex. The anterior ambulacrum is indistinct and has toward the edge of the test, ambulacral tubes identical to those of adjacent regions. The anterior lateral ambulacra are located nearly on the continuation of each of them. The few pores form convergent lines. The posterior lateral ambulacra are very wide, naked. The have primary tubercles only toward the edge of the test. The posterior interradius is triangular, elongated, with a very slight posterior protuberance.

The peristome is located nearly equal distance between the middle of the ventral surface and the anterior edge of the test. It is sunken, in the form of a narrow crescent. The lip is large and wide It extends back to the level of the middle of the second ambulacral plate. Its anterior forms a very marked ridge in the form of an obtuse beak that hides part of the peristome.

The posterior surface is vertical and narrow. The periproct is small, at least one and a half times longer than wide, pointed above and below and flush with the test.

The peripetalous fasciole is clearly longer than wide. Its contour is a little sinuous as in $H$. cavernosus. As a whole, it is ovoid, with a slight widening at the level of the lateral anterior ambulacra. In front, its path is a little rectilinear. It passes approximately $3 \mathrm{~mm}$ from the anterior edge of the test. Behind, it is further from the edge of the test from which it is separated by 8 to 9 $\mathrm{mm}$. The band formed by this fasciole is thick. The clavules are fine, elongated, widened toward the end whose free border is extended in unequal points.

The primary tubercles are small, unequal, perforated and crenelated. They are smaller and denser on the dorsal surface as well as on the posterior end, larger and more spaced on the contrary on the ventral surface. As for the ventral ambulacra, the have only miliary tubercles.

The spines are rather long, fine and very dense. On the dorsal surface, they are nearly straight, sometimes slighted arched, a little widened at the end They become a little longer on the ventral surface. The marginal spine of the posterior interradius, as well as some other interradial spines, are clearly spatulate. At the posterior end of the body, on the ventral surface, the spines elongate on each side and thus form two symmetrical very marked tufts, which gives the ventral surface of H. elongatus a certain resemblance to Maretia planulata. The spines that surround the periproct are also longer. They come close together, like the preceding, at their ends to form a small median tuft.

None of the specimens has the least trace of a brood. Moreover, the petals of the dorsal surface are very narrow, as is the case in the male in the genus Hemiaster.

The pedicellariae are of four kinds. 
There are first large globiferous pedicellariae, with a robust head, elongated and thick (fig. 154). The calcareous stem of the stalk extends up to the base of the valves. It has at some distance from its end, a fusiform and little marked thickening. The basal part of the valves is triangular with small dense perforations. It is nearly as long or slightly longer than the blade. This has the form of an open gutter in its distal half and closed in the proximal region by very short beams. There are two terminal hooks, strong and extremely elongated. The head of the pedicellaria and the distal end of the stalk after the swelling are surrounded by a thick connective tissue deeply colored brown. The whole forms an ovoid thickening whose length exceeds $1 \mathrm{~mm}$.

The pedicellariae of the second kind are rostrate pedicellariae, with thin valves and rather large perforations (fig. 155). The basal part is triangular and short. The blade is nearly two times longer. It is at first very thin. Then it widens in its latter third and has, on the straight internal border, a row of small denticulations. These pedicellariae resemble those that DôDERLEIN represented in $H$. cavernosus (Echinoideen der deutschen Tiefsee Expedition, pl. 1. fig. 6, u), but the end is wider in H. elongatus and they are larger. These pedicellariae are of variable dimensions and there are large and small ones. The first measure $0.8 \mathrm{~mm}$ in length and the small are only $0.5 \mathrm{~mm}$.

The tridactyl pedicellariae (fig. 156 and 157), rarer than the preceding, have wider valves. They recall the pedicellariae of $H$. cavernosus represented by DôDERLEIN (loc. cit., pl. 1. fig. 7, $d$-g). They are only $0.4 \mathrm{~mm}$ in length.

Finally, the fourth form is trifoliate pedicellariae, small, with convex valves, short and wide, finely denticulated on the edges (fig. 158).

The spicules of the ambulacral tubes, very small, are of irregular form. They ordinarily appear as small, more or less curved rods having some elongated points on their edges. Sometimes they are straight, bifurcated or not with one of the ends with or without lateral points.

The color of the specimens in alcohol is deep gray.

Similarities and Differences.-H. elongatus is clearly distinguished from other species of the genus, notably $H$. cavernosus by its much more elongated and clearly ovoid form, the narrower and shallower anterior ambulacrum, by the form and contour of the fasciole, by the tufts of spines on the posterior end of the body and by a little different form of the pedicellariae.

\section{Hemiaster cavernosus (Philippi).}

See for the bibliography:

Dôderlein, Echinoidem der deutschen Tiefsee Expedition, p. 248.

In the bottle containing the Hemiaster elongatus that I just described, I found a fragment of the dorsal surface of a Hemiaster that must have had a great size and whose petals had the form characteristic of a female in the genus Hemiaster. This fragment is nearly completely lacking in spines. I have not been able to discover pedicellariae. It appears evident to me that it belongs to Hemiaster caverosus. The petals are unequal. The posterior ones are smaller than the anterior one as we see in the form Philippii. 


\section{Delopatagus, nov. gen.}

This genus belons to spatangoids lacking fascioles (Adetes). It can be placed beside the genus Genicopatagus. It is particularly characterized by its apical pole moved very far back and by the slight depressions that form the dorsal surfaces of the test, the anterior and posterior lateral ambulacra. These appear as petals, short and very shallow but, however, very recognizable. The test is hemispherical. The dorsal surface is greatly swollen. The ventral surface is completely flat. The peristome has two lips, a little away from the center of the ventral surface. The periproct is located on the posterior surface of the body. There are three gonopores.

Unfortunately, the ventral surface is greatly damaged posterior to the peristome and its characters cannot be indicated.

\section{Delopatagus Brucei, nov. sp. (Pl. XV. fig. 130 to 135.)}

\section{March 1903, 66 40’ lat. S., 40³ 35' long. W.; depth 2425 fathoms. A single specimen.}

The ventral surface is incomplete. The part behind the peristome is reduced to fragments. The rest of the test is preserved. The dimensions are the following.

Length, $41 \mathrm{~mm}$.

Width, 36 “

Height at the level of the apical system, $24 \mathrm{~mm}$.

Seen from above, the contour of the test is regularly ovoid, nearly circular. The apex is much nearer the posterior edge than the anterior edge. It is $22 \mathrm{~mm}$ in front of this edge. The ventral surface is completely flat. The dorsal surface is convex. It forms a regular curve that descends from the apex to the anterior edge that is thin. Behind the apex, it has a slight gibbosity that corresponds to the posterior interradius. It passes insensibly to the posterior surface of the test. This surface is truncated and nearly vertical. It unites with the ventral surface and forms a slightly accentuated rounded corner. The peristome is nearly central. Its anterior edge is $14 \mathrm{~mm}$ from the anterior edge of the test. The periproct is on the posterior surface of the test. It is ovoid, widened vertically and approaches the dorsal surface. Its lower edge is $13 \mathrm{~mm}$ from the lower edge of the test.

The apical system is compact. But I cannot distinguish the contours of the plates. The three gonopores are large and rounded. It is the right anterior pore that is missing. The madreporite occupies the right anterior genital. It is moved backwards to form a triangle with a round posterior summit. I do not see ocular plates.

The two pairs of lateral ambulacra of the dorsal surface of the test are slightly petaloid. The anterior petals together form an obtuse corner. Their length attains approximately a centimeter. They each have ten bigeminate pores. The plates that form them are quadrangular, wider than long. Beyond the petaloid region, the ambulacral plates between wider. They still have bigeminate pores on two or three plates. Then they become very large and polygonal and the pores disappear. The limits of these plates are also very difficult to see. In the petaloid region and on the following plates that have bigeminate pores. We see on each plate only one or two small tubercles. Beyond, the 
plates become much larger, each with a primary tubercle and some sparse miliary tubercles. The primary tubers are moreover of small dimensions.

The posterior ambulacra have the same characteristics as the anteriors. But they are much shorter. Their length does not exceed $6 \mathrm{~mm}$. They are also a little shallower. They form together a little less obtuse corner. The petaloid region has eight pairs of bigeminate pores. Beyond, we can still see one or two pair of pores. Then the plates become much larger and they have, like the anterior ambulacra, each a primary tubercle and some miliary tubercles.

The anterior ambulacra are flush with the test. It is formed of elongated hexagonal plates, longer than wide, whose contours are scarcely marked. The two or three first ones alone have two small rudimentary bigeminate pores.

The interambulacral plates are very large, polygonal and wide, but their limits are nearly invisible. Each of them has one or two primary tubercles and some miliary tubercles. In a general way, the primary tubercles of the dorsal surface in both the ambulacral and interambulacral regions are very spaced.

On the ventral surface, the primary tubercles are denser. As far as I can judge by the fragments that are preserved, the ambulacral must have been very wide and the posterior interradius narrow. The peristome is widened and sunken. It is constituted of large plates with indistinct contours on which we see some pedicellariae. The posterior lip is very protruding. The ambulacral tubes that surround the peristome are very developed. We find three or four on each side of the anterior ambulacrum and on the lateral ambulacra.

The periproct is located in the upper part of the posterior surface of the test. It is ovoid, thin and pointed at the two ends. It is formed of rather large plates, polygonal, with pedicellariae and spines. The primary tubercles that are found toward its periphery have particularly elongated spines, lying on the periproct and covering it. The anus is central.

The primary spines, very spaced on the dorsal surface, are fine and short. They are a little longer and stronger on the ventral surface.

The pedicellariae, which are rather abundant on the ventral surface and around the peristome and also on the periproct, are of two kinds: rostrate and tridactyl. The first, more numerous, has valves widened at the base. They narrow rapidly and continue as a narrow and regularly curved blade. These valves, widely separated, unite with each other only at their end, which is thin. Some of these pedicellariae are ventral, wide, thick. The thin part of the valves is shorter, as I have represented in Pl. XVI, fig. 134. These are less frequent. The others have longer and thinner valves. They recall the form that we see in Genicopatagus affinis for example. The length of these pedicellariae is approximately $0.6 \mathrm{~mm}$.

The tridactyl pedicellariae are small, with thick valves having some rather strong denticulations on the free edge. They are united to each other at their end by a narrow par with much finer denticulations. They are only $0.3 \mathrm{~mm}$ in length (fig. 135).

The general color of the single specimen is yellowish-gray.

Urechinus fragilis, nov. sp. (P1. XVI. fig. 159 to 162.)

18 March 1904, $71^{\circ} 22^{\prime}$ lat. S., $16^{\circ} 34^{\prime}$ long. W.; depth 1410 fathoms. A single specimen. 
This single specimen is unfortunately in very bad condition. The dorsal surface is broken into several fragment and part of the anterior surface is missing. I have had to reconstitute in some way the dorsal surface by gluing together the fragments so that I have been able to obtain a nearly complete individual that I have photographed and that is represented in Pl. XVI, fig. 159-161. The ventral surface is nearly intact. The test is extremely thin.

The dimensions are the following:

$$
\begin{aligned}
& \text { Length, } \\
& \text { Width, } \\
& \text { Maximum height, } \\
& \text { the anus. }
\end{aligned}
$$

Seen from above, the contour of the test is irregularly ovoid, a little more convex on the left than on the right. I note that the dorsal anterior ambulacrum does not correspond exactly with the anterior end and is directed a little to the left. The posterior end is pointed.

Seen from the side, the contour if the dorsal surface is regularly arched. But the ventral surface, which is nearly flat in the anterior half, is depressed after the middle and forms a rather apparent projection before the periproct. The peristome is rounded. Its anterior edge is $9 \mathrm{~mm}$ behind the anterior end of the test. The periproct is entirely located on the ventral surface. It is ovoid and longitudinally elongated. It measures $4.5 \mathrm{~mm}$ by 3 . Its posterior edge is $2 \mathrm{~mm}$ before the posterior end. There is not the least trace of the fasciole.

On the dorsal surface, the first two or three ambulacral plates of each zone are very small, then these plates increase rapidly in size. They become nearly as large as the interambulcrals, but the always remain narrower. These latter are large, wide and few. Each of them has, according to its size, one to four primary tubercles and numerous, very dense miliary tubercles. I have not been able to distinguish the ambulacral pores. The information that I can give on the apical system and on the origin of the ambulacral zones is unfortunately very incomplete because of the state of the specimen. The unpaired anterior ambulacrum begins well forward of the middle of the dorsal surface. It does not join the anterior lateral ambulacral. These do not join the posterior ambulacra either as happens in $U$. naresianus. I cannot distinguish either the madreporite or the gonopores.

The ventral surface is rather well preserved, but the contours of the plates are poorly indicated. The posterior interradius is indistinct, but it forms however a very marked protrusion before the periproct. It has some primary tubercles a little larger than the others. The ambulacra are rather narrow. They have miliary tubercles with rare primary tubercles. On the rest of the ventral surface, the primary tubercles are a little larger and more numerous than on the dorsal surface, especially toward the edges.

The rounded peristome has no indication of a posterior lip. It is covered with small unequal polygonal plates. The relatively very large periproct is notably longer than wide. It is covered with small plates. The anus is nearer its posterior edge. It is located entirely on the ventral surface.

The specimen nearly completely lacks spines. Those that are preserved are short and fine, of a deep gray-violet.

I find only two kinds of pedicellariae. The most widespread, whose length varies between 0.3 and $0.4 \mathrm{~mm}$, are tridactyl pedicellariae. Their valves, narrow and separated in the basal region, are united for approximately half their length by an edge with very fine denticulations (Pl. XVI, fig. 162). As for the others, these are ophiocephalous pedicellariae. I have found only a single example in a preparation mounted in baum. It is entire and is rather poor for study. However, it greatly 
recalls the ophiocephalous pedicellariae of $U$. giganteus and naresianus represented by MORTENSEN.

$U$. fragilis recalls more, by its contour, U. giganteus Agassiz, which came from the Gulf of California. It is likewise distinguished from it by the ventral position of the periproct and also by the much reduced size.

Similarities and Differences.-Of the three known species of Urechinus two have been encountered in the southern seas. $U$. fragilis differs from $U$. naresianus Sladen that the Challenger dredged at $42^{\circ}$ and $50^{\circ}$ lat. S., by the location of the periproct, which is entirely located on the ventral surface, while it is located on the posterior surface of the test and, moreover, widened transversely in $U$. naresianus. The posterior interradius also forms a less pointed protrusion before the anus, and this protrusion is more elongated from the posterior end in $U$. fragilis than in $U$. naresianus.

U. Drygalskii Mortensen, discovered by the Expédition antarctique Suédoise, has a distinct sub-anal fasciole. The periproct is located just above the ambitus.

$U$. fragilis recalls more, by its contour, U. giganteus Agassizi that comes from the Gulf of California. It is likewise distinguished from it by the ventral location of the periproct and also by the much reduced size.

\title{
Pourtalesia carinata, Agassiz.
}

\author{
Agassiz, Reports of the "Challenger": Echinoidea, p. 133, pl. xxviiia. pl. xxxviii. fig. 30-31 pl. lxi. fig. \\ 49-52, pl. 1xii. fig. 24-25, pl. 1xiii. fig. 20-23, pl. 1xv. fig. 46-52. \\ Loven, Pourtalesia, 1884, passim, pl. vi. fig. 42-46, pl. vii. fig. 47. \\ Agassiz, "Panamic Deep-sea Echini," Mem. Mus. Comp. Zool., vol. xxxi., 1904, p. 127.
}

10 March 1903, 66 40' lat. S., 40 35' long. W.; depth 2425 fathoms. One specimen.

21 March $1904.69^{\circ} 33^{\prime}$ lat. S., $15^{\circ} 19^{\prime}$ long. W.; depth 2620 fathoms. A small fragment of the posterior end of the test.

The specimen of 10 March 1903 is in rather good condition. It is covered with its spines, but the ventral surface is missing to a certain extent. The color is a deep purple. Its dimensions are the following:

Length, $58 \mathrm{~mm}$.

Maximum width, $27 \mathrm{~mm}$.

Maximum height, $22 \mathrm{~mm}$.

As this is the only specimen, I did not want to strip it to study the characters of the test, especially as it was made very fragile by a fracture of the ventral surface. As far as I can judge, it conforms well to the descriptions of AGASSIZ and LOVEN, at least in what concerns the test, because the pedicellariae that AGASSIZ has represented without describing, do not all relate to the figures of this scholar. Thus, I have not found the small pedicellariae of the type he called "clypeasteroid" and that he represented in pl. xliii, fig. 21-23. The other forms more or less conform to the figures of AGASSIZ.

Those that I observe are of three kinds 
The first are the tridactyl pedicellariae whose head measures 0.20 to $0.25 \mathrm{~mm}$. They are represented by AGASSIZ, pl. xliii, fig. 20. The valves, wide at the base, narrow rapidly, then widen again having on their edges a regular row of triangular denticulations, dense and very fine. These pedicellariae are very abundantly distributed on all the surface of the test.

There is a second form of tridactyl pedicellariae whose head measures 0.7 to $0.8 \mathrm{~mm}$ in length. They correspond to those that AGASSIZ has figured, pl. xlii, fig. 24 and 25 and pl. xlvi, fig. 46 and 47, that he named "large-headed, coarsely reticulated hooked pedicellaria." The valves, very wide at the base, narrow rapidly, then keep a nearly constant width to widen only in their terminal part. These have five of six teeth close together, while the valve ends in strong hook, pointed and hyalin. Moreover, before the hook, the external surface of the valves has a row of teeth like those that have been represented by AGASSIZ (pl. xliii, fig. 24). The calcareous mesh is large and corresponds well to the figure of AGASSIZ (pl. lxvi, fig. 46). A pigmented membrane covers the valves and more or less hides it contours. These pedicellariae occur especially in the area of the peristome and the periproct.

The pedicellariae of the third kind have a smaller, denser head and a length of only $0.4 \mathrm{~mm}$. The valves, very widened at the base, narrow abruptly. They are ordinarily inflected. They end in two curved hooks. They are surrounded by a compact, strongly pigmented tissue. AGASSIZ has represented these pedicellariae in pl. xlix, fig. 45. These are the globiferous pedicellariae. We find them isolated on all the surface of the test.

Pourtalesia carinata has been encountered by the Challenger at the following stations: $46^{\circ} 16^{\prime}$ lat. S., $48^{\circ} 27^{\prime}$ long. E.; $53^{\circ} 55^{\prime}$ lat. S., $108^{\circ} 35^{\prime}$ long. E.; and $34^{\circ} 7^{\prime}$ lat S., $73^{\circ} 56^{\prime}$ long. ${ }^{4}$

\footnotetext{
${ }^{4}$ While my memoir was in press, I received the beautiful work of MORTENSEN on the Echinides de l'Ingolf, part ii, 1907, and I very much regret that I cannot take advantage of it for the revision of my Echinoids. MORTENSEN has studied Pourtalesia carinata. I noted before it arrived, in his studies of the pedicellariae and his comparisons with the figures of AGASSIZ, some results very similar to mine. However, I have not described, as we see above, rostrate pedicellariae. After the memoir of MORTENSEN arrived, I have searched for them again and with the greatest care without being able to discover them. The Danish naturalist scholar, to whom I have written on this subject, has told me that these pedicellariae were not found on all the specimens and that explains my lack of success.

Regarding the structure of the test, I have said above that the fear of damaging a single specimen prevented from examining it closely. After having read what MORTENSEN wrote on the ventral surface, I have returned to my specimen I believe I can confirm what my scholar-friend has written. Unfortunately, the state of the ventral surface has not permitted me to follow all the contours of the plates, especially in the median region where is found a large hole, whose presence had the additional inconvenience of greatly weakening the test.
} 


\section{SECOND PART.}

\section{ECHINODERMS COLLECTED BY THE “SCOTIA” DURING ITS VOYAGE AND RETURN.}

The few species that remain for me to study were encountered by the Scotia in the course of its return voyage at the Cape, Saint Helena, Ascension and the Cape Verde Islands. I shall add two ophiuroids, of which one is new, found during the outward voyage at $18^{\circ} 24^{\prime}$ lat. S. and $37^{\circ} 58^{\prime}$ long. W. on the Abrolhos Bank at a depth of 36 fathoms.

An echinoid coming from Ascension and related by AGASSIZ to Cidaris tribuloides appears to me to be necessary to be distinguished from it, either as a species or as a different variety. As for the other species, some of them merit more than a simple mention because they have insufficiently studied and it appeared useful to me to figure them and describe them completely.

The total number of species collected raises to eighteen in all that are distributed in classes in the following way.

\section{ASTEROIDS}

Cribrella ornata (Perrier). Cape of Good Hope.

Moiraster magnificus, J. Bell. Ascension. Depth 40 fathoms.

Patiria bellula, Sladen. Cape.

Asterina calcarata (Valentin). Cape.

Linckia Bouvieri, Perrier. Saint Helena.

Chataster longipes (Retzius). Ascension.

\section{OPHIUROIDS}

Amphiura murex, nov. sp. $18^{\circ} 24^{\prime}$ lat. S., $37^{\circ} 58^{\prime}$ long. W. Depth 36 fathoms.

Amphiura capensis, Lyman. Cape.

Ophiopsila maculata (Verrill). $18^{\circ} 24^{\prime}$ lat. S., $37^{\circ} 58^{\prime}$ long. W. Depth 36 fathoms.

Ophiothrix fragilis, form pentaphyllum, Lyman. Cape.

Ophiothrix triglochis, Müller and Troschel. Cape.

\section{ECHINOIDS.}

Tretocidaris spinosa, Mortensen. Ascension. Depth 49 fathoms.

Cidaris minor, sp. aut var. nov. Ascension. Depth 40 fathoms.

Cidaris tribuloides, Lamarck. Saint Helena.

Coelopleurus floridanus, Agassiz. Ascension. Depth 40 fathoms.

Echinometra subangularis (Leskc). Ascension (40 fathoms) and Saint Vincent (24 fathoms).

Paracentrotus angulosus (Leske). Cape.

Pseudoboletia maculata, Troscbel. Ascension. Depth 40 fathoms. 


\section{ASTEROIDS.}

Cribrella ornata (Perrier). (Pl. XII. fig. 105 and 106.)

Echinaster arnatus, Perrier, "Pédicellaires et ambulacres," Ann. Sc. Nat. Zool. (5), vol. xii., 1869, p. 59.

Cribrella ornata, Perrier, "Révision des Stellérides du Muséum," Arch. Zool. exp. (1), vol. vi., 1875, p. 112.

Saldanha Bay (Cape) Three specimens.

$\mathrm{R}$ varies from 30 to $34 \mathrm{~mm}$ and 4 , from 9 to $10 \mathrm{~mm}$. The arms are rather rounded and conical.

I have compared these specimens to the two types of PERRIER that are found at the Jardin des Plants. I have confirmed that they absolutely conform to them. But I note that the adambulacral spines are not arranged as PERRIER indicates as well on the species of the Scotia as those of the Museum. I find, in fact, on each ambulacral plate, a transverse row of four large spines, cylindrical and round at the end, and, inside, a very small spine hidden by the ambulacral tubes. Sometimes there are only three spines. This is always the number in the second half of the arm.

The row of latero-ventral plates that immediately follows the adambulacrals has two parallel rows of short and obtuse spines. There are three and sometimes four in each row. Sometimes, this regular order is not completely constant. In addition, the row in question does not always correspond to the adambulacrals, a latero-ventral plate is missing here and there. Outside this first row, we see another more or less distinct one. The plates of these two rows are very close to each other and the papulae that we can see between them are not numerous. Outside this second row, the plates are irregularly arranged in a network identical to that of the dorsal surface. The papulae become much more numerous.

One of the specimens of the Jardin des Plantes is a little larger than those of the Scotia. It measures $40 \mathrm{~mm}$. The arms are thinner. The other specimen is smaller $(\mathrm{R}=30 \mathrm{~mm})$. It recalls more the specimens of the Scotia. But it is deformed and flat so that the comparison is uncertain.

SLADEN relates Cr. ornata to Cr. obesa that he described according to specimens found by the Challenger at the Falkland Islands (depth 12 fathoms) and at the entrance to the Smyth Channel (depth 245 fathoms). It is certain that these two species are very close. The adambulacral spines that I see in Cr. ornata are very like the arrangement that SLADEN has figured in Cr. obesa. However, the specimens of the Cape do not have the dorsal network with a large mesh nor the regular rows of plates on the sides of the arms that SLADEN indicates in Cr. obesa. But these variations are of little importance. It is possible that the two species must be combined into one.

Since, on the other hand, we agree to consider as synonyms the different sub-Antarctic cribellas described under the names of Cr. Pagenstecheri, Hyadesi, Studeri and obesa, it is not impossible that the same species of cribrella extends from the Cape of Good Hope to Cape Horn, showing numerous variations. This question can be resolved only by a comparison of all the original specimens of the described forms.

Moiraster magnificus (J. Bell). (Pl. XII. fig. 107 to 110.)

Archaster magnificus, J. Bell, "Description of a new Species of Archaster from St Helena," Ann. and Mag. Nat. Hist. (5), vol. viii., 1881, p. 440. 


\section{Moiraster magnificus, Sladen, Reports of the "Challenger"; Asteroidea, p. 193.}

10 June 1904, Pyramid Point, Ascension; depth 40 fathoms. A single specimen.

$\mathrm{R}=72$ for the longest arm, $\mathrm{r}=19$. One of the arms is regenerating.

The type of this species comes from Saint Helena. It is represented by a single specimen much larger than the specimen of the Scotia, the dimensions indicated by BELL being $\mathrm{R}=207 \mathrm{~mm}$ and $\mathrm{r}$ $=50 \mathrm{~mm}$. The specimen of the Scotia is a little different from the type of BELL. It appears to me useful to describe and figure it, but the slight differences that I see are without doubt due to the young age of the individual.

The disk is very large. The arms are very wide with a base that measure $20 \mathrm{~mm}$. It tapers rapidly to the end that is rather pointed.

The dorsal surface of the disk and arms, nearly flat, is covered with dense and small paxillae. In the central region of the disk, they are confluent and their contours cannot be recognized. But they are very distinct in the peripheral half of the disk and on the arms. The largest is 0.7 to 0.8 $\mathrm{mm}$ in diameter. Each paxilla has a central group of three to five granules surrounded by a peripheral circle with nearly the same dimensions. On the arms, the paxillae form a median band in which they are a little smaller and closer together. From this band leave very regular and slightly oblique rows to the dorsal marginal plates. At the base of the arms, there are about ten paxillae in each of the rows. The paxillar area of the arms is relatively wide.

The anus is invisible. The madreporite is small and rounded, while BELL says that it is large. It has divergent grooves that leave from the center. It is nearer the edge than the center of the disk.

The dorsal marginal plates are small. They are much wider than long. The last are extremely small. They are close together. I count fifty on each arm. They are separated by shallow grooves and covered with rounded granules that are larger in the central part and become smaller toward the periphery. These granules do not form rows more distinct in the middle of the plates than toward the edge.

The latero-ventral plates form rows extending from the adambulacrals to the marginals. The transverse separations of these plates are not very apparent because of the spines that cover them. But the alignments they form are very regular and distinct. There are approximately eight successive plates in the row nearest the median interradial line. Then the number of plates decreases rapidly in each row. We can follow these lateral plates up to the middle of the arm. They have a very dense covering of small, cylindrical spines with a rounded end. Usually, these small spines form on the plate a peripheral border surrounding one or two central spines, a little larger, but especially wider, flatter and obtuse at the end. This arrangement recalls that we see in various species of Astrogonium. It is a little different from that which BELL described.

The ventral marginal plates also have small spines in the peripheral region, while in their median region, the spines elongate and especially widen at the same time that they flatten. We can distinguish in general three or four of these large spines, and sometimes five in the interbrachial arch. All are relatively short. They have a very obtuse end. The next to the last of these spines occupies the edge of the plate. They form a slight protrusion that is visible on the dorsal surface.

The adambulacral plates have three successive rows of spines. The first is a row of four to five unequal spines, unequal, small, flat, with a rounded end. The second has two or three spines, sometimes four, of which two in general are distinguished by the great width. They are flat. The 
third row, more irregular, has four or five spines, of which one or two are much wider than the others.

The teeth, not very protruding, have on their free edge, a row of spines that continues the internal adambulacral spines. These then become cylindrical and elongate, especially toward the end of the tooth. The ventral surface of the teeth has short spines, widened at the end that is obtuse and arranged in two or three irregular rows, very near their counterparts of the opposite side.

The ambulacral tubes are elongated, compressed, conical and pointed.

\section{Patiria bellula, Sladen.}

SLADEN, Reports of the "Challenger": Asteroidea, p. 385, pl. 1xiii. fig. 1-2, and pl. Ixiv. fig. 5-6.

Saldanha Bay (Cape). One specimen completely conforming to the type of SLADEN that also came from the Cape.

\section{Asterina calcarata (Valenciennes).}

See for the bibliography:

MEISSNER, "Die von Plate aus Chile und Feuerland beimgebrachten Seesterne," Arch. für Nat., 1896, p. 97.

8 May 1904, False Bay (Cape). Four specimens.

19 May 1904, Saldanha Bay (Cape), Several specimens.

The average dimensions of the specimens are the following: $\mathrm{R}=12 \mathrm{~mm}$ and $\mathrm{r}=10 \mathrm{~mm}$. In some individuals, $\mathrm{R}$ measures 14 and $15 \mathrm{~mm}$ All the specimens have five arms, except one that has six.

I have compared these specimens to others coming from the coast of Chile and that have been sent to me from different coasts. I have confirmed their complete identity. A. calcarata can thus ascend higher toward the north than we had believed.

\section{Linckia Bouvieri, Perrier.}

Perrier, "Révision des Stellérides du Muséum," Arch.Zool. exp., $1^{\circ}$ série, vol. v., p. 150.

2 June 1904, Saint Helena. One specimen of small size: $\mathrm{R}=35 \mathrm{~mm}$ and $\mathrm{r}=4 \mathrm{~m}$.

Despite these small dimensions, the specimen is very well characterized. I figure this species according to adult specimens collected by S. A S the PRINCE OF MONACO in a memoir presently in press.

The species still has not been reported in the S. Atlantic. 


\section{Choetaster longipes (Retzius).}

See for the bibliography:

LUDWIG, Fauna und Flora des Golfes von Neapel: Asteroidea, 1897, p. 134.

10 June 1904, Pyramid Point, Ascension. Depth 40 fathoms. Two specimens in which R $=42$ $\mathrm{mm}$ and $\mathrm{r}=5 \mathrm{~mm}$.

Despite their small size, these specimens are very recognizable. They are identical to individuals from the Mediterranean.

The species still has not been seen in the S. Atlantic and its discovery at Ascension is very interesting.

\section{OPHIUROIDS.}

Amphiura murex, nov. sp. (Pl. XIII. fig. 115 AND 116.)

20 December $1902,18^{\circ} 24^{\prime}$ lat. S., 37 58' long. W. Depth 36 fathoms. Two specimens.

Diameter of the disk, $2.5 \mathrm{~mm}$. The arms are very fine, slender and elongated, rather strongly contorted that prevents measuring them. But they must have been at least $25 \mathrm{~mm}$ in length.

The disk is rounded. The dorsal surface is covered with rather large plates, unequal, little or not imbricated. In one of the specimens, we do not recognize primary plates, while in the other, these plates are very distinct. On the periphery of the disk, we find a border of larger and wider plates. The radial shields are rather larger, contiguous on nearly all their length and separated inside only by a small triangular plate. Their interradial edge is strongly convex and their length is a little greater than a third of the radius of the disk.

The ventral surface of the disk has distinct plates, but it is covered with small granules, very find and very dense, pointed and conical. The genital slits are very wide. I do not distinguish plates at their edges.

The buccal shields, of medium size, are triangular with a pointed proximal corner and a distal edge strongly convex. They are as wide as long or a little longer than wide. The adoral plates are rather strong, widened outside, narrow and contiguous inside. The oral plates are small. The buccal papillae are arranged as in the species of the section Amphipholis. The external papilla is large and rectangular. The two others are short, thick and subequal.

The dorsal brachial plates are pentagonal, as wide as long, with an obtuse proximal corner and straight lateral edges united by rounded corners at the distal side that is nearly straight or slightly rounded. They are separated from the base of the arm.

The first ventral plate is extremely small, pentagonal, with a proximal corner whose two sides are contiguous with the distal edge of the external buccal papilla. The following plates, of medium 
size, are pentagonal, as wide as long, with a very obtuse proximal corner and a distal side with a slight notch in its center. They are widely separated. The lateral plates have three cylindrical spines, unequal and with an obtuse end.

The tentacular pores have two very small scales.

Similarities and Differences. - A. murex belongs to the section Amphipholis. It is extremely near A. granulata Lütken and Mortensen. I have even hesitated to separate them. However, some differences do not permit confusing them. The dorsal brachial plates of A. Murex have a different form. In addition, they are as wide as long and separated. The ventral brachial plates, while recalling by their form those of $A$. granulata, are as wide as long. Finally, the brachial spines are not pointed. These differences could perhaps be due to age, my specimens being of very small size. Nevertheless, it does not seem to me possible to unite them with A. granulata. I do not speak here of the primary plates, because one of my specimens has them while they are not distinct in the other.

Amphiura capensis, Lyman.

See for the bibliography:

LyMAN, Reports of the "Challenger": Ophiuroidea, p. 129.

21 May 1904, Saldanha Bay (Cape); depth 25 fathoms. Several specimens.

10 June 1904, Ascension, a single specimen.

The tentacular scale is not quite as large as in the figures of LYMAN. The primary plates are in general very distinct as indicated by LYMAN, but it should noted that he has not included them in his figure. I likewise note that the buccal papillae are represented in a more correct manner in the figure of the Mem. Mus. Comp. Zool._than in those of the Challenger publication.

I observe in general seven spines at the base of the arms.

\section{Ophiopsila maculata (Verrill).}

Amphipsila maculata, Verrill, "Report of the Ophiurids collected by the Bahama Expedition," Bull. from the Lab. Nat. Hist., State University, Iowa, vol. v., 1899, p. 55, pl. iii. figs. 4-4a.

20 December $1902,18^{\circ} 2^{\prime}$ lat. S., $37^{\circ} 58^{\prime}$ long. W.; depth 36 fathoms. A single specimen.

Diameter of the disk, $3.5 \mathrm{~mm}$.

There are only five brachial spines. The two lower ones are longer than the others, but it is especially the ventral spine that is longest. It is, in addition, slightly curved, a character that Verrill does not indicate. 
There are elongated brown spots on the sides of the dorsal surface of the arms and in the middle of the dorsal brachial plates. We note equally a double row of brown spots on the ventral surface of the arms and a brown point on each buccal shield. The disk is gray, with some large, irregular yellow spots.

I do not believe it is necessary to separate this ophiuroid from A. maculata, although the type of Verrill has a larger number of brachial spines. This difference is due without doubt to my specimen being very young, because that of Verrill was $6 \mathrm{~mm}$ in diameter.

The type came from Havana and was collected at a depth of 200 fathoms. This station is not far from that where the Scotia found the species, but it belongs to the boreal Atlantic.

\section{Ophiothrix fragilis (Abildgard).}

See: Koehler, "Révision des Ophiures du Muséum," Bulletin Scientifique, 1907, p. 332.

Saldanha Bay (Cape). Three specimens.

These specimens belong to the form pentaphyllus as I have defined it. They absolutely conform to some individual that I possess in my collection and that come from the Strait of Dover.

It was not without extreme surprise that I encountered this Ophiothrix in the collections of the Scotia. If there is not an error of the label, we see that this form descends much further toward the south than we would have supposed.

Ophiothrix triglochis, Liitken.

See for the bibliography:

Koehler, "Ophiures nouvelles ou peu connues," Mém. Soc. Zool. France, 1904, p. 114, fig. 41 to 45.

8 May 1904, False Bay. A single specimen. Diameter of the disk, $8 \mathrm{~mm}$.

The rods of the dorsal surface of the disk are larger than usual and are constituted of spines ending in three of four spinules. The brachial spines also have denticulations stronger than usual. 


\section{ECHINOIDS.}

Tretocidaris spinosa, Mortensen. (Pl. XVI. fig. 163 and 164.)

Tretocidaris spinosa, Mortensen, The Danish Ingolf Expedition: Echinoidea, 1903, p. 17, pl. x. fig. 10, 11 and 16.

10 June 1904, Pyramid Point, Ascension; depth 40 fathoms. Four specimens.

In the largest specimen that I have represented in Pl. XVI, fig. 163 and 164, the diameter of the test, without spines, is approximately $35 \mathrm{~mm}$ and the height, 22. In the two others, this measures respectively, 30 and $37 \mathrm{~mm}$. The last individual, very small, is only $7 \mathrm{~mm}$, but it is already very recognizable. It has some characteristic pedicellariae.

The name of Tretocidaris spinosa was applied by MORTENSEN to an echinoid of the British Museum coming from Saint Helena without other indication. It differs from T. Bartleti by the form of the globiferous pedicellariae. Here is the information that MORTENSEN gives on the test and spines:

"The spines have grooves, close together, and rather fine denticulations. They are widened at the end. Their length is equal to the diameter of the test. The actinal spines are delicate, smooth, and not widened at the end. The small spines have a red color. A naked median line extends the length of each interambulacral area so that the large spines are more numerous than usual. This gives the urchin a very characteristic appearance. The tubercles of the ambulacral areas are arranged as in T. annulata."

In a private letter, MORTENSEN has very kindly given me the following additional information, found in his notes, on the T. spinosa of the British Museum:

"The ocular plates join the plates of the periproct and thus separate the genital plates. Each interambulacral plate corresponds to twelve ambulacral plates in the middle of each row. There are secondary spines between all the spines, so that the areoles are not confluent. The tubercles are not crenelated."

The specimens of the Scotia have some slight differences with the type of MORTENSEN, differences that relate mainly to the form of the spines and the number of primary tubercles of the interambulacral areas. But MORTENSEN, who has very kindly looked at my specimens, has confirmed my identification. He thinks these differences, notably those that related to the number of primary tubercles, are due to the young age of these specimens because, he has written me, the type of the British Museum is much larger.

Here are the characters that I see in the largest individual:

The interambulacral plates number seven, whose dimensions increase progressively from the first up to the fifth, the sixth being nearly as large as the fifth. In one of the two rows, we note between the last interambulacral plate and the circle of genital and ocular plates, a very small triangular plate that represents an eighth plate. The tubercles, perforated, are not crenelated. The scrobicular areas, at first elliptical, tend to become circular above the ambitus. All the rest of the surface of the plates is covered with secondary tubercles and very close together miliaries. On the largest plates, we distinguish a rather regular first circle of secondary tubercles surrounding the scrobicular depression. Then, outside, are two more distinct circles of secondary tubercles 
separated by miliary tubercles. The two first depressions are confluent. A single row of granules separates the second from the third, and third from the fourth. Finally, the others are separated by a double row and even by two double rows of granules. The tubercles do not go to the sutural border. The zig-zag median line in each interambulacral zone is naked.

At the ambitus, an interambulacral plate corresponds to a dozen ambulacral plates. The poriferous zones are rather wide and the pores of each pair are far from each other. Each pair is separated from the following by a slightly raised border. Each ambulacral plate has a secondary tubercle, immediately inside the poriferous zone. These tubercles form a very regular row. Inside, we see on each plate, either a single tubercle or two smaller ones.

The genital plates are very large, quadrangular, nearly as long as wide or a little wider than long, with small, rather dense small tubercles. The small gonopores are located toward the external third of the plate. The madreporite is not distinguished from the others by its size and the pores are scarcely distinct. The ocular plates are small, triangular, with the external edge notched. They are located in the intervals of the genital plates and, in general, contiguous with the periproct. In the specimen before my eyes, three plates have a truncated proximal corner and contiguous with the anal plate. The fourth has a pointed tip but still touches the anal plate. Finally, the last is far from the anal plate. The is filled with sparse and irregular plates, relatively large outside and smaller toward the center.

Most of the primary spines are missing or broken in the individual I describe. In the others, the spines appear as MORTENSEN says, very clearly canaliculated. The ridges that separate the grooves are strongly rugose, but they are scarcely widened at the end. They can be longer than the diameter of the test. Thus, in an individual $30 \mathrm{~mm}$ in diameter, the longest spine is $40 \mathrm{~mm}$. These spines have wide bands alternating pink and brown.

The grooves fade on the spines of the ventral surface that end by being completely smooth. They flatten at the same time.

The secondary spines are dense and flat. They have very fine grooves. They leave naked the middle of the interambulacral zones. They are very bright reddish brown in color, with a greenish base.

The characters of the pedicellariae have been very well described by MORTENSEN, to whose description and figures I have nothing to add.

Cidaris minor sp. aut var. nov. (Pl. XV. fig. 136 to 138.)

Cidaris tribuloides juv., Agassiz, Reports of the "Challenger": Echinoidea, p. 36, pl. i., fig. 3, 5 and 6.

10 June 1904, Pyramid Point, Ascension; depth 40 fathoms. A single specimen.

The specimen is very small. The diameter of the test does not exceed $11 \mathrm{~mm}$.

In the Report on the echinoids of the Challenger, AGASSIZ relates to Cidaris tribuloides some specimens of echinoids found at Bahia and at Fernando Noronha at 7 to 20 fathoms of depth. All are of small size, the diameter of the largest not exceeding $17 \mathrm{~mm}$. At first glance, AGASSIZ said these urchins had some resemblance to young Phyllacanthus verticillata, but as a whole, they have the characters of Cidaris tribuloides. The differences we see with the adult are not more marked than those that we can find in Goniocidaris tubaria. Moreover, these young individuals have been 
found in localities precisely where Cidaris tribuloides lives. AGASSIZ thus has considered this cidarid as belong to this latter species. He has represented it in pl. I, fig. 3, 5 and 6 of his memoir.

MORTENSEN, who has seen these echinoids at the British Museum, is of the opinion to separate Cidaris triibuloides, to make a new species. However, a simple glance at the figures of AGASSZI shows that the specimens collected by the Scotia belong to the same form. Perhaps it is simply a matter of a simple variety of $C$. tribuloides. I propose to give it the name of $C$. minor, without being able to decide formally if it is a species distinct from $C$. tirbuloides or a simple variety of the latter. To the indications provided by AGASSIZ, I shall add some remarks that, together with the figures that I give, will permit recognition of this Cidaris. Unfortunately, the single specimen that I have in hand does not permit giving a complete description of this interesting form because I wanted to leave it intact. I must limit myself to describe the animal covered with its spines.

The interambulacral zones have each five primary spines whose length increase from the first ventral to the last dorsal, that attains 8 to $9 \mathrm{~mm}$. These spines have conical teeth arranged in longitudinal rows. In some places, the teeth become much stronger. They come together to make a kind of whorl. On the largest spines of my specimen, the number of these whorls does not exceed two. But in the largest individual, the number is perhaps higher because AGASSIZ indicates three or four. Finally, the end of the spines is widened and has eight or ten teeth. The characters are especially marked on the dorsal spines. They fade progressively on the other spines. The ventral spines have simply rows of fine denticulations. These spines can have alternating pale and dark parts. The pale parts correspond to the whorls.

The very dense secondary spines are flat and finely grooved. In the ambulacral zones, they are red with one or two white bands more or less apparent, while in the interradius, they are white with one or two red bands.

The genital plates are slightly trapezoidal, nearly as long as wide. The gonopore is found a little outside the middle of the plate. Ocular plates are triangular, wider than long, with the proximal corner slightly truncated and contiguous to the periproct. This is covered by rather large plates that have small spines, conical and erect.

I have found only one kind of pedicellaria, very rare and very small. These are globiferous pedicellariae that resemble the small globiferous pedicellariae figured by MORTENSEN in Cidaris affinis and by AGASSIZ and LYMAN CLARK in C. triibuloides. The terminal opening is large. The terminal tooth is very developed. The edges have teeth that are very close together and fine and pointed (fig. 138).

If $C$. minor is a distinct species, it is probable it remains at a very small size. Up to now, the largest specimens known do not exceed $17 \mathrm{~mm}$ in diameter. It is to be hoped that other specimens will be found so that we can study in a more complete way the characters of the test and decide first, by the examination of the gonads, if the individuals of the size collected by the Scotia are adults. And then, by a more complete study of the exterior characters, if they represent a distinct species or if they form only a variety of $C$. tribuloides

\section{Cidaris tribuloides, Lamarck.}

See for the bibliography:

KoeHLer, Résultats scientifiques des campagnes du Prince de Monaco, fasc. xii., 1888, "Échinides et Ophiures," p. 8. 
And add:

LYMAN Clark, "The- Echinoids and Asteroids of Jamaica," Johns Hopkins Univ. Circ, vol. xviii., 1898, p. 4; "The Echinoderms of Porto Rico," Bull. U.S. Fish Comm. for 1900, p. 252; "Bermudan Echinoderms," Proc. Boston Soc, vol. xxix., 1901, p. 344.

Agassiz and Lyman Clark, "Hawaian and other Pacific Echini," Mem. Mus. Comp. Zool., vol. xxiv., 1906, p. 3, pl. ii. fig. 1-4.

2 June 19041 James Bay, Saint Helena. Two specimens.

\section{? Colopleurus floridanus, Agassiz.}

See for the bibliography:

DöDERLEIN, Echinoideen der deutschen Tiefsee Expedition, 1906. p. 181, pl. xlv. fig. 2.

10 June 1904, Pyramid Point, Ascension; depth 40 fathoms. A single specimen.

This individual has a nearly completely denuded test. It is moreover of very small size. Its diameter does not exceed $9 \mathrm{~mm}$. Some ophiocephalous pedicellariae are preserved. They are identical to those that DÔDERLEIN has represented in this species. The ambulacral zones are a bright pink.

The determination of this very young and incomplete individual remains very doubtful. Perhaps it belongs to a new species. It is very near in any case to $C$. floridanus that is known up to now only in the equatorial region of the boreal Atlantic.

\section{Echinometra subangularis (Leske)$$
\text { = Ech. lucunter (Linné). }
$$

$1^{\text {st }}$ December 1902, Porto Grande, Saint Vincent, Cape Verde Islands; depth 24 fathoms. Two small specimens.

2 June 1904, James Bay, Saint Helena. Two large specimens.

As MORTENSEN recalls in his work on the echinoids of the Ingolf, LOVEN established that this species is the E. lucunter of LINNÉ. It is thus this name that should be used. I have kept the denomination under which it is generally known to avoid all confusion.

\section{Paracentrotus angulosus (Leske).}

See for the bibliography:

DôDERLEIN, Die Echinoideen der deutschen Tiefsee Expedition, p. 124. 
Saldanha Bay (Cape) and Cape Town. Several specimens.

This species has been recently studied in a very complete manner by DôDERLEIN and I have nothing to add to his description.

Pseudoboletia maculata, Troschel. (Pl. XV. figs. 139 to 142; Pl. XVI. fig. 165.)

TROSCHEL, Verh. naturh. Ver. fur Rheinland und Westphalie, vol. xxvi., 1869, p. 96.

J. Bell, "On the Species of Pseudoboletia," Ann. Mag. Nat. Hist. (5), vol. xiii., 1884, p. 108.

LORIOL, "Catalogue raisonné des Échinodermes de lîle Maurice," Mém. Soc. Phys. et Hist. Nat. Genève, vol. xxviii., 1883, p. 28.

MORTENSEN, The Danish Ingolf Expedition: Echinoidea, i., p. 118.

10 June 1904, Pyramid Point, Ascension; depth 40 fathoms. Two specimens.

I have been very uncomfortable in identifying these two urchins, the genus Pseudobolitia being considered by all authors as restricted to the Indo-Pacific domain. Very happily, my excellent friend MORTENSEN, who has kindly examined them, told me that they are identical to the type of Ps. maculata that he had previously studied in the British Museum and on which he had given some information in the work cited above, showing that this species should be distinguished from Ps. indiana, with which it was generally confused.

As Ps. maculata has never been described, it appears useful to me to describe and represent the two specimens collected by the Scotia. In fact, TROSCHEL confined himself to mentioning the species, indicating only that the peristomial notches do not exceed one seventh of the diameter of the peristome. So the species is known only by the remarks published by MORTENSEN.

Troschel did not indicate the origin of Ps. maculata. The specimen of the British Museum gave no indication of the locality. The discovery, by the Scotia, of this species at Ascension is thus very interesting because it does not only fix its origin, but it shows in addition that the genus Pseudoboletia, which we believed restricted to the Indo-Pacific domain, can also be found in the Atlantic.

The larger specimen reported by the Scotia is in an excellent condition. It has preserved its spines but there are generally broken at the end. The other, a little smaller, has the test completely spineless. It is this one that I have represented (Pl. XV, fig. 139 to 141, and Pl. VI, fig. 165).

Here are the dimensions of these two individuals:

Height: $24 \mathrm{~mm}, 20 \mathrm{~mm}$.

Diameter: 65 “, 53 “.

The test is very low and its contour is sub-pentagonal. The ventral surface is flat. The ambulacral areas, nearly as wide as half the interambulacral areas, has about thirty plates. Each of these has a primary tubercle very near the poriferous zone. Between it and the arc of pores is another tubercle. It is first very small and can even be missing on the first ambulacral plates. But the dimensions increase toward the ambitus where it attains the size of a secondary tubercle. On the other side, the plates have another tubercle whose dimensions increase rapidly in a way to attain nearly the size of a principal tubercle at the ambitus. All the rest of the plate is filled with 
rather dense secondary tubercles and miliaries. Above the ambitus, the middle of the ambulacral zones have only few tubercles. Each zone thus has at the ambitus, four nearly equal tubercles. The pores are arranged in arcs of five pairs (fig. 141).

The interambulacral zones are very wide. They each have twenty-five pairs of plates. Each plate has, toward its external edge, a primary tubercle whose dimensions do not decrease much toward the apical system. Outside this principal row, i.e., between it and the poriferous zone, we see a second row that begins on the first plates with very small tubercles but whose dimensions increase progressively in a way to equal, at the ambitus, the tubercles of the first row. On the other side of his main row, there is a third that appears only toward the seventh plate and whose tubercle increase rapidly in a way to equal the two preceding rows at the ambitus. Finally, inside this third row, we find a fourth, that appears even further than the preceding from the apical system and that attains, at the ambitus, a size nearly equal to that of the other three. This latter does not continue very far below the ambitus. We see thus, that at the ambitus, each interambulacral plate has a row of four unequal primary tubercles. The rest of the plate is covered with secondary and miliary tubercles, rather dense at the ambitus and below, but much less numerous above, so that the middle of the interambulacral zones is a little bare.

The apical system is small and resembles that of Ps. indiana. The genial plates are pentagonal and unequal. The gonopores are large and oval. The plate that has the madreporite is the largest. It has, inside this body, three small alligned tubercles. The left anterior plate, elongated, has a large primary tubercle, surrounded by miliary tubercles. The other plates have similar arrangements, but the principal tubercle is smaller. Two ocular plates touch the periproct. They are nearly rectangular and a little larger than the others that are pentagonal with a proximal corner. They are covered with small tubercles. The periproct is small, oval, covered with rather large plates, but that rapidly become small in the area of the anus. They have a principal tubercle and two or three others that are smaller.

The peristome is large. It measures $19 \mathrm{~mm}$ in diameter in the smaller specimen. The notches are shallow. They are scarcely $2 \mathrm{~mm}$. They are thus a little shorter than indicated by TROSCHEL, according to whom that are equal to a seventh of the diameter of the peristome. They are a little more strongly marginalized on one side than the other. The ten buccal plates are large and circular. They have a central depression surrounded by a circle of five principal tubercles having elongated spines. There are, in addition, some miliary tubercles with pedicellariae. The rest of the buccal membrane is covered with small plates, very numerous and dense within the circle of ten buccal plates, larger and more spaced outside. These latter have each a small tubercle.

The spines are nearly all broken at the end. Those that remain entire on the ventral surface measure 12 to $15 \mathrm{~mm}$ in length. These spines end in a very slightly widened truncated end. Their surface is very finely striated. It has alternating bands of white and pale green. The first ones are wider. At the ambitus and on the dorsal surface, the spines are purplish brown on the first third. The rest is white with sometimes a pale violet band.

The denuded test has a white color on the ventral surface. On the dorsal surface, the middle of the ambulacral and interambulacral areas is white, but we note pale-brown parts that form elongated patches in the poriferous zones. There are in addition, immediately above the ambitus, five patches widened transversely in each interambulacral zone.

The pedicellariae have already been described by MORTENSEN. The globiferous pedicellariae, very few in number, resemble those of Ps. indiana. The tridactyl pedicellariae are not very abundant. In contrast, I see on the large specimen, a considerable number of voluminous glandular pedicellariae, but reduced to three large, rounded glands, with the least indication of rudiments of 
calcareous valves (Pl. XV, fig. 142). The wall of these glands is full of C-shaped spicules, widened at the ends, identical to those in the globiferous pedicllariae. We also find these spicules in the integument of the stem. It continues between the three glands in the form of a rod with a widened end.

LYON, 8 July 1907. 


\title{
EXPLANATION OF THE PLATES.
}

\author{
Plate I.
}

Fig. 1. Dytaster felix.

Fig. 2. " " "

Fig. 3. " "

Fig. 4. Hymenaster densus.

Fig. 5 .

Fig. 6. "6 " "

Fig. 7. " " .

Fig. 8. Hymenaster campanulatus. Ventral surface. Mag. = 3 .

Fig. 9. " " " ,

Fig. 10. Odontaster pusillus

Fig. $11 . \quad$ " "

Dorsal surface. Mag. $=2$.

Ventral surface. Mag. $=2$.

\author{
Dorsal surface. Mag. $=35$. \\ Ventral surface. Mag. $=3.5$.
}

Dorsal surface. Natural size.

Vemtral surface. Natural size.

Enlarged portion of dorsal surface. Mag. $=6$.

Enlarged portion of the dorsal surface. Mag. $=6$.

Teeth and dental.spines. Mag. $=7$.

Enlarged portion of the dorsal surface. Mag. $=11$.

\section{PlATE II.}

Fig. 12. Hymenaster edax.

Fig. 13

Fig. 14

“.

Dorsal surface. Mag. $=4$.

Ventral surface. Mag. $=4$.

Portion of dorsal surface. Mag. $=12$.

Teeth and dental spines. Mag. $=22$.

Fig. 15.

".

Fig. 16. Psilasteropsis facetus.

Fig. 17

Fig. 18.

"

Dorsal surface. Natural size.

Ventral surface. Natural size.

Enlarged portion of the dorsal surface. Mag. $=6$.

Fig. 19. Hymenaster campanulatus. Dorsal surface. Mag. $=3$.

Fig. $20 . \quad$ " $\quad$ " $\quad$. Lateral view. Mag. $=3$.

Fig. 21. " " $\quad$. Teeth and dental spines. Mag. = 22 .

\section{Plate III.}

Fig. 22. Marcelaster antarcticus.

Fig. 23. " " "

Dorsal surface. Natural size.

Ventral surface. Mag. $=2$.

$\begin{array}{lll}\text { Fig. } 24 . & \text { " } & \text { " } \\ \text { Fig. } 25 & \text { " }\end{array}$

Fig. 26. Ganeria attenuata.

Fig. 27.

"

Fig. 28. Hymenaster fucatus.

Fig. 29.

66

Fig. 30.

6

Fig. 31.
Portion of the dorsal surface. Mag. $=4$.

Young specimen seen by the dorsal surface. Mag. $=4.5$.

Dorsal surface. Natural size.

Ventral surface. Natural size.

Dorsal surface. Mag. $=2$.

Ventral surface. Mag. $=2$.

Portion of the dorsal surface. Mag. G. $=5$.

Teeth and dental spines Mag. $=10$. 


\section{PlATE IV.}

Fig. 32. Chitonaster Johanna.

\begin{tabular}{|c|c|c|}
\hline Fig. 33 & 66 & 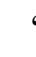 \\
\hline Fig. 34. & ، & 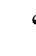 \\
\hline Fig 35. & “ & 6، \\
\hline Fig. 36. & “ & \\
\hline Fig. 37. & “ & ، \\
\hline
\end{tabular}

Fig. 38. Scotiaster inornatus.

Fig. 39. " "

Fig. 40. Solaster Lorioli.

Fig. 41. " " "

Fig. 42. Lophaster abbreviatus.

Fig. 43.

" "

Fig. 44. Styracaster robustus.

Fig. 45.

Lateral view of the largest specimen. Natural size.

Dorsal surface. Natural size.

Ventral surface. Natural size.

Dorsal surface of another specimen. Natural size.

Dorsal surface of a third specimen. Mag. = 3'5.

Dorsal surface of the smallest specimen. Mag. = 3"5.

Dorsal surface. Natural size.

Ventral surface. Natural size.

Dorsal surface. Mag. $=2.5$.

Ventral; surface. Mag. $=2.5$.

Dorsal surface. Mag. $=2$.

Ventral surface. Mag. $=2$.

Dorsal surface. Natural size.

Ventral surface. Natural size.

\section{Plate V.}

Fig. 46. Stolasterias Brucei.

Fig. 47. "، '

Dorsal surface. Natural size.

Ventral surface. Natural size.

Straight pedicellaria of the ambulacral groove. Mag. 100.

Portion of the dorsal surface. Mag. $=6$.

Fig. 49.

Fig. 50. Diplasterias Brandti. size.

Fig. 51.

“

specimen. Mag. $=32$.

Fig. 52. Anasterias cupulifera.

\section{Plate VI.}

Dorsal surface. Natural size.

Dorsal surface of an arm in the genital region. Mag. $=5$.

Dorsal surface of an arm beyond the genital region. Mag. =

Ventral surface of the disk and arms. Mag. $=5$.

Dorsal surface of the disk. Mag. = 5.

Ventral surface. Natural size.

Portion of the dorsal surface. Mag. $=5$.

Young individual. Mag. $=2$. 


\section{PLATE VII.}

Fig. 61. Asterias pedicellaris.

Fig. 62. " "

Fig. 63, , ,

Fig. 64, 65 and 66. Asterias pedicellaris. Valves isolated from the pedicellariae of the dorsal surface. Mag. $=24$.

Fig. 67. Asterias pedicellaris. $=24$.

Fig. 68. Diplasterias induta.

Fig. 69. " " "

Fig. $70 . \quad$ " "

Fig. 71. Hyphalaster Scotice.

Fig. 72.

“

"

Fig. 73. Belgicella Racovitzana.
Dorsal surface. Natural size.

Large pedicellaria from the dorsal surface. Mag. $=24$.

Another pedicellaria. Mag. $=24$.
Basal piece of a pedicellaria from the dorsal surface. Mag.

Dorsal surface. Natural size.

Ventral surface. Natural size.

Portion of the dorsal surface. Mag. $=6$.

Dorsal surface. Mag. $=2$.

Ventral surface. Mag. $=2$.

Dorsal surface. Mag. $=3$.

\section{PlATE VIII.}

Fig. 74. Asterias pedicellaris. $\quad$ Ventral surface of a specimen other than that of fig. 611 Mag. $=3$.

Fig. 75. " " " Pedicellaria of the ventral surface. Mag. $=55$.

Fig. 76, 77 and 78. Asterias pedicellaris. Valves isolated from a pedicellaria of the ventral surface.

Fig. 79. Ophioglypha integra. $\quad$ Dorsal surface. Mag. $=3.5$.

Fig. 80. " " " Ventral surface. Mag. = 3.5.

Fig. 81. Ophioglypha Brucei. $\quad$ Dorsal surface. Mag. $=2$.

Fig. 82. " " " Ventral surface. Mag. $=5$.

\section{PLATE IX.}

Fig. 83. Ophioglypha figurata.

Fig. 84.

Fig. 85. Ophioglypha ossiculata.

Fig. 86.

66

Fig. 87.

Fig. 88. Ophioglypha mimaria

Fig. 89.
Dorsal surface. Mag. $=4$.

Ventral surface. Mag. $=4$.

Dorsal surface. Mag. = 3 .

Dorsal surface. Mag. $=4$.

Dorsal surface of a smaller specimen. $\mathrm{Mag}=4$.

Dorsal surface. Mag. $=4$.

Ventral surface. Mag. $=5$. 


\section{Plate X.}

Fig. 90. Ophioglypha lenticularis.

Fig. 91. “ '،

Fig. 92. Ophioglypha anceps.

Fig. 93.

Fig. 94. Ophioglypha partita.

Fig. 95.

Dorsal surface. Mag. $=2.5$.

Ventral surface. Mag. $=3$.

Dorsal surface. Mag. $=4$.

Ventral surface. Mag. $=4$.

Dorsal surface. Mag. $=1.5$.

Ventral surface. Mag. $=5$.

\section{Plate XI.}

Fig. 96. Ophioglypha inops.

Fig. 97.

"6

Fig. 98. Ophioglypha scissa.

Fig. 99.

"

Fig. 100. Ophiocten Ludwigi.

Fig. 101.

"

Fig. 102. Ophiernus quadrispinus

Fig. 103.

“6

Fig. 104. Amphiura magellanica

Fig. 105. Cribrella ornata.

Fig. 106. " " "

Fig. 107. Moiraster magnificus.

Fig. 108. " " "

Fig. $109 . \quad$ " " "

Fig. $110 . \quad$ "6 "

Fig. 111. Amphiura magnifica.

Fig. 112. Ophioglypha scissa.

Fig. 113. Amphilepis antarctica.

Fig. 114.

6

Fig. 115. Amphiura murex

Fig. 116.

Fig. 117. Amphiura consors.

Fig. 118.

'

Fig. 119. Amphiura magnifica.

Fig. 120. Astrotoma Agassizii.

\section{Plate XIII.}

Dorsal surface. Mag. $=4$.

Ventral surface. Mag. $=5$.

Dorsal surface. Mag. $=3$.

Ventral surface. Mag. $=3.5$.

Dorsal surface. Mag. $=55$.

Ventral surface. Mag. $=5$.

Dorsal surface. Mag. $=4.5$.

Ventral surface. Mag. $=6$.

Ventral surface. Mag. $=16$.

\section{Plate XII.}

Dorsal surface. Natural size.

Ventral surface. Mag. = 2 .

Dorsal surface. Natural size.

Ventral surface. Natural size.

Portion of the dorsal surface. Mag. $=5$.

Portion of the ventral surface. Mag. $=5$.

Dorsal surface enlarged a little more than 2 times.

Ventral surface. Mag. $=3$.

Dorsal surface. Mag. $=30$.

Ventral surface. Mag. $=30$.

Dorsal surface. Mag. $=28$.

Ventral -surface. Mag. $=28$.

Dorsal surface. Mag. = 3.5.

Ventral surface. Mag. $=4.5$.

Ventral surface magnified a little more than 3 times.

Dorsal surface of a very young individual. Mag. $=5$. 


\section{PLATE XIV.}

Fig. 121. Amphiura Mortenseni.

Fig. 122.

" "

Fig. 123. Ophiacantha frigida.

Fig. 124.

Fig. 125.

Fig. 126. Ophiomitrella ingrata.

Fig. 127.

Fig. 128. Ophiacantha opulenta

Fig. 129.

Dorsal surface. Mag. $=6$.

Ventral surface. Mag. $=18$.

Dorsal surface. Mag. $=10$.

Ventral surface. Mag. $=10$.

Spines from the dorsal surface of the disk. Mag. 80.

Dorsal surface. Mag. $=24$.

Ventral surface. Mag. $=24$.

Dorsal surface. Mag. $=4$.

Ventral surface. Mag. $=4.5$.

\section{PlATE XV}

Fig. 130. Delopatagus Brucei.

Fig. 131.

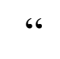

Fig. 132.

"،

66

Fig. 133.

$66 \quad 66$

Fig. 134.

66

66

Fig. 135.

Fig. 136. Cidaris minor.

Fig. 137. " "

Fig. 138. " “

Fig. 139. Pseudoboletia maculata

Fig. 140.

Fig. 141.

Fig. 142.
66

“6
Dorsal surface. Mag. $=2$.

Ventral surface. Mag. $=2$.

Lateral surface. Mag. $=2$.

Posterior surface. Mag. $=2$.

Large rostrate pedicellaria. Mag. $=85$.

Tridactyl pedicellaria. Mag. $=85$.

Dorsal surface. Mag. = 2.5.

Lateral surface. Mag. $=2.5$.

Globiferous pedicellaria. Mag. $=240$.

Dorsal surface slightly enlarged.

Lateral surface slightly enlarged.

Portion of the test at the ambitus. Mag. $=4$.

Glandular pedicellaria. Mag. $=40$.

\section{Plate XVI.}

Fig. 143. Sterechinus Neumayeri. Lateral view of a specimen in part lacking its spines. Natural size.

Fig. 144. “

Portion of the test at the ambitus. Mag. $=5.2$

Dorsal surface of the large specimen. Natural size.

Lateral view of the same specimen.

Ventral surface of the same.

Posterior surface of the same.

Ventral surface of a specimen a little smaller and in part

Fig. 149. lacking spines. Natural size.

Fig. 150. " " " " $\quad$ Dorsal surface the same specimen.

Fig. 151. " " " " $\quad$ Dorsal surface of the small specimen. Natural size.

Fig. 152. " " " " $\quad$ Lateral surface of the same specimen.

Fig. 153. " " " " $\quad$ Ventral surface of the same specimen.

Fig 154. " " “ $\quad$ Globiferous pedicellaria. Mag. $=40$. 


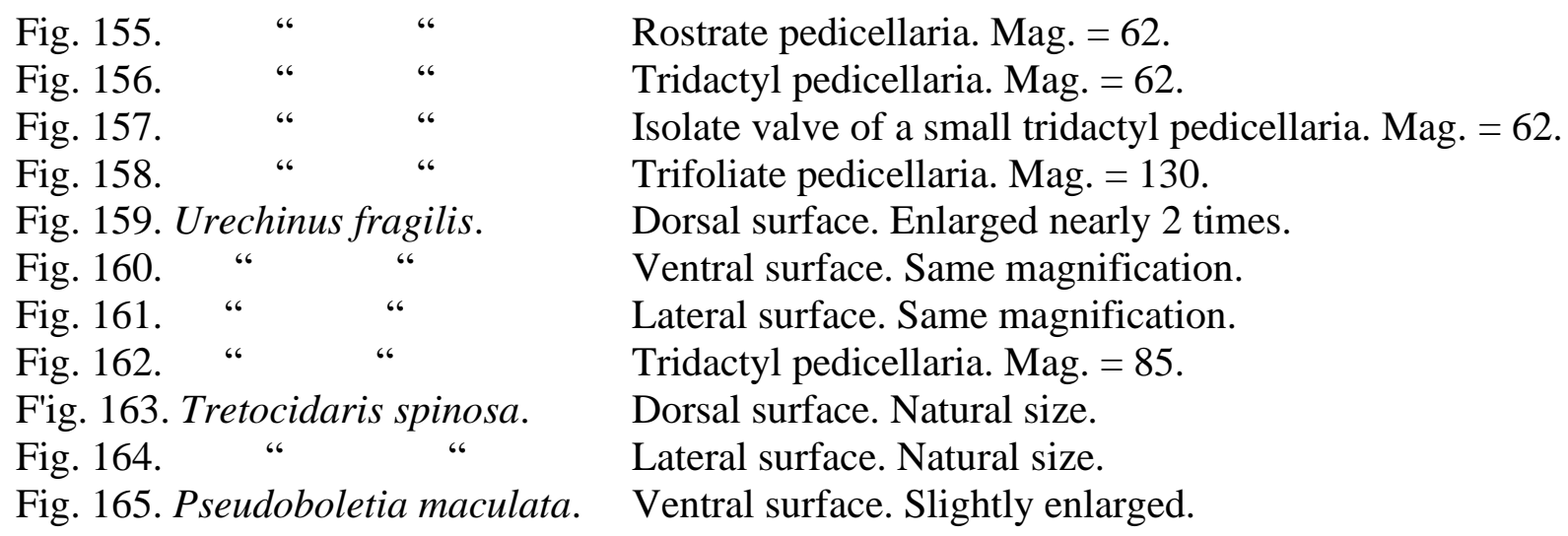


Køhler: Asteroidea, Ophiuroidea, Echinoidea. - Planche I.
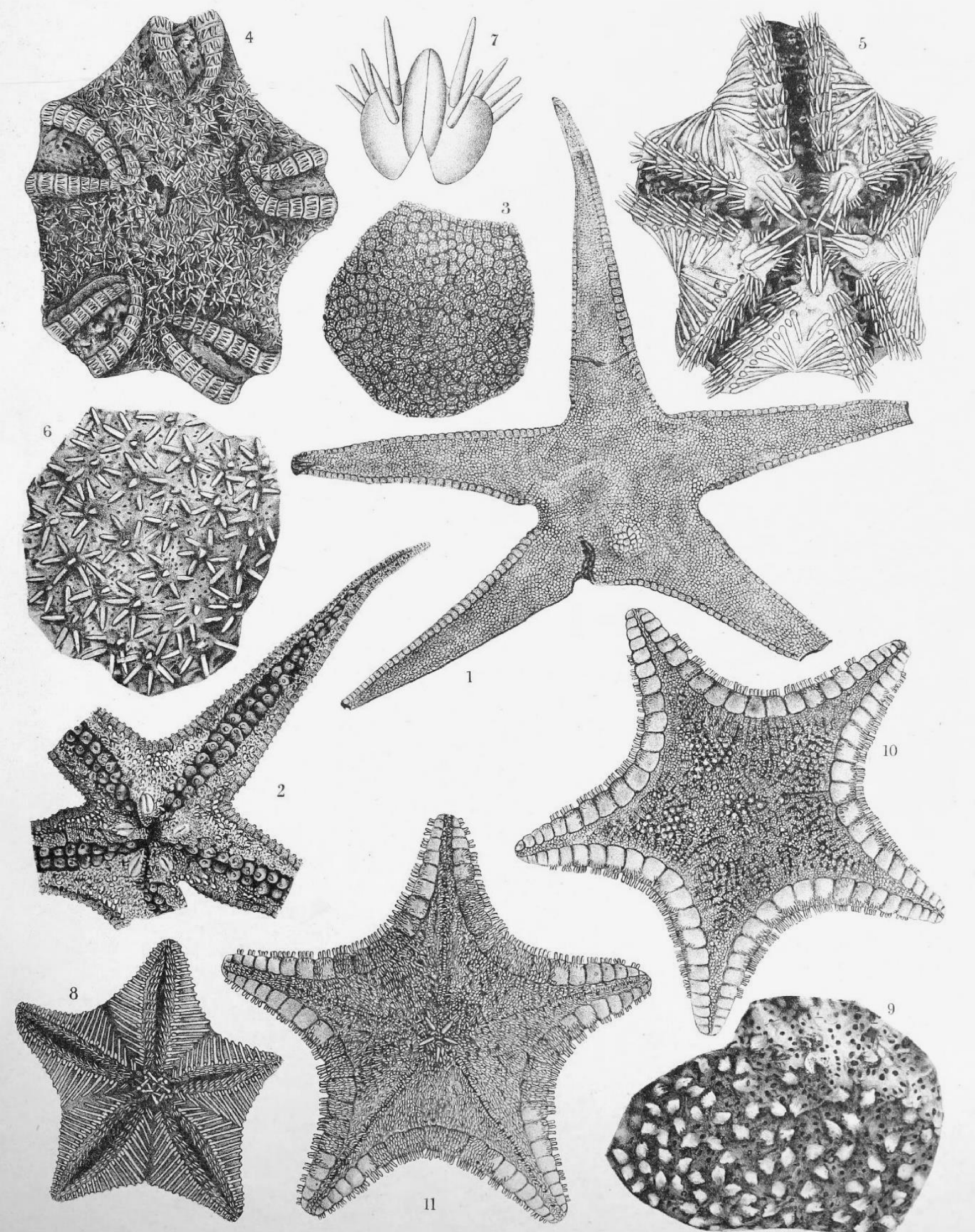

R. Kohler, del.

Fig. 1, 2 et 3 . Dytaster felix.

Fig. 8 et 9 . Hymenaster campanulatus.
Fig. 4 à 7 . Hymenaster densus.

Fig, 10 et 11 . Odontaster pusillus. 
Kqehler: Asteroidea, Ophiuroidea, Echinomba. - Planche II.

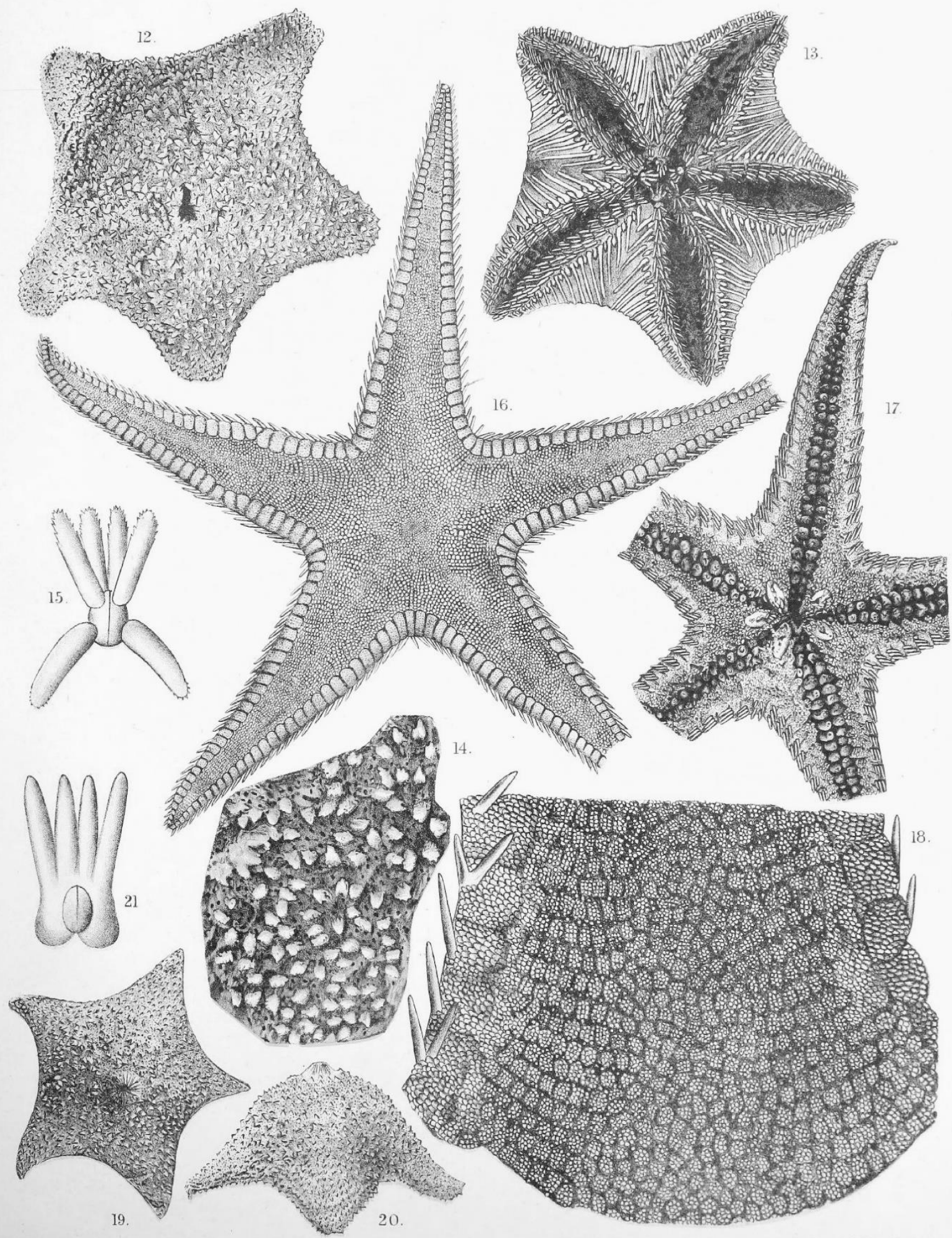

R Køhler, del

Fig. 12 à 15. Hymenaster edax.

Fig. 16, 17 et 18 . Psilasteropsis facetus.

Yc. Farlune \& Erekine, Lith, Edid.

Fig. 19, 20 et 21 . Hymenaster campanulatus. 
Kehler: Asteroidea, Ophiuroidea, Echinoidea. - Planche III.

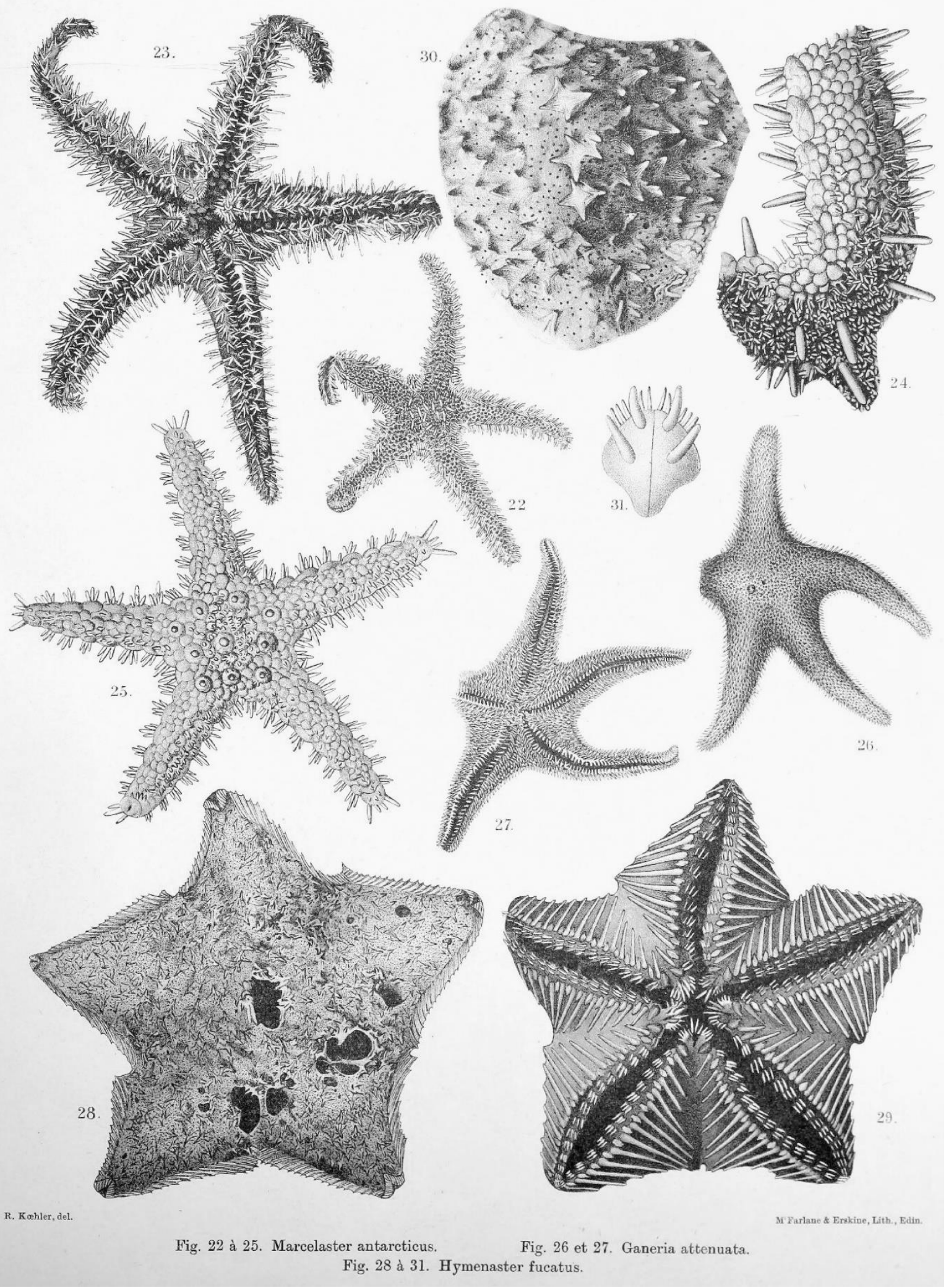


Kqehler: Asteroidea, Ophiuroidea, Echinoidea. - Planche IV.

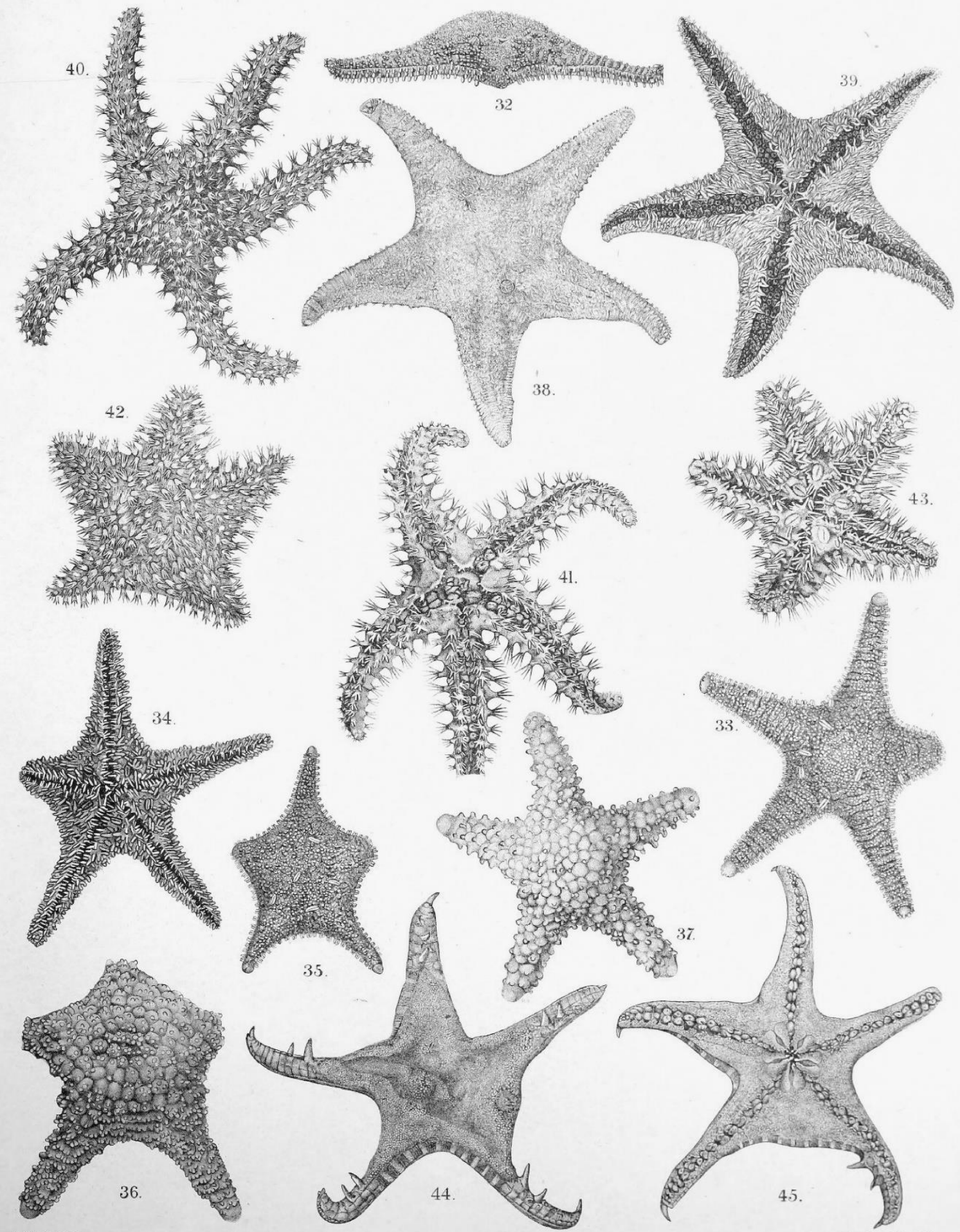

R. Køhler, del.

Fig. 32 à 37 . Chitonaster Johannæ.

Fig. 40 et 41 . Solaster Lorioli.

Fig. 38 et 39 . Scotiaster inornatus,

Fig. 42 et 43 . Lophaster abbreviatus.

Fig. 44 et 45 . Styracaster robustus. 
Kghler: Asteroidea, Ophiuroidea, Echinoidea. - Planche V.

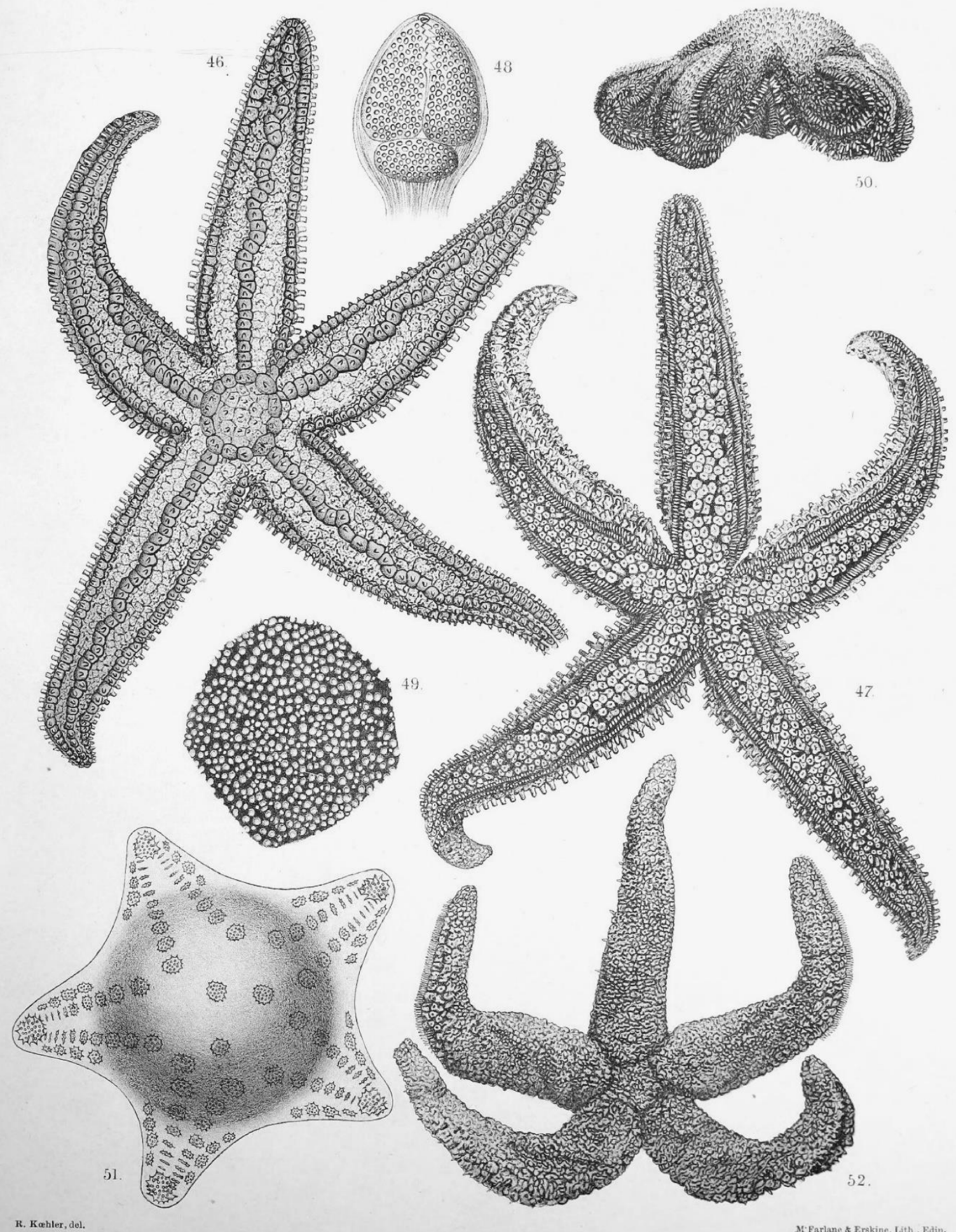

R. Kæhler, del.

Fig. 46 et 47. Stolasterias Brucei.

Fig. 50 et 51. Diplasterias Brandtii.

Fig. 48 et 49 . Granaster biseriatus.

Fig. 52. Anasterias cupulifera. 
Køhler: Asteroidea, Ophuroidea, Echinomea. -Planche VI.

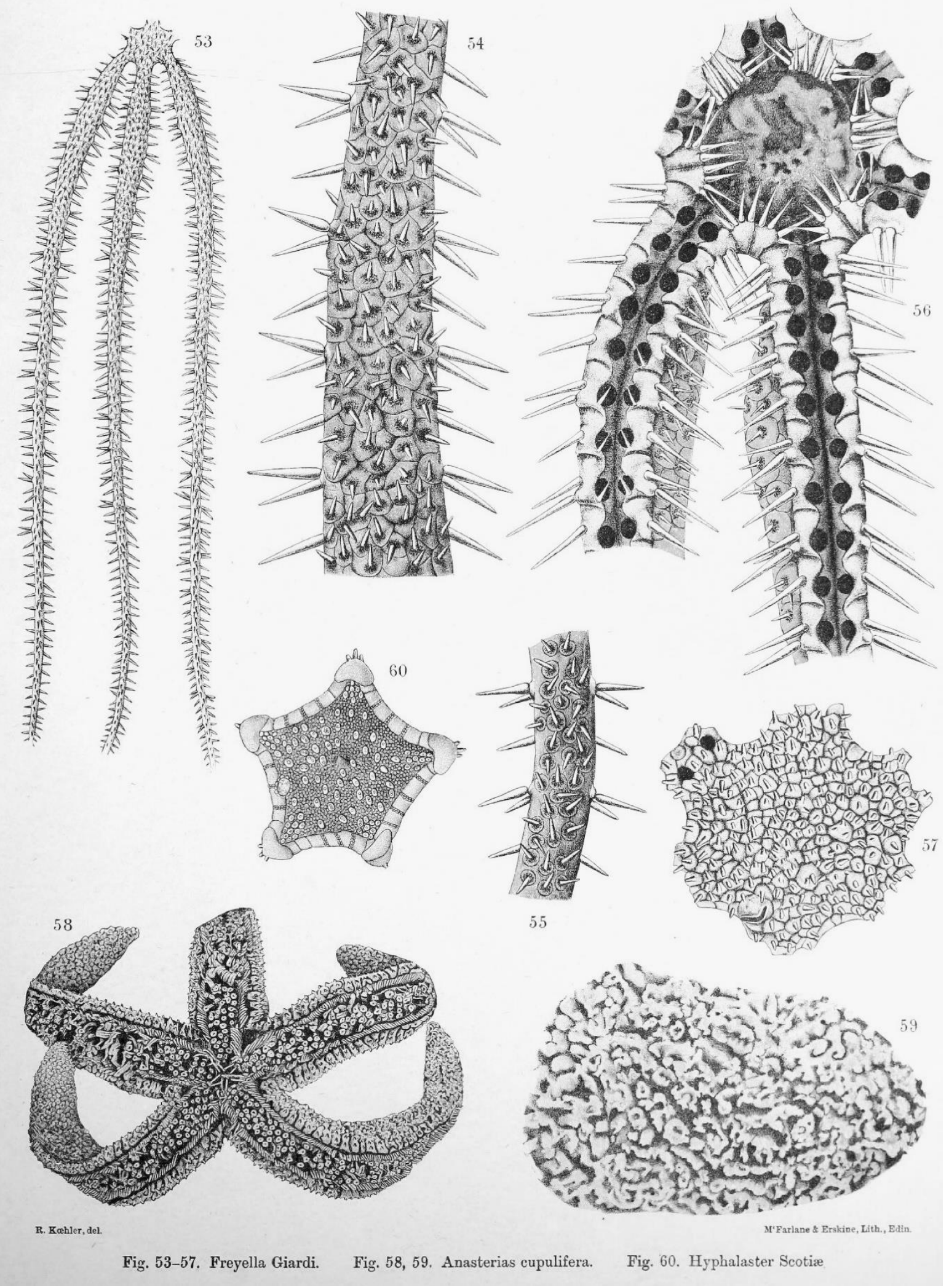


Kqhler: Asteroidea, Ophindoidea, Echinoidea. - Planche Vil.

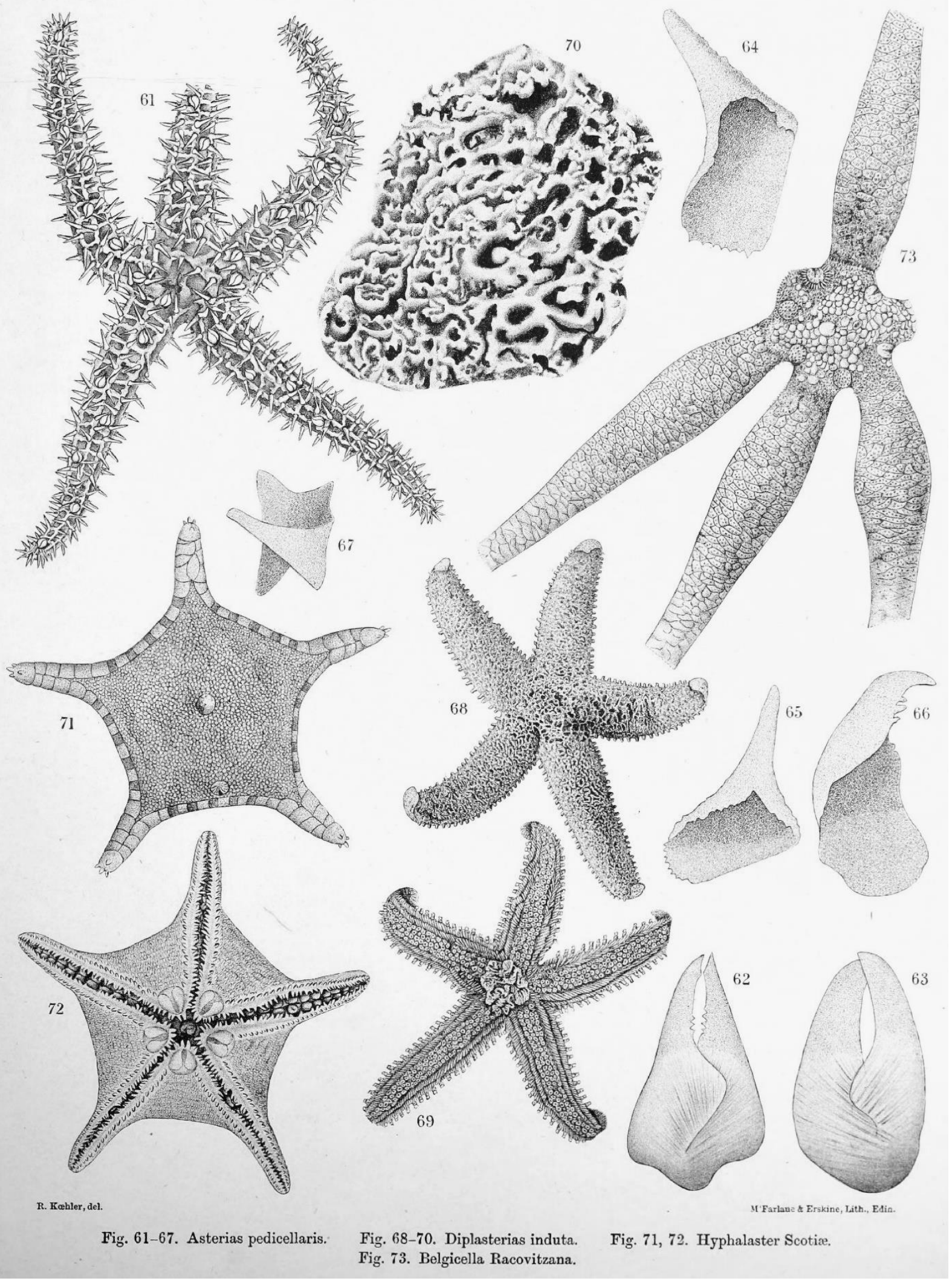


Kqhler: Asteroidea, Ophiuroidea, Echinoidea. - Planche Vill.

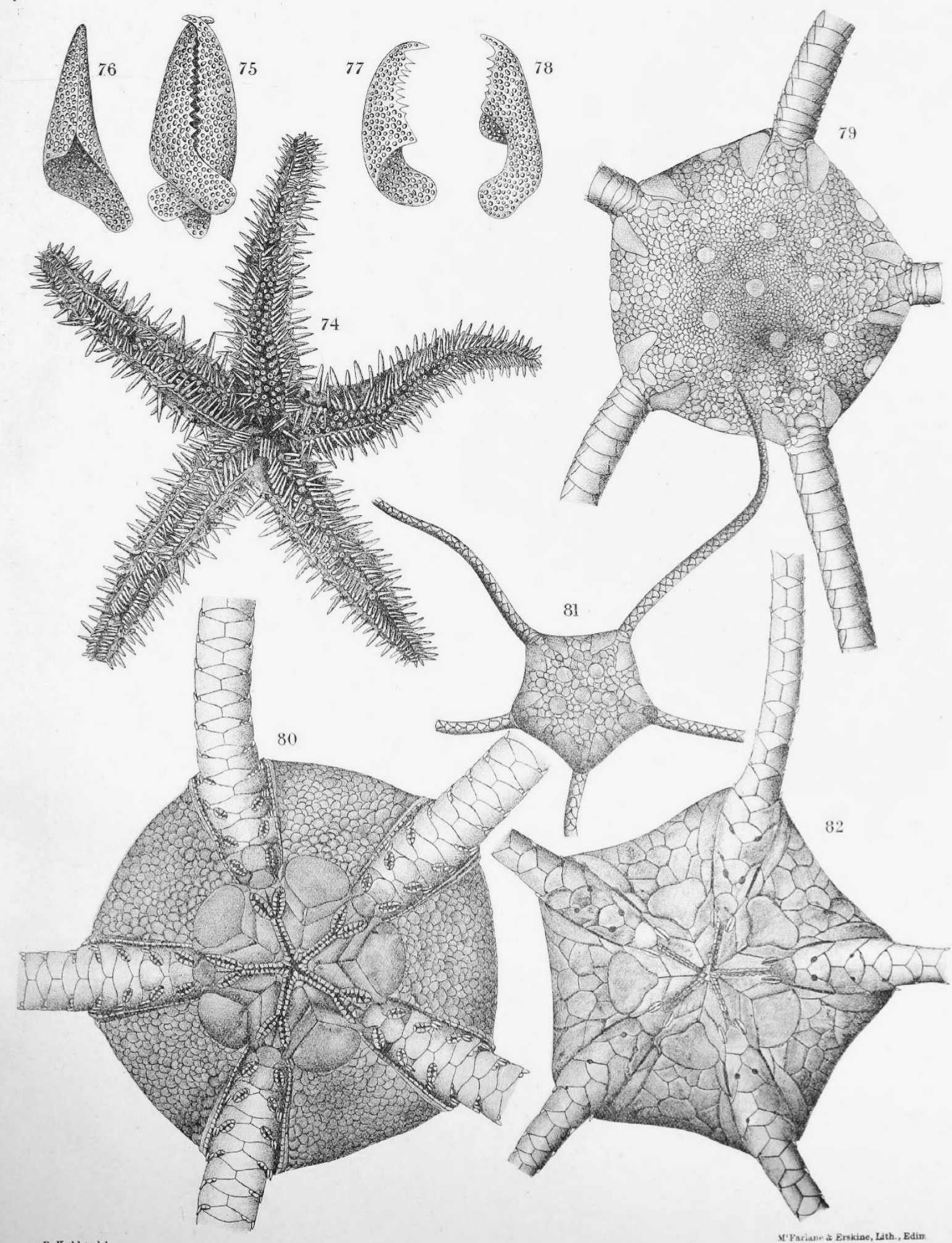

R. $\mathbf{K} œ h]$ r, del.

Fig. 74 à 78 . Asterias pedicellaris.

Fig. 79 et 80. Ophioglypha integra.

Fig. 81 et 82 . Ophioglypha Brucei. 
Scot Nat. Ant. Exp

Vol. V.

Kqehler: Asteroidea, Ophuroidea, Echinoidea. - Planche IX.

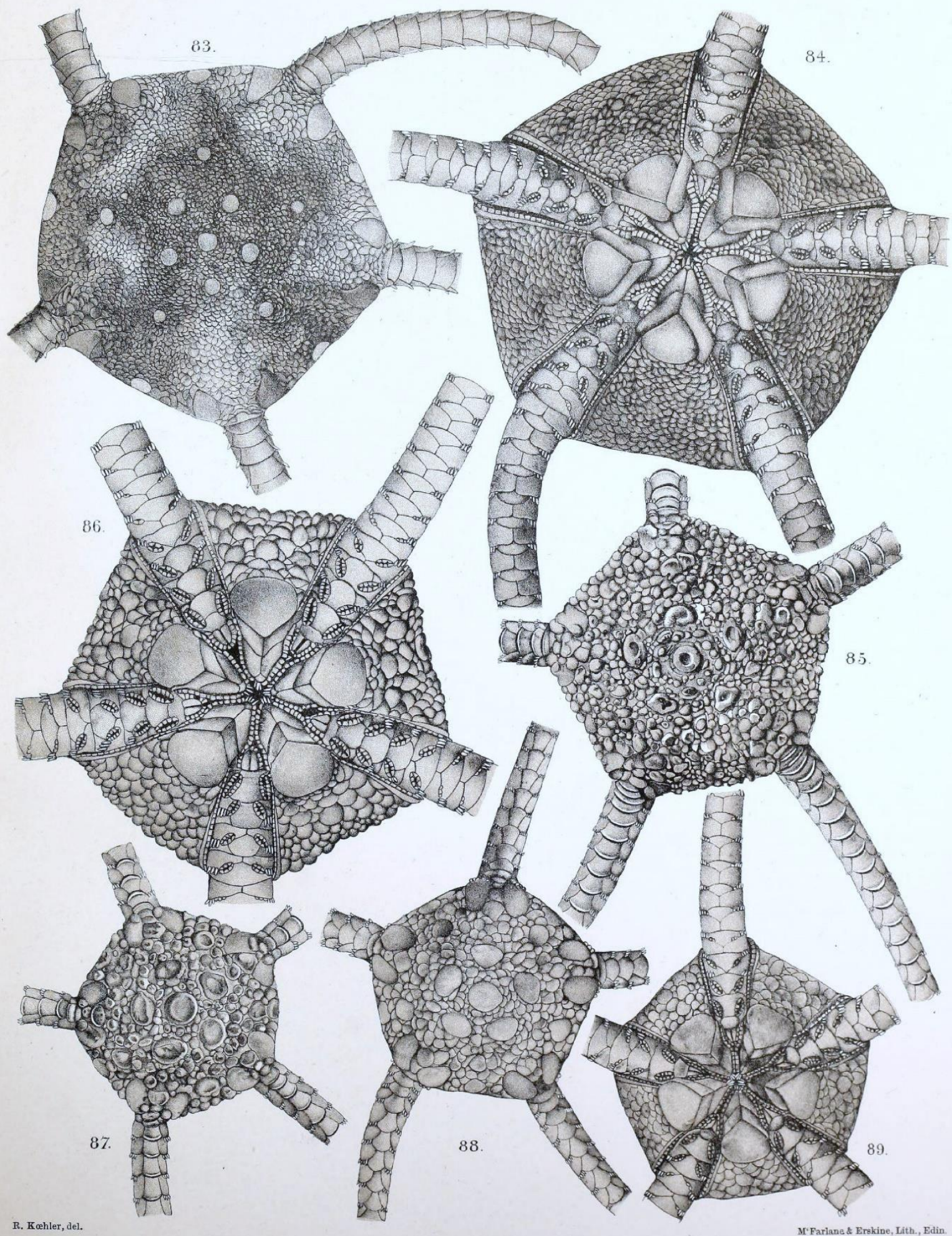

Fig. 83 et 84 . Ophioglypha figurata. Fig. 85 , 86, et 87 . Ophioglypha ossiculata. Fig. 88 et 89 . Ophioglypha mimaria. 
Kehler: Asteroidea, Ophiuroidea, Echinoidea. - Planche X.

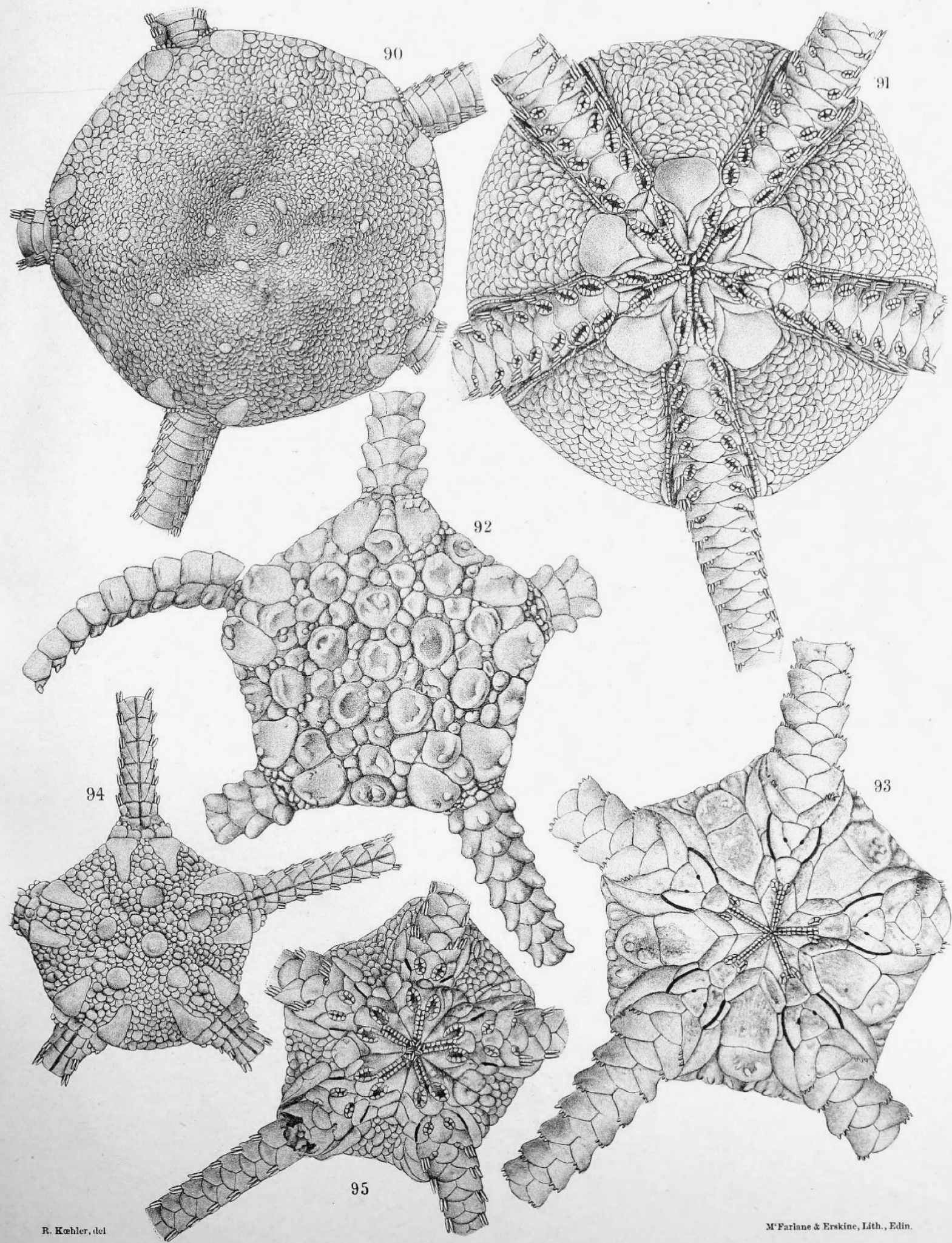

Fig. 90, 91. Ophioglypha lenticularis.

Fig. 92, 93. Ophioglypha anceps.

Fig. 94, 95. Ophioglypha partita. 
Kqhler: Asteroidea, Ophiuroidea, Echinoidea. - Planche XI.

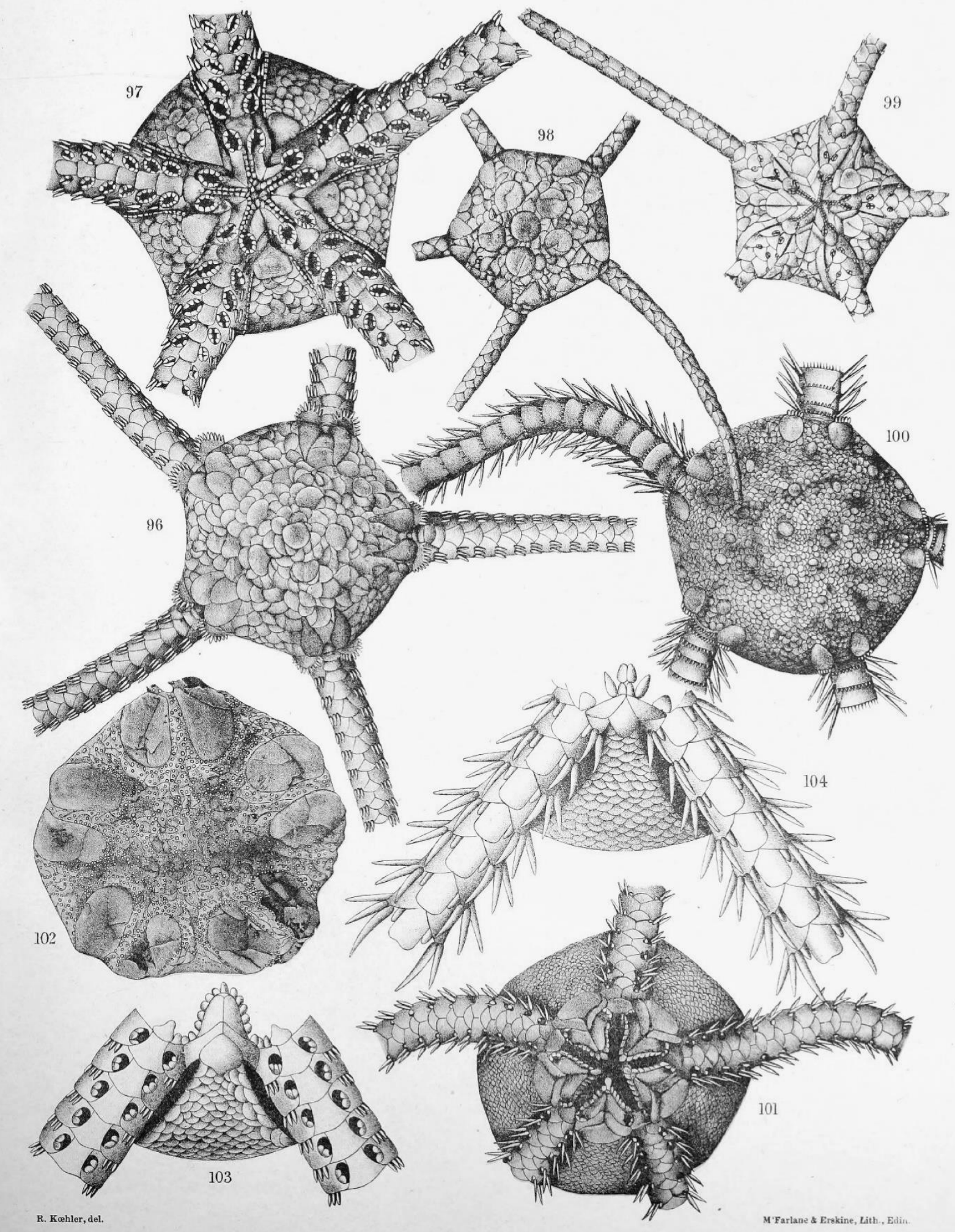

Fig. 96 et 97. Ophioglypha inops. Fig. 98 et 99. Ophioglypha scissa. Fig. 100 et 101 . Ophiocten Ludwigi.

Fig. 102 et 103. Ophiernus quadrispinus. Fig. 104. Amphiura magellanica 


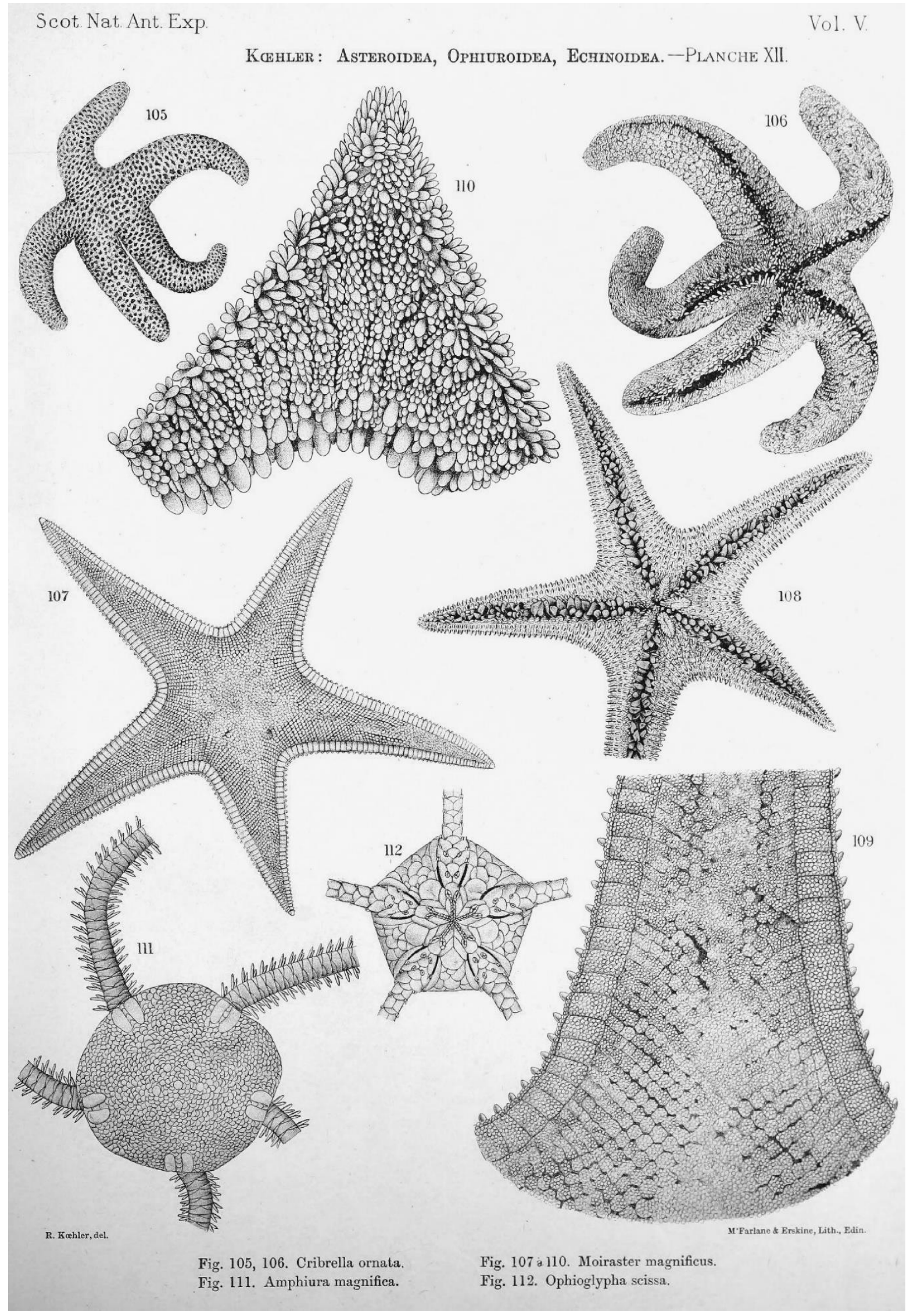


Keghler: Asteroidea, Ophiuroidea, Echinoidea. - Planche Xill.
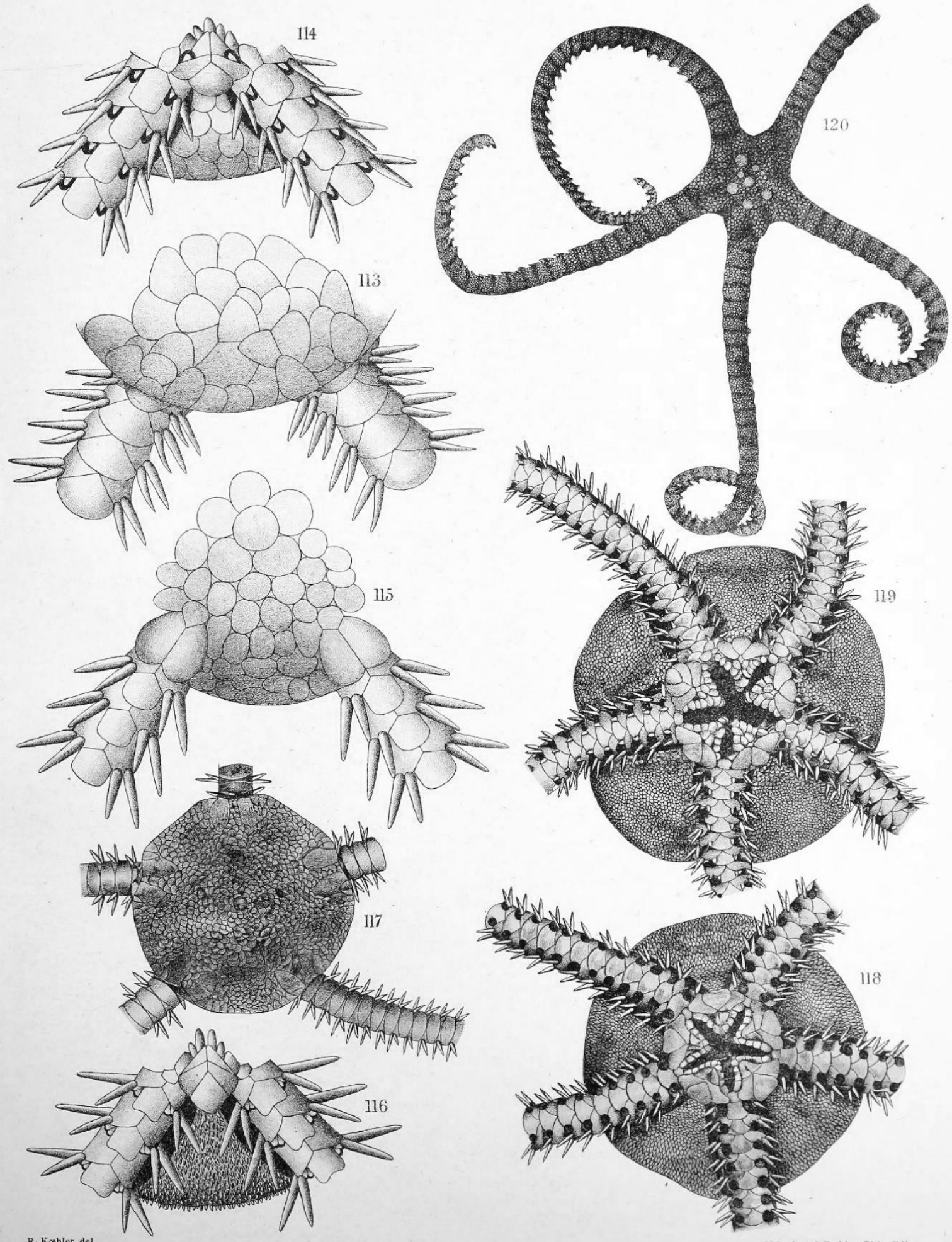

Fig. 113 et 114. Amphilepis antarctica. Fig. 115 et 116. Amphiura murex. Fig. 117 et 118. Amphiura consors. Fig. 119. Amphiura magnifica. Fig. 120. Astrotoma Agassizii. 
Kgehler: Asteroidea, Ophiuroidea, Echinoidea.-Planche XIV
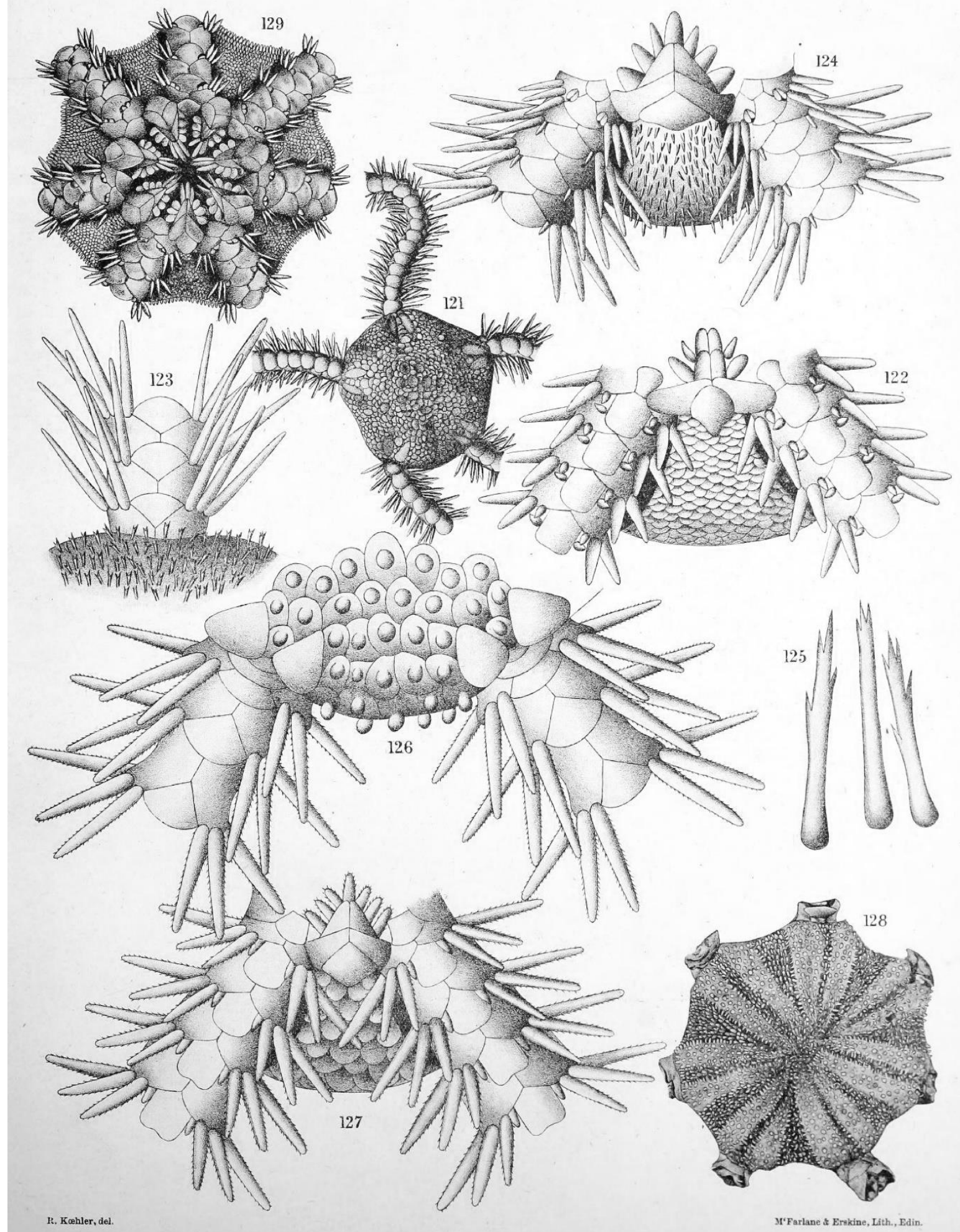

Fig. 121 et 122. Amphiura Mortenseni. Fig. 126 et 127 . Ophiomitrella ingrata.

Fig. 123 à 125. Ophiacantha frigida. Fig. 128 et 129. Ophiacantha opulenta. 
Kegler: Asteroidea, Ophiuroidea, Echinoidea. - Planche XV.

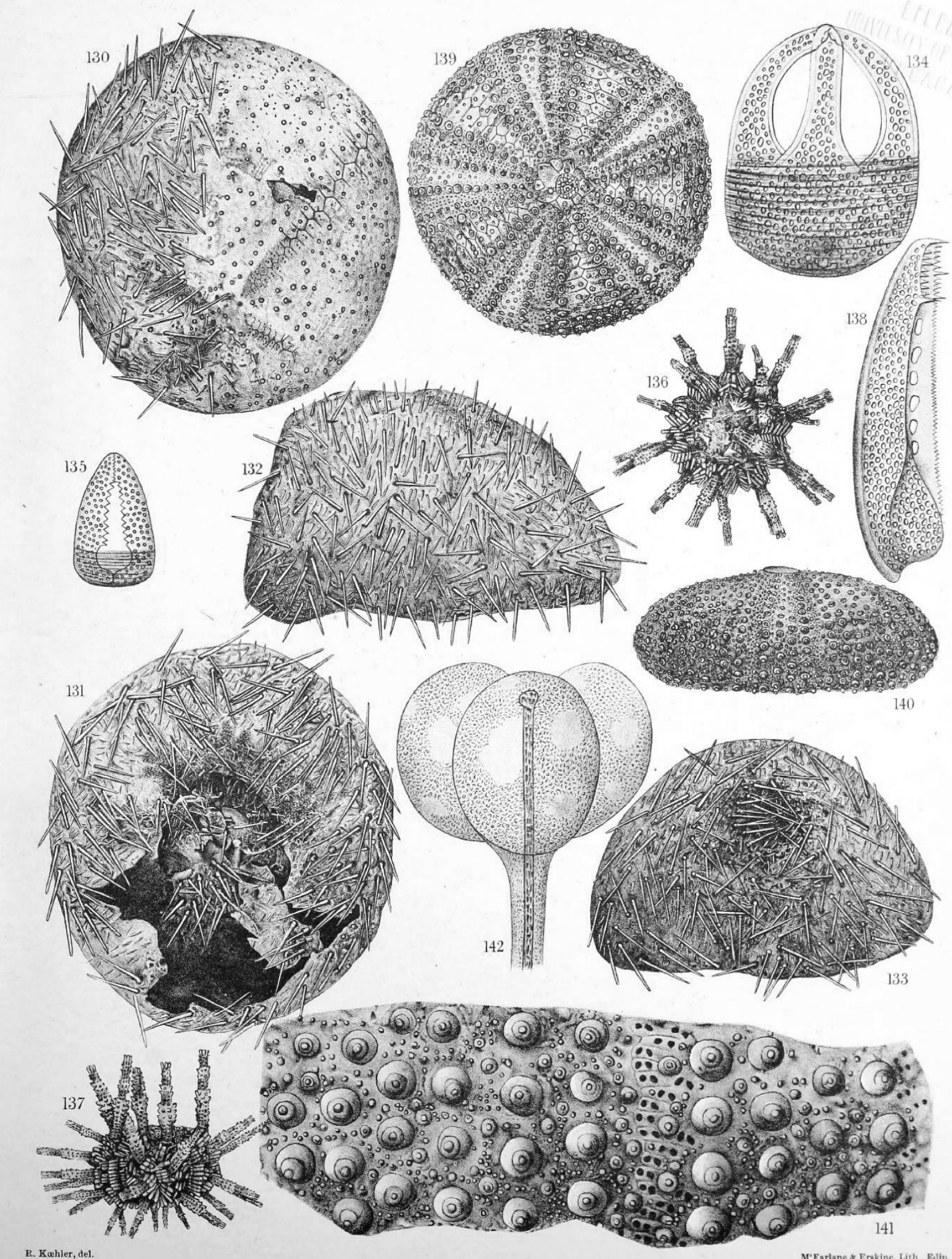

Fig. 130 à 135. Delopatagus Brucei.

Fig. 136, 137 et 138 . Cidaris minor.

Fig. 139 à 142. Pseudoboletia maculata. 
Scot. Nat. Ant. Exp

Kgehler: Asteroidea, Ophiuroidea, Echinoidea,-Planche XVI.
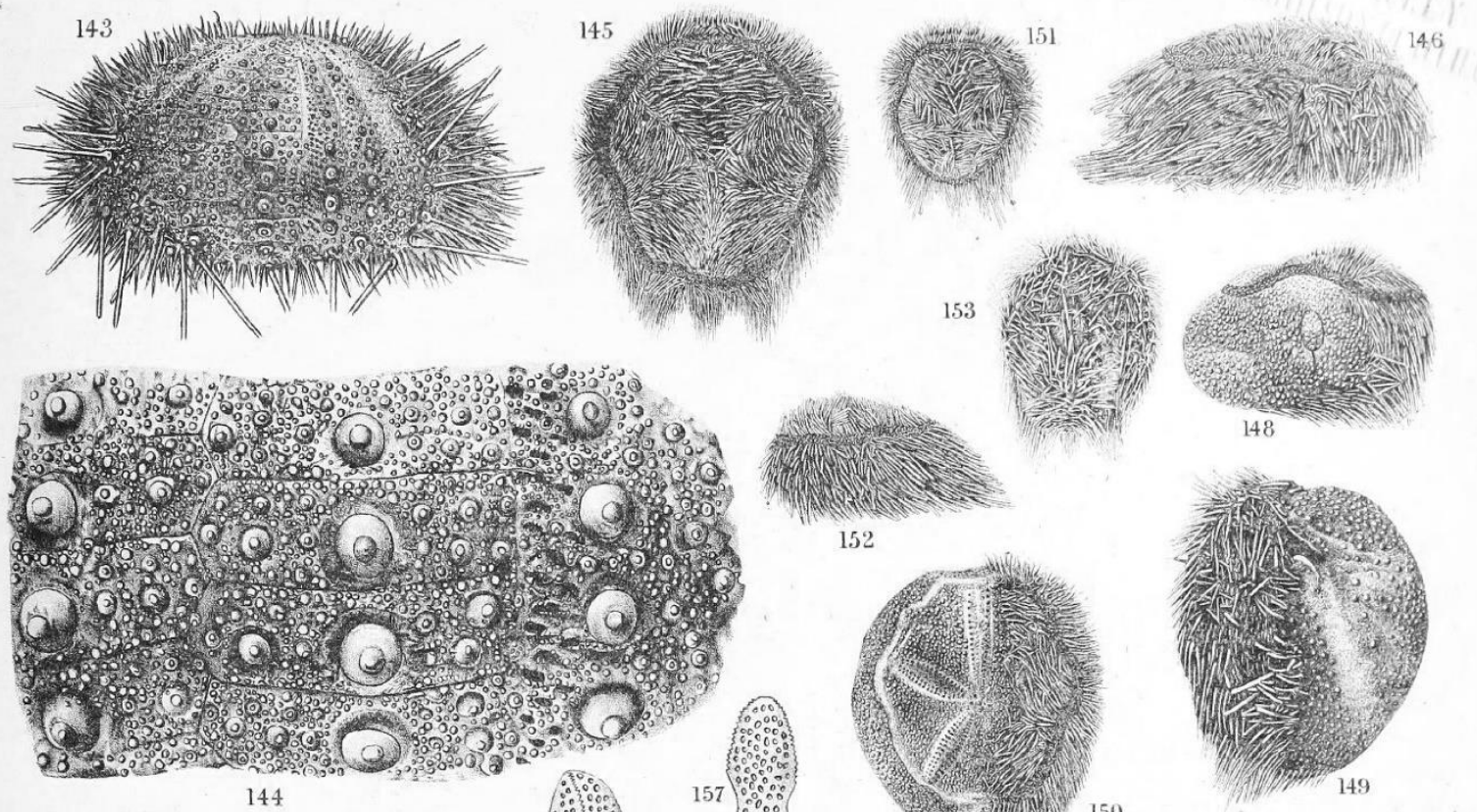

153
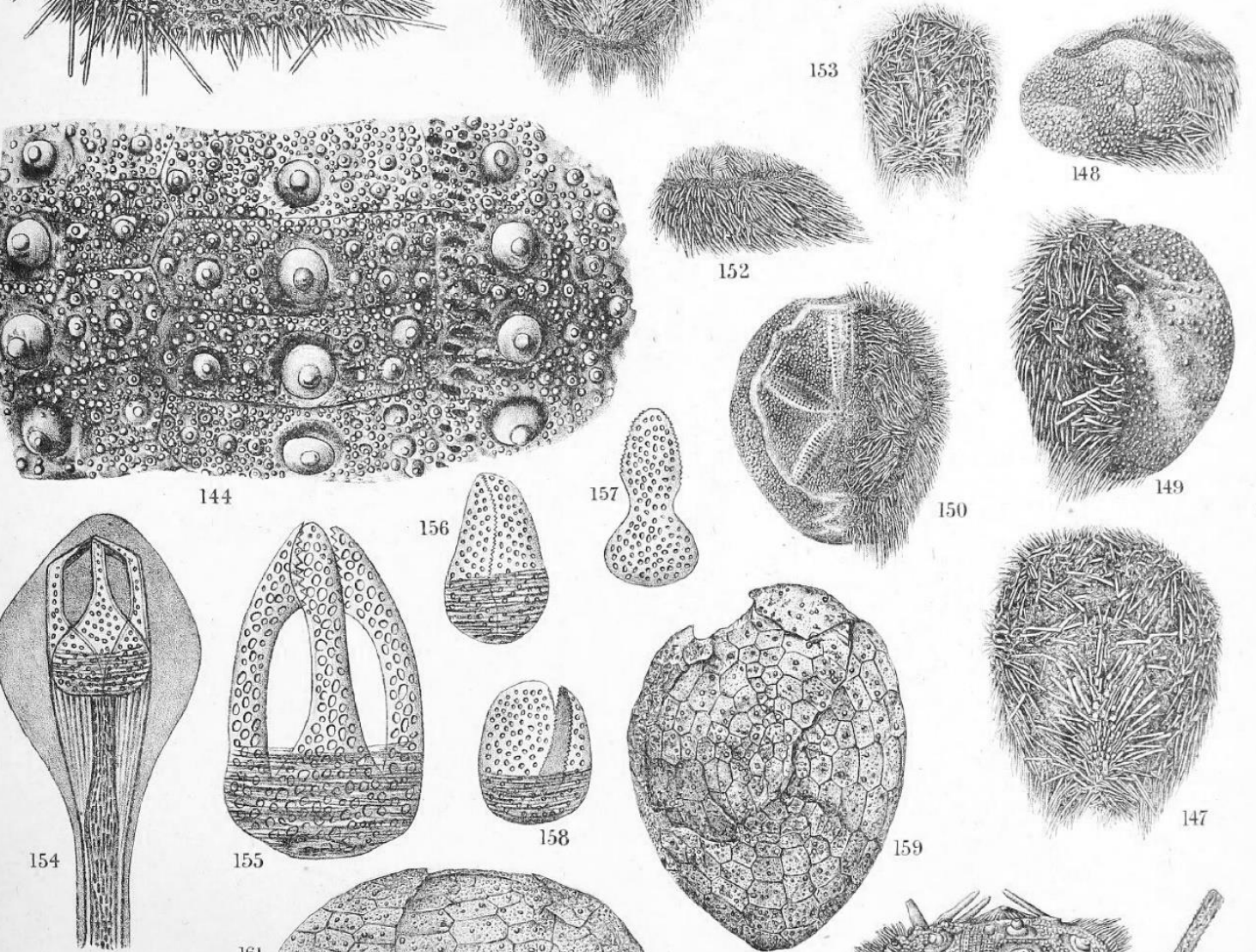

156
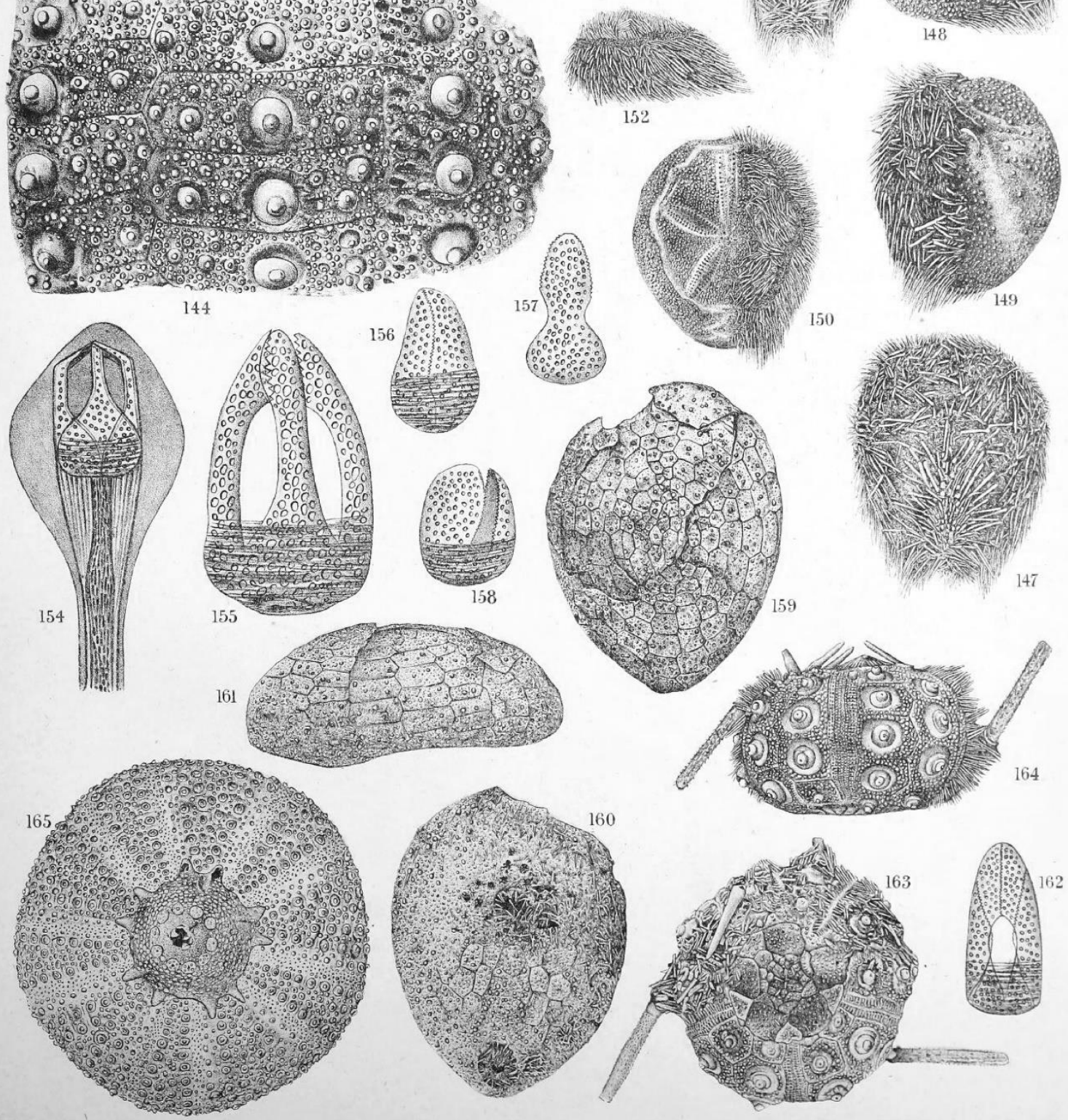

Fig. 143 et 144. Sterechinus Neumayeri. Fig. 159 à 162 . Urechinus fragilis.

Fig. 145 à 158 . Hemiaster elongatus. Fig. 163 et 164. Tretocidaris spinosa. Fig. 165. Pseudoboletia maculata. 